UNIVERSITY OF CALIFORNIA AT LOS ANGELES
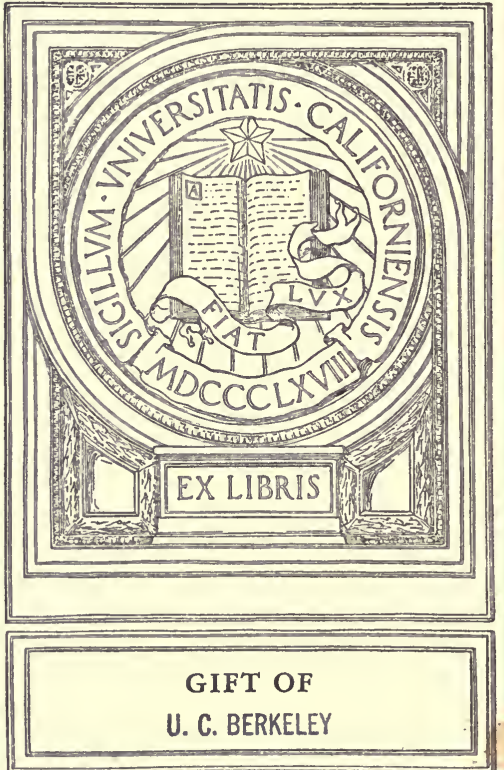

\section{U. C. BERKELEY}




UNIVERSITY OF PEN NSYLVANIA THE UNIVERSITY MUSEUM

\title{
ANTHROPOLOGICAL PUBLICATIONS
}

\author{
VOLUME VI
}

PHILADELPHIA

THE UNIVERSITY MUSEUM

1914-1916 



\section{O N T E N TS}

Number 1. Human Skulls from Gazelde Peninsula, George Grant MacCurdy, pages 1 to 22, plates I to X

Number 2. The Dance Festivals of the Alaskan Eskimo, E. W. Hawkes, pages 1 to 42, plates XI to XV

Number 3. A Pre-Lenape Site in New Jergey, E. W. Hawkes and Ralph Linton, pages 43 to 80 , plates XVI to XXIV 

UNIVERSITY OF PENNSYLVANIA THE UNIVERSITY MUSEUM ANTHROPOLOGICAL PUBLICATIONS VOL. VI NO. 1

\title{
HUMAN SKULLS FROM GAZELLE PENINSULA
}

\author{
BY \\ GEORGE GRANT MACCURDY
}

PHILADELPHIA

PUBLISHED BY THE UNIVERSITY MUSEUM

1914 


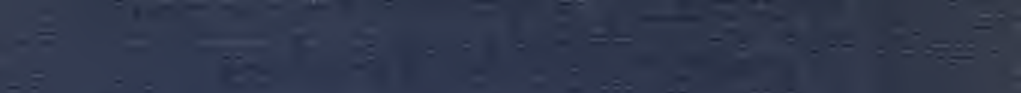

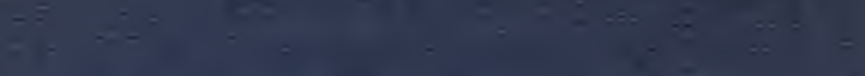

$=$

$=$

$=$

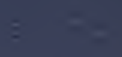$$
\text { 18 }-2=
$$$$
-
$$

(1)

1 




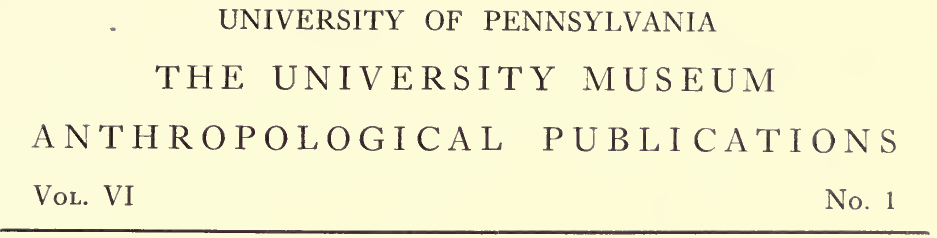

\title{
HUMAN SKULLS FROM GAZELLE PENINSULA
}

\author{
BY \\ GEORGE GRANT MAC CURDY
}


*4. 


\section{HUMAN SKULLS FROM GAZELLE PENINSULA.}

Thirty years ago "Crania Ethnica" made its appearance. Referring to the inhabitants of New Britain, now called Neu Pommern, de Quatrefages and Hamy declared that: "nothing is known of their crania of which there is not a single example in the scientific collections." ${ }^{1}$ Neu Pommern is the first large island directly east of German New Guinea; Gazelle Peninsula is the eastern end of Neu Pommern.

Large collections of crania have been made since then, but they have been only partially described; so that our knowledge of Neu Pommern craniology is still meager. In 1899 learning of a series of twenty-four skulls from Gazelle Peninsula, the property of the University Museum, I obtained permission to examine them. The study which I now present was begun at that time and finished in the summer of 1913 .

The present inhabitants of Melanesia are of mixed blood; Negrito, Papuan, and Dravidian being the chief elements. The several islands are not uniformly affected by intermixture. Thus according to Turner, ${ }^{2}$ two distinct types of skull have been met with in New Guinea-a brachycephalic in which the breadth of the cranium as a rule exceeds the height; and a dolichocephalic in which the height usually exceeds the breadth. I have yet to hear of a brachycephalic type existing in Gazelle Peninsula. The crania under consideration certainly do not reveal it. They are not only all dolichocephalic, but with a single exception (11613 and perhaps 11612 ), are also remarkably homogeneous in character.

${ }^{1}$ Text, p. 276.

${ }^{2}$ Challenger report. 
Dr. R. Hartman ${ }^{1}$ speaks of the men as varying in height from $1.60 \mathrm{~m}$. to $1.80 \mathrm{~m}$., generally slender and the muscles only moderately well developed. The head is high and narrow (hypsistenocephaly) with here and there a tendency to scaphocephaly. According to the same author, the frontal protuberances are rather large. The torus occipitalis transversus is sometimes prominent, the superciliary arches well developed; the demarcation between forehead and nose is sharp, a character common among Melanesian races. The nose is rather flat, the chin broad; the eyes are deep set, appear small, and are dark to grayish-brown. The ears are well-formed; the muscles which move the jaws are strong. The large teeth are white when not colored yellowish-brown by chewing betel.

\section{General Cranial Characters}

Eleven of the skulls from Gazelle Peninsula are of the male sex, eight are of the female sex, and five are of youths and children. The average age of the adults was about thirtyeight years.

Norma occipitalis. - Viewed from behind, there is a prominent crest at the vertex in Nos. I69I and 18283, male and female respectively. In the female series, there is a pronounced depression in two crania (1 1614,18283 ) along the sagittal suture from the lambda to within $27 \mathrm{~mm}$. of the bregma.

The norma lateralis in the males reveals prominent glabella and superciliary ridges with the exception of No. 11622 . When resting on their bases, the mastoid processes do not touch in any of the male crania; No. 18280 rests on the occipital condyles; and all others, on either the posterior margin of the foramen magnum, or the occipital immediately back of the foramen magnum. Only one female cranium rests on the mastoid processes; one rests on the condyles, and all the others, on either the posterior margin of the foramen magnum or the occipital just back of the foramen.

\footnotetext{
${ }^{1}$ Forschungsreise S.M.S. "Gazelle" in den Jahren 1874 bis 1876 , I.
} 
The inion is not prominent, never exceeding 2 of Broca's scale even among the males. The linea nuchae suprema is easily visible in four males and one female. The occurrence of parietal foramina may be shown to best advantage by tabulation:

\begin{tabular}{c|c|c|c}
\hline Males & Side & Females & Side \\
\cline { 2 - 3 } 11621 & right & 11620 & right \\
11610 & " & 11613 & " \\
11612 & " & 11609 & " \\
11611 & " & 18284 & " \\
16911 & " & 11619 & left \\
11617 & left & 16913 & both \\
11618 & " & & \\
18282 & " & & \\
11615 & both & & \\
\hline
\end{tabular}

Region of the pterion.-The frequency with which a contact between the frontal and temporal bones takes place varies among the different races of mankind.

In the series from Gazelle Peninsula the temporo-frontal articulation occurs on both sides in three crania and on one side in four crania. In two of the latter the temporal bone touched the frontal by means of a point only, instead of along a suture line. The so-called pterion retourné is found therefore either on one or both sides in 29 per cent of the crania. Or to put it in another way out of total of 48 pterions (counting the two sides in every case) the reverse form occurs ten times, which is 20.8 per cent of the whole. There are only three occurrences of wormian bones in the region of the pterion (in one case on both sides). Thus ten out of the twenty-four crania have anomalies of the pterion. This is practically the same percentage (41.6) as in the series of 150 crania from Neu Pommern and Mioko described by Krause. He found the reversed pterion in 32 out of 150 crania $(21.3$ per cent); in 
fourteen of these it occurred on both sides, making 46 reversed pterions out of a total of 300 (15.3 per cent). Krause also reports epipteric bones in 31 crania (on both sides in 18). The Papuans are also noted for the relatively great number of irregularities in the pterionic region. In a collection of fourteen crania from New Guinea belonging to Yale University Museum, I found the reversed pterion in five (on both sides in four of these); while epipteric bones were present in seven out of the fourteen crania. Dorsey ${ }^{1}$ also found a high percentage of irregularities of the pterion in a series of twenty crania from New Guinea, only half of them having the normal pterion in $\mathrm{H}$; two crania with pterion in $\mathrm{K}$, four with pterion reversed by a frontal process from the temporal bone, and four with epipteric bones. Thus the natives of New Guinea as well as of the islands directly to the east are characterized by an unusually high percentage of anomalies in the region of the pterion.

Articulatio spbeno-maxillaris.-A union of the ala magna of the sphenoid with the superior maxillary; i. e., the failure of the cheek bone to reach the fissura orbitalis, takes place in nineteen out of twenty-three skulls (82.6 per cent) and as follows:

\begin{tabular}{|c|c|c|c|}
\hline Males & Side & $\begin{array}{c}\text { Females } \\
\text { and Youths }\end{array}$ & Side \\
\hline 18280 & Both sides & 1828 I & Both sides \\
\hline 11621 & " & 18283 & " " \\
\hline 1610 & “ & 11609 & “ \\
\hline 11617 & “ & 16912 & “ \\
\hline 11612 & " & 11619 & “ \\
\hline 11618 & “ & 11616 & “ \\
\hline 18282 & “ & 16913 & “ \\
\hline 11622 & “ & 16914 & “ \\
\hline $\begin{array}{l}16911 \\
11615\end{array}$ & $\begin{array}{c}\text { Left side } \\
\text { “ }\end{array}$ & 11620 & “ \\
\hline
\end{tabular}

${ }^{1}$ Field Columbian Museum, Publication 21. 
The external auditory meatus is not affected, in a single instance, by exostoses.

Foramen pterygo-spinosum.-The spheno-pterygoid foramen is formed by the ossification of the ligamentum pterygospinosum. It occurs as follows in the series from Gazelle Peninsula:

No. 18282, male. Right side, the foramen is complete, the processes from the pterygoid lamina and spina angularis meeting in a suture line. On the left side, the two processes lack $12 \mathrm{~mm}$. of joining.

No. 11613, female. On right side, a completely ossified ligament forming a small spheno-pterygoid foramen.

No. 11614, female. Processes for attachment of the ligament at either end, $5 \mathrm{~mm}$. apart on right side, and $6 \mathrm{~mm}$. apart on left side.

Turner found the spheno-pterygoid foramen with complete osseous boundaries in three skulls of the Challenger series. According to Roth, ${ }^{1}$ the percentage of occurrences for 287 Europeans is 4.8. Its percentage with partial and complete bony walls, is much higher among some races: Asiatics, 32 per cent; Australians and Papuans, 50 per cent; Africans, 30.6 per cent; American Indians, 20 per cent.

The Pars tympanica (anterior portion) of the temporal bone is either perforated or extremely thin in two male (11617, $11615)$ and three female crania (11614, 18283, 11613). Five males (Nos. 18280, 11610, $11612,16911,18282$ ) and two females $(18283,11609)$ have prominent para-mastoid processes.

There is a prominent third occipital condyle in No. 18283 . This anomaly ${ }^{2}$ is important in that it admits of comparisons being made with the single median condyle of birds and scaly reptiles. J. F. Meckel ${ }^{3}$ was the first to call attention to the condylus tertius in man. In a series of 876 crania at Leiden, Dr. Halbertsma found seven well developed cases of the third

${ }^{1}$ Arcbiv für Antbropologie, XIV, 73.

${ }^{2}$ Blake, Antbropological Review, V, p. CXVII.

${ }^{3}$ Meckel's Arcbiv, 1815, I, 644. 
condyle, not including those in which there is merely an articular groove for the tooth of the epistropheus. Dr. H. Allen states that in the Morton collection of crania, ten specimens possess a third condyle. Sir William Turner mentions four cases among the 143 crania described in the Challenger Report. He also describes a skull from Port Moresby, ${ }^{1}$ New Guinea, possessing the condylus tertius. According to Krause there are three cases of condylus tertius in 150 crania from $\mathrm{Neu}$ Pommern and Mioko.

There are slight traces of the metopic suture in three crania, two males (11612,11615) and one youth (16913).

The frontal bone articulates with a process of the superior maxillary between the lachrymal and the os planum (lamina papyracea) of the ethmoid in two crania (11610, 11619) and, in each case, on the left side only. This marks a reversion to the pithecoid arrangement as pointed out by Sir William Turner. $^{2}$ Among anthropoids, the os planum is triangular, and the fronto-maxillary articulation always occurs between it and the lachrymal.

The infra-orbital suture is present in two males (1162I, 11612 ), and two females (18283, 11609). The fossae caninae are pronounced in all.

Apertura pyriformis.-The anterior nasal opening presents anthropoid characters in every instance. Four of the male crania ( $11615-17-18,16911$ ) possess accentuated simian grooves or gutters; while the fossa pre-nasalis is pronounced in six male (11610-12-2I-22, 18280-82) and four female crania (11613-14-19-20). The characteristic human type (forma anthropina) does not occur once in the series.

In two instances, the nasal bones reach to the level of the lower margin of the orbital opening. The anterior nasal spine averages less than No. 2 of Broca's scale. The spina nasalis posterior exhibits no marked variations. It is never

1 Journal of Anatomy and Pbysiology, XXI1, 360.

2 Report on Human Crania, Vol. X of the Challenger Report, p. 12. 
prominent and, in every instance, is formed by the facies nasalis of the right and left os palatinum. The sutura incisivum is fairly distinct in No. 11612, an adult male.

There is not a single example of os zygomaticum duplex (os Japonicum) in the series. The direction of the malotemporal suture is rather steep, and the suture is short in all but three of the males (11611-22, 16911). The same may be said of the female crania, with two exceptions (11623, 18283).

Wormian bones are rare and generally insignificant in size. They occur in only eleven crania, five male, three female, and three children. In addition, there is the suggestion of an os Incae in Nos. 11621 and 16914. In the former, the sutures branch off from the lambdoid suture very near the asterion to disappear after a course of some fifteen $\mathrm{mm}$.; in the latter, the same condition obtains, except that the sutures branch off directly from the asterion. In No. 18282, a child of ten years, there is an epactal bone. The sutures are simple, generally falling between 1 and 3 of Broca's scale.

Krause found the interparietal bone in fifteen out of the 150 crania described by him; in six of these the interparietal might be classed as a true Inca bone.

\section{THE TEETH}

The teeth that remain are remarkably well preserved, and in only five crania do any of the alveoles manifest a pathological condition. The wisdom tooth is never lacking. There are two examples of supernumerary teeth, as follows: one on the lingual side of the lower right canine in 11621 (male), and one on the lingual side of second lower left premolar in 11609 (female).

Almost without exception, the upper molars of both the males and females have three roots, and these are generally spreading. The first molar is the largest except in three crania where all three are of about equal size. In three 
instances, the third upper molar has a single conical root; and in four, there is a tendency to fusion of the roots.

The first upper premolars have two roots in eight out of seventeen skulls. In one of these, there is the suggestion of a third root by the deep grooving of one of the two roots. The roots of the first upper premolars are flattened and grooved in the other crania. The second upper premolars have divided roots in three crania; in thirteen, the roots are grooved or flat; and in only one, are there single, conical roots.

The alveolar arch of the upper jaw is massive and projects beyond the third molar $8.6 \mathrm{~mm}$., on an average, among the males; and $5.2 \mathrm{~mm}$., among the females. There is but a single case of crowding of the teeth, and then only the incisors are affected. The palate inclines to be deep.

The length in situ of the lower molars averages $34.6 \mathrm{~mm}$. The three are generally of about equal size; when not, it is the third or the first which is the largest. In two cases, the third molar has three roots. All other third lower molars have two roots, with a single exception, where there is a fusion of the two roots. All the first lower molars have five cusps where the number can be determined with certainty. Fifty per cent of the second lower molars, and 21.4 per cent of the third, have only four cusps.

The first lower premolar is supplied with an anterior root in five crania; while in nine, there is a single, grooved or flattened root; and in four, there is a single, conical root. There is one example of a divided root among the second lower premolars; five examples of a grooved or flat root; and twelve, of a conical root.

The third molar is generally situated well in front of the ascending ramus of the lower jaw, when the jaw is so held as to bring the anterior margins of the rami in a line with the eye. With the lower jaw held in this position, the entire crown of the third molar can be seen in thirteen out of a total of eighteen cases. Fortunately each cranium is supplied with its own lower jaw. 


\section{Measures}

Capacity.-The capacity ${ }^{1}$ (measured by shot) is small, averaging, for the males, $1345.2 \mathrm{cc}$; and for the females, 1214.5. The range of variation for both sexes is small also (1078-1470), both extremes being of the male sex.

Of the Hamburg ${ }^{2}$ collection, twenty-six are from Neu Pommern, and 120 are from Mioko, the principal island immediately to the east of Neu Pommern. The crania from both these islands are described as being very much alike, recalling the Viti Island type. The average capacity for the males is $1267 \mathrm{cc}$; ; that for the females is $1180 \mathrm{cc}$; and for both sexes $1232 \mathrm{cc}$. (maximum 1530, minimum 990). As Mioko is separated from Gazelle Peninsula only by the narrow St. George Channel one would expect to find unity in the ethnic type. The comparison of averages is largely deprived of its significance if the series are too small, the sexes mixed, and methods employed are different. Whatever the method great care must be exercised in order to eliminate the personal equation; otherwise the results for the same cranium may vary as much as 100 or even $150 \mathrm{cc}$. The following table then simply indicates that the cranial capacity for Neu Pommern and Mioko is small whatever the method or whoever the operator:

\begin{tabular}{|c|c|c|c|}
\hline Authority & No. & Sex & Capacity \\
\hline Krause... & 150 & $\begin{array}{l}\text { Male..... } \\
\text { Female... }\end{array}$ & $\left.\begin{array}{l}1267 \\
1180\end{array}\right\}$ millet \\
\hline MacCurdy..... & 18 & $\begin{array}{l}\text { Male (10) } \\
\text { Female }(8\end{array}$ & $\left.\begin{array}{l}1345 \\
1214\end{array}\right\}$ shot \\
\hline
\end{tabular}

Virchow $^{3}$ refers to a female skull from Neu Pommern with a capacity of only $860 \mathrm{cc}$. It came from the same burial

${ }^{1}$ Broca's methods of measurement, unless otherwise specified have been followed.

${ }^{2}$ J. D. E. Schmeltz and R. Krause. Die ethnographisch-anthropologische Abteilung des Museum Godefroy in Hamburg. Hamburg, 1881.

${ }^{3}$ Zeitscbrift für Etbnologie, 1894, XXVI, 505. 
ground as two male skulls, one with a capacity of 2 Ioo cc., and the other $1250 \mathrm{cc}$. The large skull was probably that of a hydrocephalous individual; and the female skull, that of an idiot. They were collected by Finsch. This goes to show how great individual variations may be even in the same savage race. The three were all of the same type and contemporaneous.

Cepbalic index.-The male crania are, each and all, dolichocephalic, with an average index of 70 (range 67.4 to 75 ). The female crania are dolichocephalic, with the exception of a single case of hyperdolichocephaly; having an average index of $\mathbf{7 2 . 5}$ (range 69.5 to 77.2). The appended table will show the lengthbreadth index to be very uniform in Neu Pommern and Mioko:

\begin{tabular}{|c|c|c|c|}
\hline Authority & No. & Sex & Cephalic Index \\
\hline Krause...... & 150 & Male and Female. & $72 \cdot 3$ \\
\hline MacCurdy.. & 18 & $\begin{array}{l}\text { Male (I I) } \ldots \ldots \ldots \\
\text { Female }(8) \ldots \ldots\end{array}$ & $\left.\begin{array}{l}70.8 \\
72.5\end{array}\right\} 71.2$ \\
\hline
\end{tabular}

Frontal diameter.-Broca's stephanic diameter is no longer employed by the French school; they having substituted the maximum frontal which is the greatest diameter of the frontal bone wherever found; this coincides very closely with the stephanic breadth. The average maximum frontal diameter for the eleven male skulls is $108.7 \mathrm{~mm}$., the extremes being I $16 \mathrm{~mm}$. and $106 \mathrm{~mm}$., respectively. The average for the eight female skulls is $104 \mathrm{~mm}$. (extremes 108 and 98). The average minimum frontal diameter in the male series is $\mathbf{9 3 . 2}$ $\mathrm{mm}$. (range 98 to 89 ); while that in the female series is 90.2 $\mathrm{mm}$. (range 95 to $8 \mathrm{r} .5$ ).

Eight out of ten male crania have a greater vertical or length-height index than cephalic (the two exceptions being Nos. 11622 and 11615 ). In other words, the height is greater 
than the greatest breadth. This is also true of one of the two types of skull found in New Guinea. In the female series, the two indices are practically equal, while the average for both sexes is in favor of the vertical index:

\begin{tabular}{l|c|c|c}
\hline & Males & Females & Both Sexes \\
\hline Average vertical or length-height index... & 73.6 & 71.5 & 72.5 \\
Average cephalic or breadth index........ & 70.8 & 71.6 & 71.2 \\
\hline
\end{tabular}

$n$. The same character (hypsistenocephaly) is brought out by the large transverso-vertical index $\left(\frac{\text { height } \times \text { Ioo }}{\text { greatest breadth }}\right)$; the average for the males being 104.1; for the females, 99.7; and for both combined, I01.9.

It naturally follows that the crania are markedly phaenozygous, the bizygomatic diameter averaging $18.4 \mathrm{~mm}$. longer than the maximum frontal $(14.7 \mathrm{~mm}$. for males, and $22.1 \mathrm{~mm}$. for females) and even $1.7 \mathrm{~mm}$. longer than the greatest breadth of the skull:

\begin{tabular}{l|c|c|c}
\hline & $\begin{array}{c}\text { Ten } \\
\text { Males }\end{array}$ & $\begin{array}{c}\text { Eight } \\
\text { Females }\end{array}$ & Both Sexes \\
\hline Bizygomatic diameter........................................ & 133.4 & 126.1 & 129.7 \\
Maximum frontal diameter... & 129.9 & 126.2 & 128 \\
Maximum transverse diameter....
\end{tabular}

Prognathism is a prominent feature in the entire series, the average index, Gnathic ${ }^{1}$ of Flower, being 106.7 (range 102 to I I I.6).

$1\left(\frac{\text { Basi-alveolar length } \times 100}{\text { Basi-nasal length }}\right)$. See Journal of the Anthropological Institute, X, 163, 164. 
ANTHROPOLOGICAL PUBLICATIONS UNIVERSITY MUSEUM VOL. VI.

\begin{tabular}{l|c|c|c|c}
\hline & $\begin{array}{c}\text { Orthognathous } \\
\text { (Below 98) }\end{array}$ & $\begin{array}{c}\text { Mesognathous } \\
(98 \text { to 103) }\end{array}$ & $\begin{array}{c}\text { Prognathous } \\
\text { (Above 103) }\end{array}$ & Average \\
\hline Males........... & o & I & 9 & Prognathous \\
Females.......... & o & 1 & 7 & “ \\
\hline
\end{tabular}

It will be seen from the following table that other Melanesian groups are also prognathous:

\begin{tabular}{|c|c|c|c|}
\hline Authority & Number & Sex & Gnathic Index \\
\hline Flower. . & 8 (Fiji lslands)..... & Male and Female.. & 103.7 \\
\hline Turner... & 4 (New Guinea).... & Male and Female.. & 104.9 \\
\hline Thomas. & $\begin{array}{l}18 \text { (New Guinea)... } \\
17 \text { (New Guinea)... }\end{array}$ & 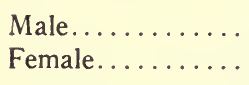 & $\left.\begin{array}{l}106.5 \\
107.7\end{array}\right\} 107.1$ \\
\hline Dorsey. & $\begin{array}{l}8 \text { (New Guinea).... } \\
7 \text { (New Guinea)... }\end{array}$ & $\begin{array}{l}\text { Male............. } \\
\text { Female........ }\end{array}$ & $\left.\begin{array}{l}107 \\
110\end{array}\right\} 108.5$ \\
\hline MacCurdy. & $\begin{array}{r}\text { Io (Neu Pommern) } \\
7 \text { (Neu Pommern) }\end{array}$ & $\begin{array}{l}\text { Male } . . . . . . . . . \\
\text { Female........ }\end{array}$ & $\left.\begin{array}{l}107.5 \\
105.9\end{array}\right\} 106.7$ \\
\hline
\end{tabular}

Facial index.-The facial index expresses the ratio of the breadth to the height of the face. The distance from the root of the nose (nasion) to the most prominent point on the alveolar margin between the two upper median incisors (prosthion) is multiplied by 100 and divided by the bizygomatic breadth. The average facial index for the males is 48.8 and for the females 47.8. Both are chamaeprosopic, a character associated with lowly forms.

Index of palate.-The palates are all long in proportion to their breadth, the average index for males as well as females being what Broca would call microsème. None of the palates 
are megasème. The human hard palate has been classified as rectilinear and curvilinear. When the branches of the alveolar arch are rectilinear and divergent there is produced the hyperbolic or human type; when the branches are parallel and rectilinear the result is the hypsiloid or simian type. Curvilinear branches are either divergent and hence parabolic or convergent and elliptic. The elliptic is a simian form. The arch of the hard palate is elliptic in eight cases (five males and three females), and hypsiloid in the case of three males. In more than half of the entire series therefore the hard palate is of a simian type.

Nasal index.-No matter which system is employed (French or German), the series easily falls within the platyrhine class; eight out of ten males and six out of eight females being platyrhine.

The naso-malar index $\left(\frac{\text { naso-malar length } \times 100}{\text { bimalar length }}\right)$ represents the degree of prominence of the nasal bridge beyond a straight line connecting the anterior margins of the malar bones. It was used by Oldfield Thomas ${ }^{1}$ with valuable results, and has since been used extensively by $\mathrm{Mr}$. Risley ${ }^{2}$ in India, who accepts Mr. Thomas' nomenclature, but applies the terms to slightly different groupings of the indices. The series from Gazelle Peninsula is arranged according to both methods:

THOMAS

$\begin{array}{c|c|c|c|c}\hline & \text { Platyopic } & \text { Mesopic } & \text { Pro-opic } & \multicolumn{1}{|c}{\text { Average }} \\
$\cline { 2 - 4 } \text {$\left.Males............. } & 6 & 4 & 0 & \text { Platyopic } \\
\text { Females............ } & 3 & 4 & 1 & \text { Mesopic }\end{array}\right\}$\begin{tabular}{l}
107.3 \\
\hline
\end{tabular}

${ }^{1}$ Account of a collection of skulls from Torres Straits. Journal of the Anthropological Institute, XIV, 1885, p. 332.

${ }^{2}$ The Study of Ethnology in India. Journal of the Anthropological Institute, XX, 1891, p. 255. 
RISLEY

$\left.\begin{array}{c|c|c|c|c}\hline & \text { Platyopic } & \text { Mesopic } & \text { Pro-opic } & \text { Average } \\ \hline \text { Males............ } & \text { I0 } & 0 & 0 & \text { Platyopic } \\ \text { Females........... } & 7 & \text { I } & 0 & \text { Platyopic }\end{array}\right\}$ 107.3

The general average index of 107.3 makes the series platyopic, whichever method is used, since the maximum limit placed by Thomas for platyopism is 107.4 and Risley's maximum limit is 109.9 .

Thomas gives an interesting comparative table of average naso-malar indices, to which that of the series under discussion is added:

\begin{tabular}{|c|c|c|}
\hline Number and Kind & Average Index & Range \\
\hline 7 Gorillas.... & 103 & 101.7 to 103.8 \\
\hline 9 Mongols............ & 105.9 & 105.1 to 106.9 \\
\hline 9 Timor Laut Malays.......... & 107.4 & 104.4 to 109.5 \\
\hline 5 Andamanese..$\ldots \ldots \ldots \ldots \ldots$ & 107.5 & 105.5 to 108.5 \\
\hline 25 West African Negroes........... & 108.5 & 106.1 to 113.3 \\
\hline 35 Torres Straits Islanders.. & I08.7 & 106.1 to 112 \\
\hline 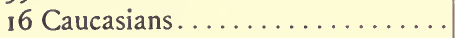 & III. I & 109.1 to 114.2 \\
\hline I 8 Gazelle Peninsula (MacCurdy)... & $107 \cdot 3$ & 104.8 to 110.1 \\
\hline
\end{tabular}

Dental index ${ }^{1}$. On the whole, extreme indices seem to characterize the male sex in any given race. That is to say, indices which commonly fall below 100 average higher, and those greater than 100 average lower in the female sex than in the male. In the Neu Pommern series, for instance, the eleven indices smaller than 100, average 77.7 for the males, and 78.3 for the females; while the three indices greater than 100 ,

${ }^{1}$ Flower, Journal of the Anthropological Institute, XIV, 183. 
average 106.1 for the males and 104.2 for the females. A comparative study of the published results for other series and races would probably reveal a like relation. This sexual difference of the indices, if indeed it prove to be a general one, is well illustrated in the proportion which the combined length of the upper premolars and molars in situ bears to the basinasal length:

\begin{tabular}{|c|c|c|c|c|}
\hline Authority & Number and Country & Sex & $\begin{array}{l}\text { Dental } \\
\text { Index }\end{array}$ & $\begin{array}{l}\text { Average } \\
\text { Index for } \\
\text { Both Sexes }\end{array}$ \\
\hline Flower ....... & 2 I (Melanesia)...... & Male.. & $44 \cdot 2$ & \\
\hline Flower. . . . . . . & 9 (Andaman lslands).... & Male... & 44.4 & \\
\hline Flower........ & 8 (Andaman Islands).... & Female.... & $\begin{array}{l}44 \cdot 4 \\
46.5\end{array}$ & $45 \cdot 5$ \\
\hline Flower. . . . . . . & 22 (Australia)... & Male....... & 44.8 & \\
\hline Flower....... & ${ }_{14}$ (Australia)..... & Female.... & 46.1 & $45 \cdot 5$ \\
\hline Flower... & 9 (Tasmania)... & Male....... & 47.5 & \\
\hline Flower...... & 4 (Tasmania)....... & Female..... & 48.5 & 48.1 \\
\hline Thomas.... . & 5 (Torres Straits).. & Male....... & $43 \cdot 5$ & \\
\hline Thomas... & 2 (Torres Straits) & Female..... & 44.1 & 43.8 \\
\hline Dorsey........ & 4 (New Guinea)..... & Male....... & 41 & \\
\hline Dorsey... . & 6 (New Guinea)..... & Female.... . & & 43 \\
\hline MacCurdy.... & I (Gazelle Peninsula).... . & Male....... & $44 \cdot 9$ & \\
\hline MacCurdy.... & 3 (Gazelle Peninsula).... & Female ..... & $45 \cdot 4$ & $45 \cdot 3$ \\
\hline
\end{tabular}

In the series from Gazelle Peninsula, the combined length in situ of the premolars and molars of the lower jaw averages from $2 \mathrm{~mm}$. to $6 \mathrm{~mm}$. greater than that of the upper jaw. It was, therefore, thought desirable not to calculate indices from measurements on the lower teeth where these were present and the upper teeth were missing. 
All the above groups belong to megadont races, the highest index being reached by the Tasmanians; and in each series, as might have been inferred, the average dental index of the female crania is higher than that of the males. A like relation of the dental index in the two sexes holds true among anthropoids also, as pointed out by Sir William Flower.

The Spina mentalis is either wanting or barely visible. The angle of symphysis is large, being equal to or exceeding a right angle in 47 per cent of the lower jaws. The average for the males is 85.3 degrees and for the females, 89.6. A comparison of these figures with results for other series including Quaternary man places the series from Gazelle Peninsula very near to the latter:

\begin{tabular}{|c|c|c|}
\hline Authority & Number and Kind & $\begin{array}{l}\text { Angle of } \\
\text { Symphysis }\end{array}$ \\
\hline Topinard... & ${ }_{15}$ Parisian......... & $71.4^{\circ}$ \\
\hline Topinard.... & 15 African negro..... & $82.2^{\circ}$ \\
\hline Topinard.... & 15 New Caledonian... & $83.9^{\circ}$ \\
\hline MacCurdy... & I7 Gazelle Peninsula.. & $87.5^{\circ}$ \\
\hline de Vibraye... & Arcy (Quaternary)....... & $90^{\circ}$ \\
\hline Dupont..... & La Naulette (Quaternary)... & $94^{\circ}$ \\
\hline Filhol................. & Malarnaud (Quaternary)....... & $100^{\circ}$ \\
\hline Fraipont and Lohest..... & Spy No. 1 (Quaternary)....... & $107^{\circ}$ \\
\hline
\end{tabular}

Summary.-The skulls are small and all dolichocephalic. The minimum and maximum frontal diameters average respectively $20.3 \mathrm{~mm}$. and $25.7 \mathrm{~mm}$. less than for English crania. The height averages greater than the greatest breadth, a character called hypsistenocephaly. The crania are prognathous, platyrhine, platyopic, phaenozygous, and megadont. Glabella and superciliary arches, prominent. Apertura pyriformis, simian in character. Fossae caninae, pronounced. The teeth are well preserved and not crowded. The wisdom teeth are lacking in none. There is a tendency toward a division of 
the root of the first upper premolars. The alveolar arch of the upper jaw projects considerably beyond (in one case as much as $12 \mathrm{~mm}$.) the third molars. The percentage of first lower premolars with anterior roots is high. The spina mentalis is practically wanting, and the angle of symphysis, large. 
SKULLS FROM GAZELLE

\begin{tabular}{|c|c|c|c|c|c|c|c|c|}
\hline \multirow[b]{2}{*}{ Museum Number } & \multicolumn{8}{|c|}{ Males } \\
\hline & 11610 & 11611 & 11612 & 11615 & 11617 & 11618 & 11621 & 11622 \\
\hline Capacity... & 1328 & $\ldots$ & 1470 & 1385 & 1363 & 1078 & 1305 & 1315 \\
\hline Weight of cranium ........... & 697 & .. & 600 & 760 & 633 & 703 & $63 I$ & 750 \\
\hline Weight of lower jaw.......... & 118 & & 109 & 105 & 106 & 93 & 114 & 97 \\
\hline Antero-posterior, diameter.... & 185 & 186 & 182 & I 88 & 184 & 176 & 176 & 180 \\
\hline erse maximum, diameter. & 128 & 124 & 134 & 140 & 124 & 122 & 132 & 132 \\
\hline Frontal maximum, diameter... & 108 & 106 & 116 & 113 & 107 & 106 & 108 & 110 \\
\hline Frontal minimum, diameter... & 95 & 93 & 94 & 98 & 90 & 94 & 93 & 90 \\
\hline Bizygomatic, breadth......... & 135 & $\ldots$ & 135 & 136 & 135 & 130 & 138 & 130 \\
\hline ular, breadth......... & 115 & 112 & 118 & 125 & 113 & 113 & 122 & 123 \\
\hline oregmatic, height........ & 139 & $\ldots$ & 136 & 131 & 138 & 127 & 132 & 126 \\
\hline olar, length........ & I08 & $\ldots$ & 104 & 110 & 113 & 105 & 107 & 108 \\
\hline sal, length. . . . . . . & 101 & $\ldots$ & 102 & 103 & 105 & 96 & 96 & 100 \\
\hline n magnum, length. . . . . . & 36 & .. & 39 & 31 & 37 & 31 & 31 & 37 \\
\hline num, breadth.... & 35 & $\ldots$ & 30 & 28 & 29 & 24 & 26 & 28 \\
\hline$h \ldots \ldots \ldots \ldots$ & 59 & . & 55 & 56 & 63 & 57 & 55 & 60 \\
\hline breadth . . . . . . . . . . & 35 & $\ldots$ & 30 & 28 & 29 & 24 & 26 & 28 \\
\hline 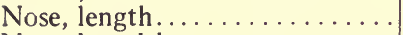 & 48 & & 53 & 48 & 48 & $4 \mathrm{I}$ & 49 & 48 \\
\hline $\mathrm{dth} \ldots \ldots \ldots \ldots$ & 26 & & 26 & 28 & 27 & 25 & 27 & 30 \\
\hline dth $\ldots \ldots \ldots \ldots \ldots$ & 38 & 38 & 37 & 38 & 37 & 39 & 38 & 38 \\
\hline eight . . . . . . . . & 33 & 32 & 36 & 34 & 34 & 33 & 31 & 35 \\
\hline l, breadth ......... & 28 & 25 & 24 & 25 & 24 & 26 & 27 & 27 \\
\hline ionic, length....... & 69 & $\ldots$ & 70 & 64 & 67 & 62 & 69 & \\
\hline breadth........ & 102 & $\ldots$ & 99 & 100 & 96 & 101 & 104 & 100 \\
\hline $\operatorname{ar} \ldots \ldots$ & I IO & ... & 104 & 105 & 105 & 109 & 109 & 107 \\
\hline lar, breadth......... & 124 & I 12 & 11.5 & 125 & 117 & 116 & 121 & 117 \\
\hline , breadth............ & 96 & 79 & 98 & 95 & 97 & 87 & 94 & 93 \\
\hline s, height. . . . . . . & 33 & 30 & 28 & 30 & 33 & 28 & 32 & 29 \\
\hline pight & 30 & 26 & 28 & 29 & 30 & 23 & 27 & 23 \\
\hline bular angle. . . . . . . & $108^{\circ}$ & $119^{\circ}$ & $109^{\circ}$ & $105^{\circ}$ & $113^{\circ}$ & $111^{\circ}$ & $121 \circ$ & $118^{\circ}$ \\
\hline mphysis....... & $88^{\circ}$ & $78^{\circ}$ & $75^{\circ}$ & $87^{\circ}$ & $92^{\circ}$ & $86^{\circ}$ & $85^{\circ}$ & $82^{\circ}$ \\
\hline 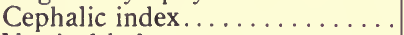 & 69 & 67 & 74 & 75 & 67 & 69 & 75 & 73 \\
\hline & 75 & $\ldots$ & 75 & 70 & 75 & 72 & 75 & 70 \\
\hline so-vertical. . . . . . . . & Iog & $\ldots$ & 102 & 94 & I I I & 104 & 100 & 96 \\
\hline 然 & 107 & $\ldots$ & 102 & 107 & 108 & 109 & III & 108 \\
\hline Pal & $6 I$ & $\ldots$ & 73 & 77 & 60 & 64 & 76 & 68 \\
\hline & 54 & & 49 & 58 & 56 & $6 I$ & 55 & 62 \\
\hline & 87 & 84 & 97 & 90 & 92 & 85 & 82 & 92 \\
\hline Facial. & $5 \mathrm{I}$ & $\ldots$ & 50 & 47 & 42 & 47 & 50 & 52 \\
\hline 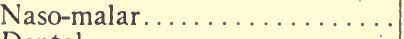 & 108 & . & 105 & 105 & 109 & 108 & 105 & 107 \\
\hline$\cdots \ldots \ldots \ldots \ldots$ & $\cdots$ & $\cdots$ & & $\cdots$ & 45 & & $\ldots$ & $\ldots$ \\
\hline
\end{tabular}


PENINSULA, NEW BRITAIN

\begin{tabular}{|c|c|c|c|c|c|c|c|c|c|c|c|c|c|}
\hline \multirow[b]{2}{*}{16911} & \multirow[b]{2}{*}{18280} & \multirow[b]{2}{*}{18282} & \multicolumn{8}{|c|}{ FEMALES } & \multirow{2}{*}{ 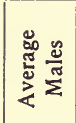 } & \multirow{2}{*}{ 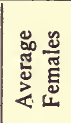 } & \multirow{2}{*}{ 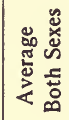 } \\
\hline & & & 11613 & 11620 & 11609 & 11614 & 11623 & 16912 & 18283 & 18281 & & & \\
\hline 1382 & 1408 & 1418 & 1190 & 1285 & 1224 & 1165 & 1200 & 1133 & 1194 & 1325 & 1345 & 1215 & 1280 \\
\hline 639 & 1014 & 718 & 649 & 580 & 471 & 486 & 414 & 460 & 515 & 540 & 715 & 534 & 625 \\
\hline 92 & 149 & 96 & 82 & 86 & 76 & 78 & 67 & 42 & 75 & 76 & 108 & 73 & 91 \\
\hline 190 & 190 & 192 & 167 & 176 & 181 & 170 & 177 & 174 & 175 & 174 & 182 & 174 & 178 \\
\hline 133 & 130 & 130 & 129 & 128 & 126 & 127 & 123 & 124 & 125 & 128 & 130 & 126 & 128 \\
\hline 108 & 108 & 106 & 106 & 106 & 106 & 101 & 105 & 98 & 102 & 108 & 109 & 104 & 107 \\
\hline 89 & 96 & 93 & 95 & 93 & 94 & 90 & $9 \mathrm{I}$ & 82 & 87 & 91 & 93 & 90 & 92 \\
\hline 130 & 136 & 140 & 128 & 123 & 129 & 124 & 120 & 132 & 124 & 129 & 133 & 126 & 130 \\
\hline 122 & 122 & 120 & 113 & 113 & 116 & 116 & 114 & 116 & 116 & 117 & 119 & 115 & 117 \\
\hline 136 & 149 & 143 & 128 & 127 & 124 & 120 & 122 & 130 & 128 & 128 & 136 & 126 & 131 \\
\hline 116 & 112 & 110 & 98 & 107 & 108 & 98 & 102 & $\cdots$ & 97 & 105 & 110 & 102 & 106 \\
\hline 104 & 106 & 105 & 92 & 97 & 101 & 95 & 98 & 99 & 95 & 98 & 102 & 97 & 100 \\
\hline 31 & 37 & 39 & 30 & 33 & 31 & 32 & 32 & 32 & 31 & 34 & 35 & 32 & 34 \\
\hline 29 & 28 & 29 & 27 & 26 & 27 & 29 & 28 & 26 & 24 & 32 & 29 & 27 & 28 \\
\hline 60 & 56 & 58 & 47 & 58 & 60 & 53 & 52 & $\ldots$ & 51 & 58 & 52 & 54 & 53 \\
\hline 29 & 28 & 39 & 33 & 33 & 42 & 35 & 39 & $\ldots$ & 39 & 36 & 39 & 37 & 38 \\
\hline 50 & 49 & 47 & 40 & 44 & 44 & 44 & 48 & 50 & $4^{6}$ & 43 & 48 & 45 & 47 \\
\hline 25 & 29 & 29 & 24 & 25 & 24 & 24 & 27 & 25 & 21 & 26 & 27 & 25 & 26 \\
\hline 37 & 37 & 39 & 38 & 38 & 38 & 35 & 36 & 37 & 36 & 36 & 38 & 37 & 38 \\
\hline 34 & 31 & 31 & 31 & 32 & 31 & 32 & 34 & 34 & 33 & 31 & 33 & 32 & 33 \\
\hline 24 & 27 & 26 & 24 & 24 & 27 & 24 & 26 & 23 & 22 & 23 & 26 & 24 & 25 \\
\hline $7 \mathrm{I}$ & 64 & 62 & 52 & $\ldots$ & 61 & 63 & 62 & $\ldots$ & 59 & 62 & 66 & 60 & 63 \\
\hline 96 & 100 & 103 & 98 & 97 & 101 & 91 & 94 & 95 & 94 & 95 & 100 & 96 & 98 \\
\hline 102 & 108 & 109 & 104 & 103 & 110 & 100 & 104 & 103 & 102 & 101 & 107 & 103 & 105 \\
\hline 115 & 121 & 122 & $11 \mathrm{I}$ & 102 & 110 & 113 & 103 & $\ldots$ & 109 & 115 & 119 & 109 & 114 \\
\hline 88 & 93 & $8 \mathrm{I}$ & 89 & 80 & $8 I$ & $8 \mathrm{I}$ & 78 & $\ldots$ & 82 & 82 & 91 & 82 & 87 \\
\hline 32 & 34 & 30 & 26 & 30 & 29 & 26 & 26 & $\ldots$ & 29 & 28 & 31 & 28 & 30 \\
\hline 27 & 35 & 24 & 24 & 23 & 25 & 24 & 22 & $\ldots$ & 27 & 24 & 27 & 24 & 26 \\
\hline $117^{\circ}$ & $107^{\circ}$ & $112^{\circ}$ & $116^{\circ}$ & $113^{\circ}$ & $111^{\circ}$ & $116^{\circ}$ & $119^{\circ}$ & . & $108^{\circ}$ & $116^{\circ}$ & $113^{\circ}$ & $114^{\circ}$ & $113^{\circ}$ \\
\hline $97^{\circ}$ & & $88^{\circ}$ & $83^{\circ}$ & $90^{\circ}$ & $92^{\circ}$ & $90^{\circ}$ & $90^{\circ}$ & $\cdots$ & $92^{\circ}$ & $90^{\circ}$ & $85^{\circ}$ & $90^{\circ}$ & $88^{\circ}$ \\
\hline 70 & 68 & 68 & 77 & 73 & 70 & 75 & 70 & $7 \mathrm{I}$ & 71 & 74 & 71 & 73 & 72 \\
\hline 72 & 78 & 75 & 77 & 72 & 69 & $7 \mathrm{I}$ & 69 & 75 & 73 & 74 & 74 & 72 & 73 \\
\hline 102 & 114 & 110 & 99 & 99 & 98 & 95 & 99 & 105 & 102 & 100 & 104 & 100 & 102 \\
\hline 112 & 106 & 105 & 107 & I I I & 107 & 104 & 104 & $\cdots$ & 102 & 107 & 108 & 106 & 107 \\
\hline 63 & 71 & 67 & 70 & 57 & 70 & 66 & 75 & $\ldots$ & 77 & 62 & 68 & 68 & 68 \\
\hline 50 & 58 & 62 & 61 & 57 & 55 & 55 & 56 & 50 & $4^{6}$ & 61 & 57 & 55 & 56 \\
\hline 92 & 84 & 80 & 83 & 84 & 82 & 91 & 93 & 92 & 92 & 86 & 88 & 88 & 88 \\
\hline 54 & 46 & 48 & 42 & 48 & 47 & 50 & 52 & $\cdots$ & 48 & 48 & 49 & 48 & 49 \\
\hline 107 & 108 & 106 & 106 & 106 & 109 & IIO & 110 & 108 & 108 & 106 & 107 & 108 & 107 \\
\hline$\cdots$ & & $\ldots$ & $\cdots$ & 49 & $\cdots$ & $4^{6}$ & $\ldots$ & $\ldots$ & 42 & $\cdots$ & 45 & 45 & 45 \\
\hline
\end{tabular}





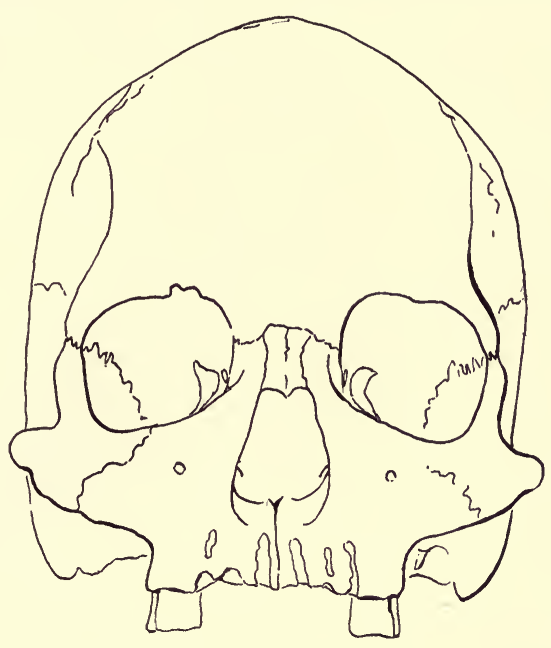

Norma Facialis

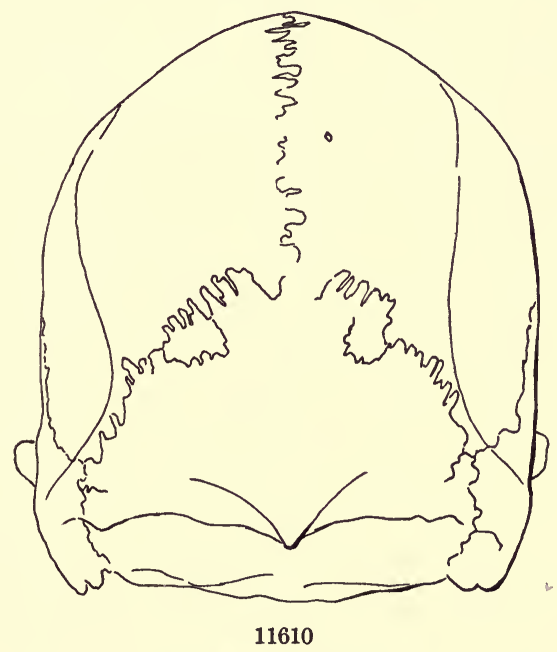

NORMa OCCIPITALIS 

$=$
$w$
$\frac{5}{a}$

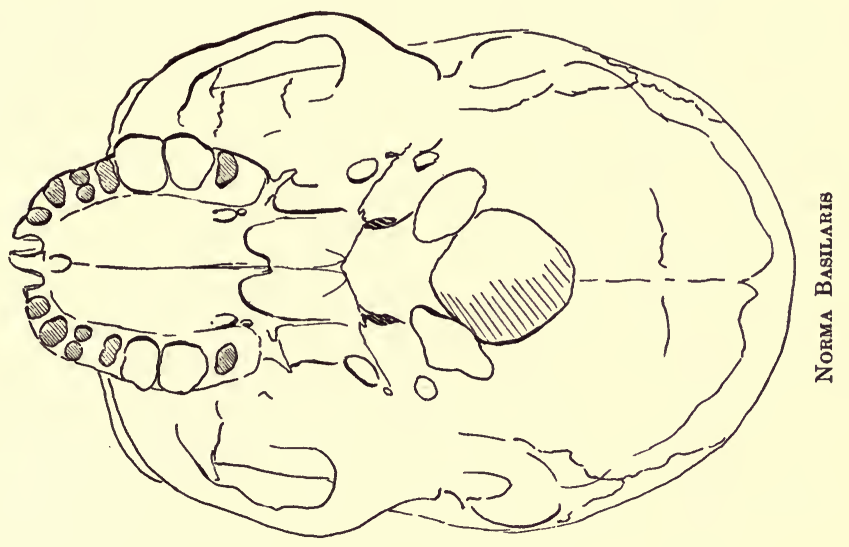

융

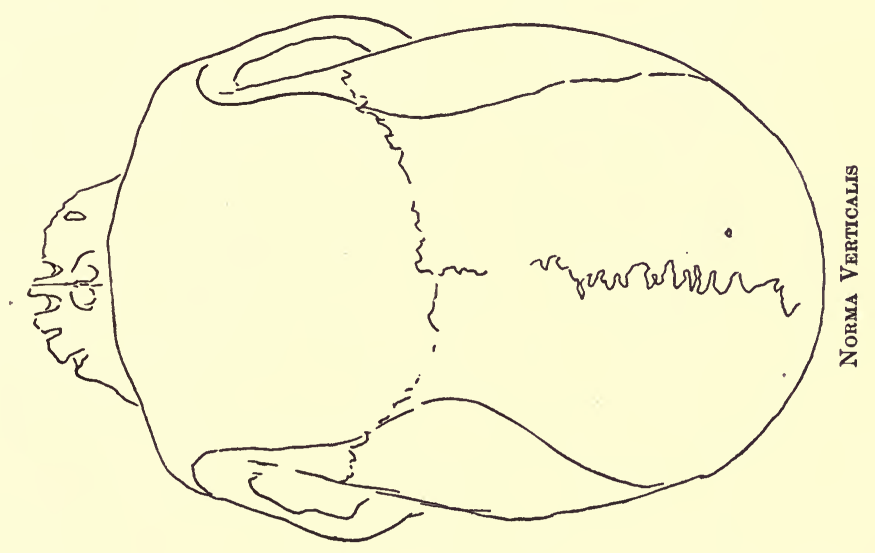





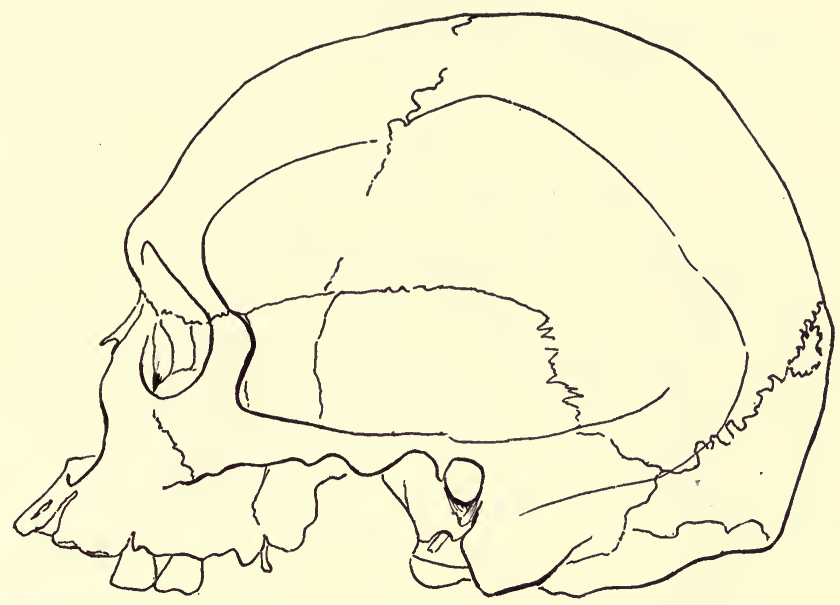

- 11610

Norma Lateralis

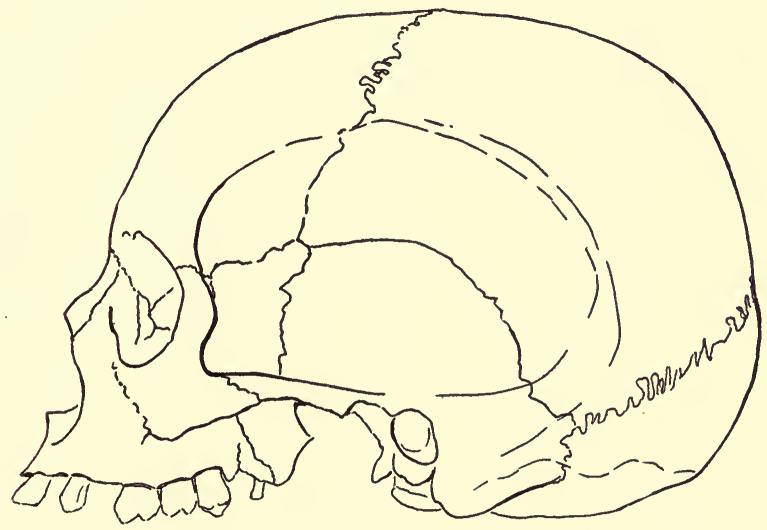

11614

Norma Lateralis 


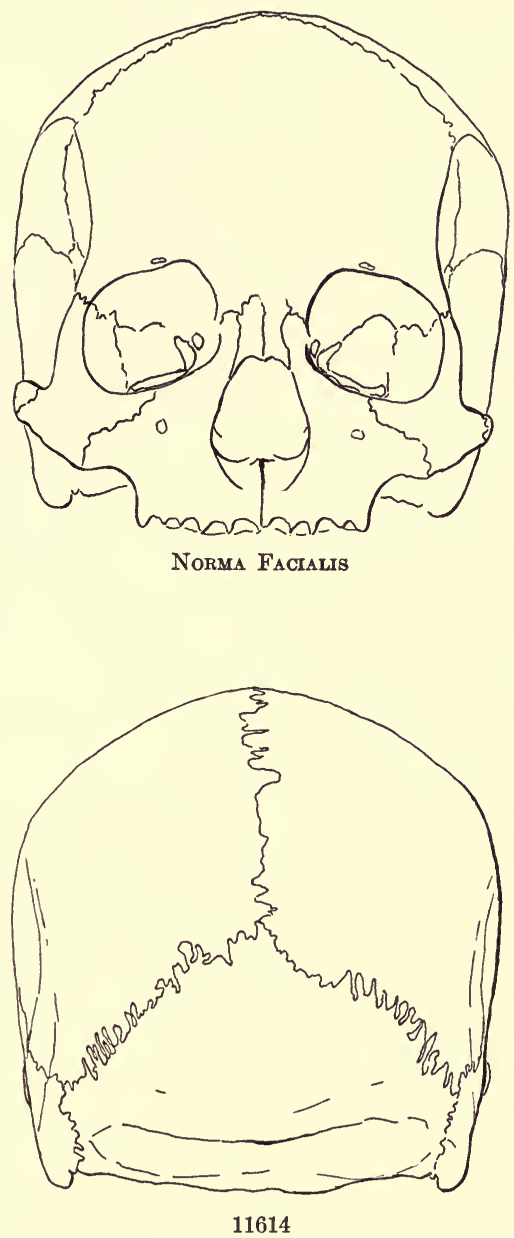

Norma Occipitalis 

ANTHR. PUB. UNIV. MUSEUM VOL. VI

PLATE $v$
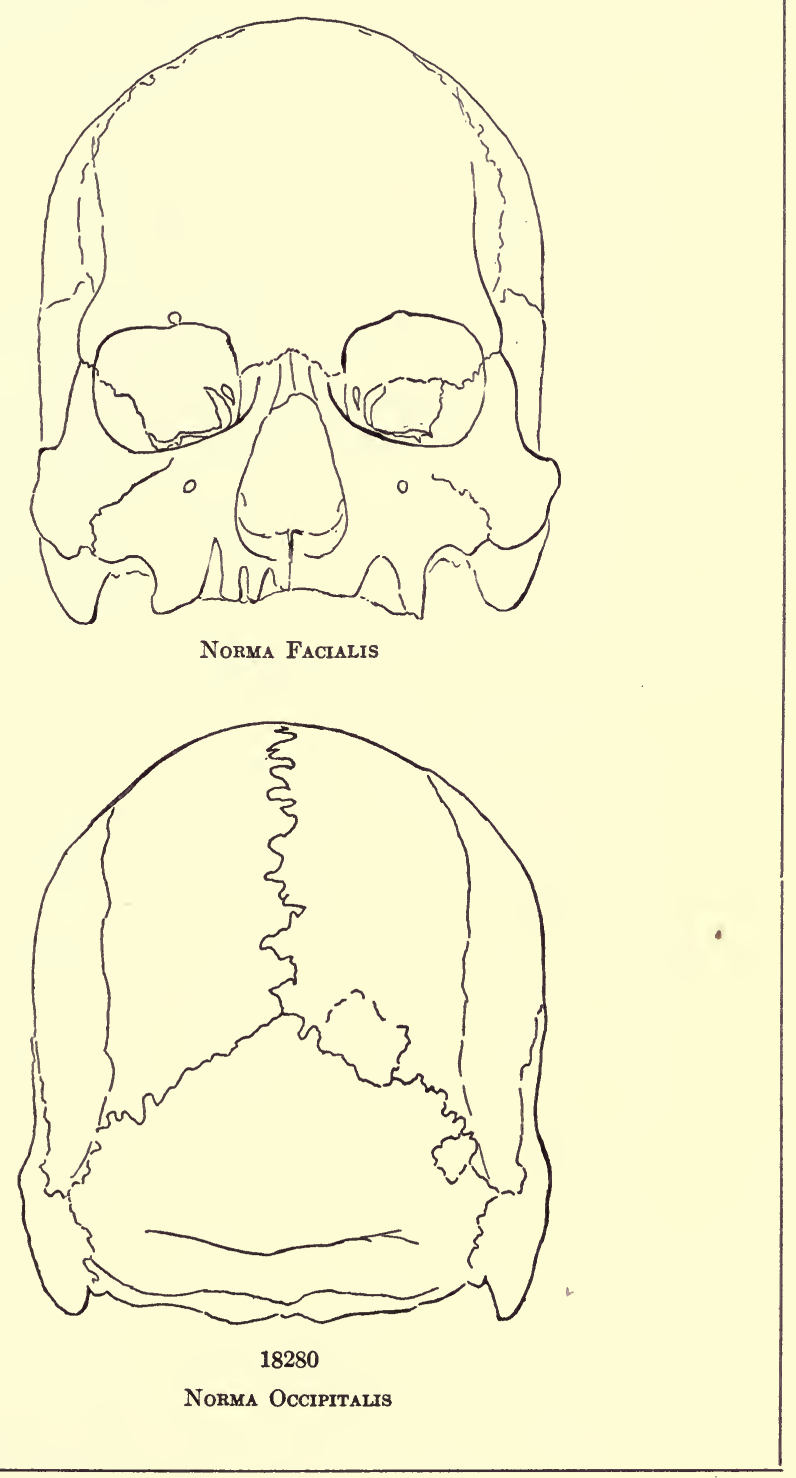



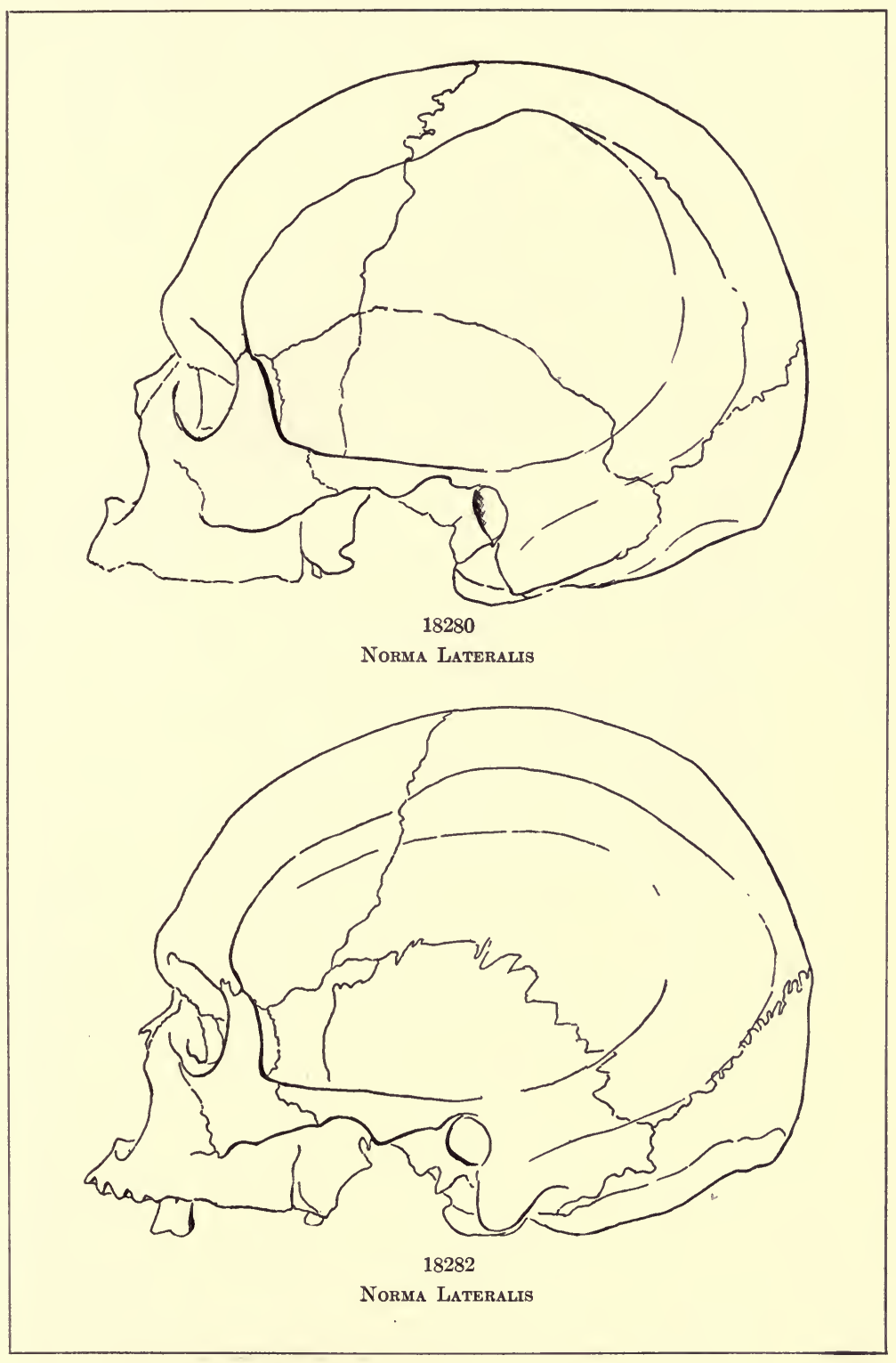





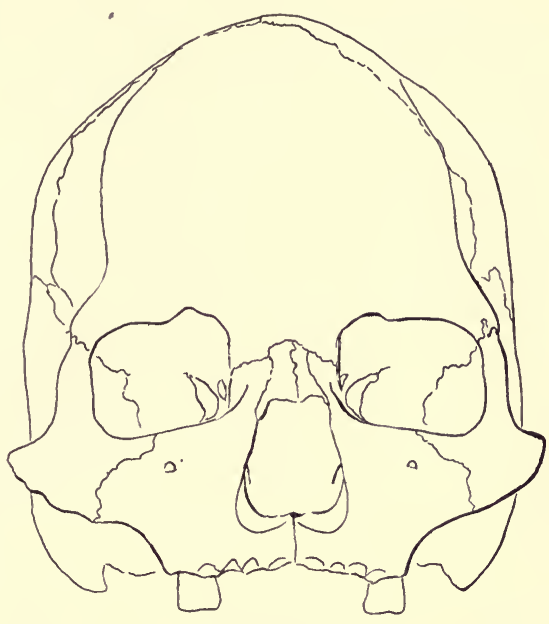

Norma Facialis

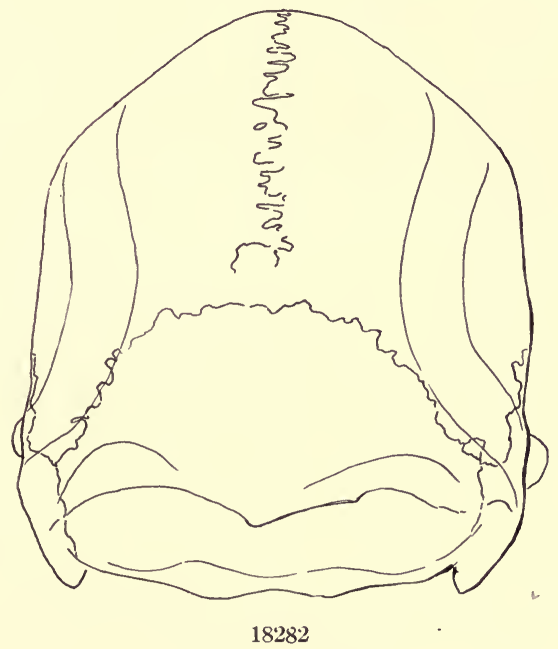

Norma Occipitalis 



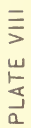

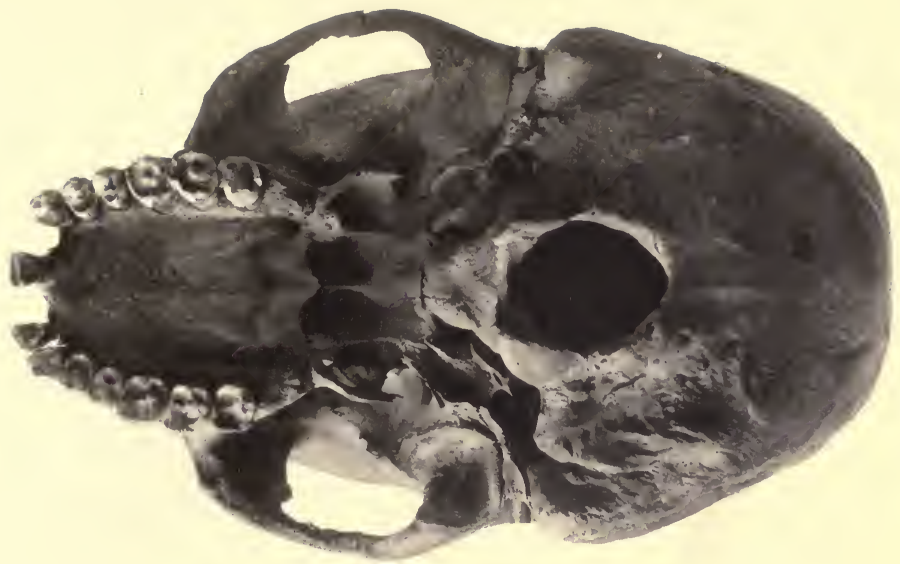

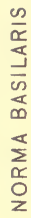

$\frac{1}{6}$

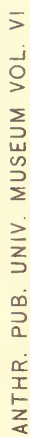

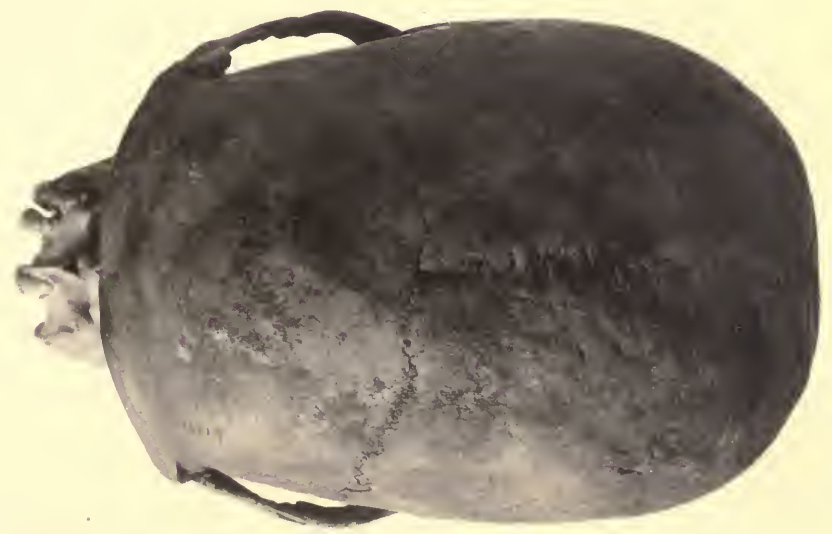

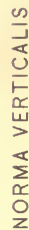



$\frac{x}{w}$

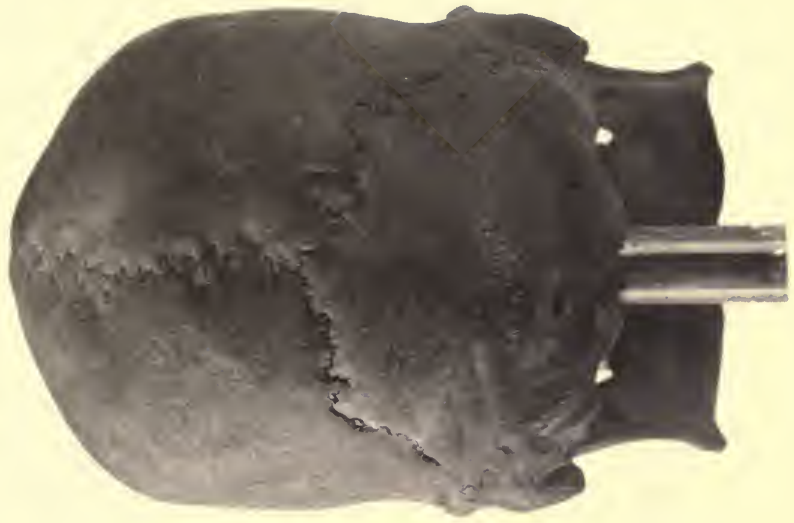

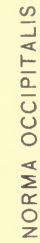

$\frac{1}{6}$ 



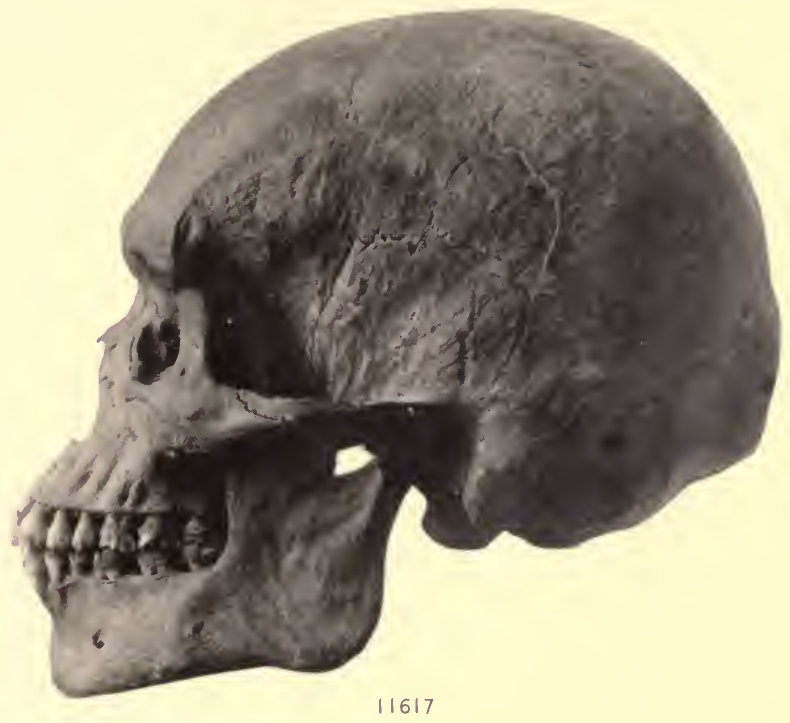

NORMA LATERALIS

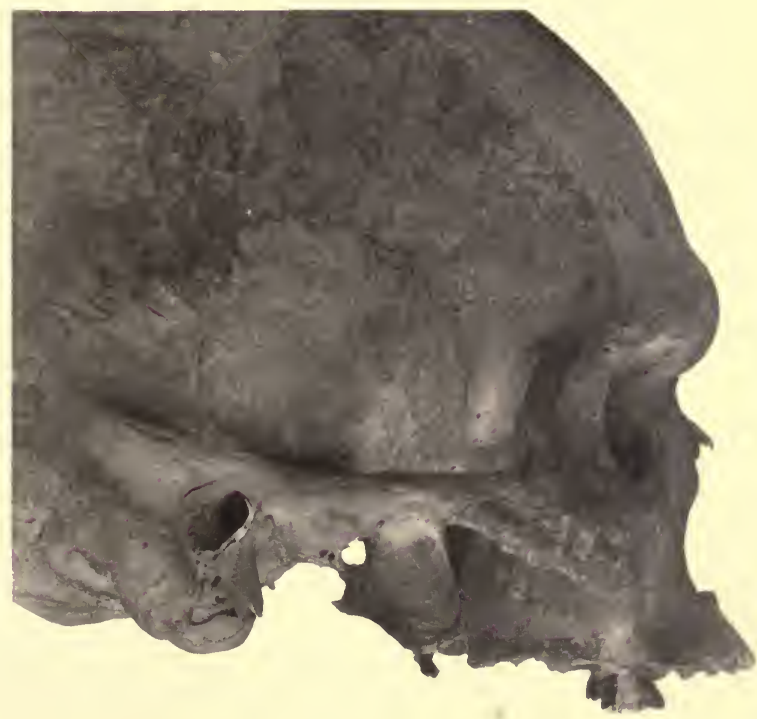

18282

FORAMEN PTERYGO-SPINOSUM PRODUCED BY THE OSSIFICATION OF THE LIGAMENTUM PTERYGO-SPINOSUM 



$\therefore-x^{2}-1$ $-\frac{5}{3}$

$-\ldots+\cdots, \ldots+=$

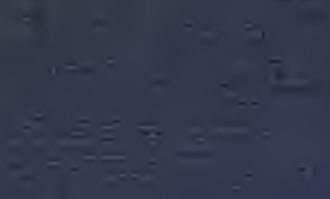

$$
=x-8
$$



UNIVERSITY OF PENNSYLVANIA

THE UNIVERSITY MUSEUM

'ANTHROPOLOGICAL PUBLICATIONS YOL Vh

No. 2

THE DANCE FESTIVALS OF THE ALASKAN RSKIMO

Bit

E. W. HAWKES

\author{
FMILADELPMIA
}

PUDLIEKED AY THE UNIVEASITY MUSEU 1914 
UNIVERSITY OF PENNSYLVANIA THE UNIVERSITY MUSEUM A NTHROPOLOGICAL PUBLICATIONS VoL. VI No. 2

\section{THE DANCE FESTIVALS OF THE ALASKAN ESKIMO \\ BY \\ E. W. HAWKES}

PHILADELPHIA

PUBLISHED BY THE UNIVERSITY MUSEUM

1914 



\section{CONTENTS}

PAGE

INTRODUCTION ................. 5

PHONETIC KEY................. 7

THE DANCE IN GENERAL.............. 9

The Chorus..................... 10

Participation of the Sexes........... I I

THE KĀSGI OR DANCE HOUSE............ I3

Paraphernalia.................... 15

THE DANCE FESTIVALS.............. 19

The Asking Festival............... 22

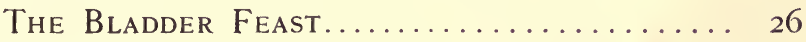

The Feasts to the Dead.............. 29

THE ANNUAL FEAST, AILÍGI............ 31

THE GREAT FEAST, AITHUKÁTUKHTUK...... 33

The Feast Givers................ 34

The Ritual..................... 35

The Clothing of the Namesakes......... 38

THE INVITING-IN FESTIVAL........... 40 



\section{INTRODUCTION}

This account of the Dance Festivals of the Alaskan Eskimo was written from material gathered in the Bering Strait District during three years' residence: two on the Diomede lslands, and one at St. Michael at the mouth of the Yukon River. This paper is based on my observations of the ceremonial dances of the Eskimo of these two localities. 



\section{PHONETIC KEY}

$\bar{a}, \bar{e}, \bar{i}, \bar{o}, \bar{u}$, long vowels.

a, e, i, o, u, short vowels.

$\ddot{a}$, as in hat.

$\hat{a}$, as in law.

ai, as in aisle.

$\mathrm{au}$, as ow in how.

h, w, y, semivowels.

$c$, as sh in should.

f, a bilabial surd.

$\mathrm{g}$, as in get.

g, a post-palatal sonant.

$\mathrm{k}$, as in pick.

1 , as in lull.

$\mathrm{m}$, as in mum.

$\mathrm{n}$, as in nun.

$\mathrm{ng}$, as ng in sing.

$\mathrm{p}$, as in pipe.

q, a post-palatal surd.

$\dot{r}$, a uvular sonant spirant.

$s$, as in sauce.

$t$, an alveolar stop.

tc, as ch in chapter.

$\mathrm{v}$, a bilabial sonant.

$\mathrm{z}$, as in zone. 



\section{THE DANCE FESTIVALS OF THE ALASKAN ESKIMO}

\section{THE DANCE IN GENERAL}

The ceremonial dance of the Alaskan Eskimo is a rhythmic pantomime-the story in gesture and song of the lives of the various Arctic animals on which they subsist and from whom they believe their ancient clans are sprung. The dances vary in complexity from the ordinary social dance, in which all share promiscuously and in which individual action is subordinated to rhythm, to the pantomime totem dances performed by especially trained actors who hold their positions from year to year according to artistic merit. ${ }^{1}$ Yet even in the totem dances the pantomime is subordinate to the rhythm, or rather superimposed upon it, so that never a gesture or step of the characteristic native time is lost.

This is a primitive 2-4 beat based on the double roll of the chorus of drums. 'Time is kept, in the men's dances, by stamping the foot and jerking the arm in unison, twice on the right, then twice on the left side, and so on, alternately. Vigorous dancers vary the program by leaping and jumping at intervals, and the shamans are noted for the dizzy circles which they run round the púgyarok, the entrance hole of the dance hall. The

\footnotetext{
1 This characterization applies to the Alaskan Eskimo only; so far as is now known the other Eskimo branches do not have totemic dances.
} 
women's dance has the same measure and can be performed separately or in conjunction with the men's dance, but has a different and distinctly feminine movement. The feet are kept on the ground, while the body sways back and forth in graceful undulations to the music and the hands with outspread palms part the air with the graceful stroke of a flying gull. Some of their dances are performed seated. Then they strip to the waist and form one long line of waving arms and swaying shoulders, all moving in perfect unison.

\section{The Chorus}

The chorus which furnishes the music, is composed of from six to ten men. They sit on the inglak, a raised shelf extending around the dance hall about five feet from the floor, and sing their dance songs keeping time on their drums. They usually sit in the rear of the room, which is the post of honor. Among the island tribes of Bering Strait this position is reversed and they occupy the front of the room. Some old man, the keeper of tribal tradition and song, acts as the leader, calling out the words of the dance songs a line ahead. He begins the proceedings by striking up a low chant, an invitation to the people assembled to dance. The chorus accompany him lightly on their drums. Then at the proper place, he strikes a crashing double beat; the drums boom out in answer; the song arises high and shrill; the dancers leap into their places, and the dance begins.

The first dances are usually simple exercises calculated to warm the blood and stretch stiffened muscles. They begin with leaping around the púgyarok, jumping into the air with both 
feet in the Eskimo high kick, settling down into the conventional movements of the men's dance. ${ }^{1}$

Quite often a woman steps into the center of the circle, and goes through her own dance, while the men leap and dance around her. This act has been specialized in the Reindeer and Wolf Pack Dance of the Aithúkaguk, the Inviting-In Festival, where the woman wearing a reindeer crest and belt is surrounded by the men dancers, girt in armlets and fillets of wolf skin. They imitate the pack pulling down a deer, and the din caused by their jumping and howling around her shrinking form is terrific.

\section{Participation of the Sexes}

There appears to be no restriction against the women taking part in the men's dances. They also act as assistants to the chief actors in the Totem Dances, three particularly expert and richly dressed women dancers ranging themselves behind the mask dancer as a pleasing background of streaming furs and glistening feathers. The only time they are forbidden to enter the kásgi is when the shaman is performing certain secret rites. They also have secret meetings of their own when all men are banished.2 I happened to stumble on to one of these one time when they were performing certain rites over a pregnant woman,

1 While the northern and southern tribes have the same general movements for their ordinary dances, they give a very different presentation of the festival dance-songs. The northerners leap and stamp about the kásgi until overcome with exhaustion; while in the south the performers sit or kneel on the floor, adorned with an abundance of streaming furs and feathers, sweep their hands through the air in graceful unison. It is a difference between rude vigor and dramatic art.

2 This custom appears to be widespread. Low writes of the Hudson Bay Eskimo: “During the absence of the men on hunting expeditions, the women sometimes amusé themselves by a sort of female "angekoking." This amusement is accompanied by a number of very obscene rites . . . . ." Low, The Cruise of the Neptune, p. 177. 
but being a white man, and therefore unaccountable, I was greeted with a good-natured laugh and sent about my business.

On the other hand, men are never allowed to take part in the strictly women's dances, although nothing pleases an Eskimo crowd more than an exaggerated imitation by one of their clowns of the movements of the women's dance. The women's dances are practiced during the early winter and given at the Aiyáguk, or Asking Festival, when the men are invited to attend as spectators. They result in offers of temporary marriage to the unmarried women, which is obviously the reason for this rite. Such dances, confined to the women, have not been observed in Alaska outside the islands of Bering Sea, and I have reason to believe are peculiar to this district, which, on account of its isolation, retains the old forms which have died out or been modified on the mainland. But throughout Alaska the women are allowed the utmost freedom in participating in the festivals, either as naskuks ${ }^{1}$ or feast givers, as participants or as spectators.

In fact, the social position of the Eskimo woman has been misrepresented and misunderstood. At first sight she appears to be the slave of her husband, but a better acquaintance will reveal the fact that she is the manager of the household and the children, the business partner in all his trades, and of ten the "oomíalik," or captain of the concern as well. Her husband is forbidden by tribal custom to maltreat her, and if she owns the house, she can order him out at any time. I have never known a woman being head of a tribe, but sometimes a woman is the most influential member of a tribe.

\footnotetext{
${ }^{1}$ Literally "Heads" or directors of the feasts.
} 


\section{THE KĀSGI OR DANCE HOUSE}

With few exceptions, all dances take place in the village kásgi or dance hall. This is the public meeting place where the old men gather to sit and smoke while they discuss the village welfare, where the married men bring their work and take their sweat baths, and where the bachelors and young men, termed kásgimiut, have their sleeping quarters. The kásgi is built and maintained at public expense, each villager considering it an honor to contribute something. Any tools or furnishings brought into the kásgi are considered public property, and used as such.

W'hen a kásgi is to be built, announcement is made through messengers to neighboring villages, and all gather to assist in the building and to help celebrate the event. First a trench several feet deep is dug in which to plant the timbers forming the sides. These are usually of driftwood, which is brought by the ocean currents from the Yukon. The ice breaks up first at the head of that great stream, and the débris dams up the river, which overflows its banks, tearing down trees, buildings and whatever borders its course as it breaks its way out to the sea. The wreckage is scattered along the coast for over a hundred miles, and the islands of Bering Sea get a small share. The islanders are constantly on the lookout for the drifting timber, and put out to sea in the stormiest weather for a distant piece, be it large or small. They also patrol the coast after a high tide for stray bits of wood. When one considers the toil and pain with which material is gathered, the building of a kásgi becomes an important matter. 
After the timbers have been rough hewn with the adze (úlimon) they are set upright in the trench to a height of seven to eight feet and firmly bedded with rock. This is to prevent the fierce Polar winds which prevail in midwinter from tearing the houses to pieces. In the older buildings a protecting stone wall was built on the sides. Most of the houses are set in a side hill, or partly underground, for additional security, as well as for warmth. The roof is laid on top of the uprights, the logs being drawn in gradually in pyramid shape to a flat top. In the middle of the top is the rálok or smoke hole, an opening about two feet square. In a kásgi thirty feet square the rálok is twenty feet above the floor. It is covered with a translucent curtain of walrus gut. The dead are always taken out through this opening, and never by the entrance. The most important feature of the room is the inglak, a wide shelf supported by posts at intervals. It stands about five feet high extending around the room. This serves the double purpose of a seat and bed for the inmates of the kásgi. The rear, the káan, is the most desirable position, being the warmest, and is given to headmen and honored guests. ${ }^{1}$ The side portions, káaklim, are given to the lesser lights and the women and children; and the front, the oaklim, being nearest the entrance and therefore cold and uncomfortable is left for the orphans and worthless men.

The floor of the kásgi is made of rough planking, and the boards in the center are left loose so that they may be easily removed. These cover the kēnéthluk or fireplace, an excavation

${ }^{1}$ The order of the seating on the inglak of invited guests is a matter of great concern to the Eskimo, as it is an indication of worth.

Children purchase their right to a seat in the kásgi by making presents, through their parents, to all the inmates, kásgimiut.

Until they do so they have no right to enter. For the same reason strangers on entering the kásgi offer a small present to the headman, who divides it among the people. 
four feet square, and four feet deep, used in the sweat baths. It is thought to be the place where the spirits sit, when they visit the kásgi, during festivals held in their honor. Offerings are poured to them through the cracks in the planks. In the center of the floor is a round hole about two feet in diameter, called the entrance hole or púgyarok. This connects with a long tunnel, the aǵveak, which leads outside. The tunnel is usually so low that it is necessary to enter in a stooping position, which the Eskimo does by placing both hands on the sides of the púgyarok, and drawing himself through. Some dancehouses have another entrance directly into the room on a level with the ground, the underground passage being used only in winter. The diagram (Plate XI) gives an idea of this arrangement.

\section{PARAPHERNALIA}

The drum (saúyit) ${ }^{1}$ is the only instrument employed in the dances. It is made of a circular hoop about eighteen inches in width over which is stretched a resonant covering made from the bladder of the walrus or seal. It is held in place by a cord of rawhide (oklinok) ${ }^{2}$ which fits into a groove on the outer rim. The cover can therefore be tightened at will. It is customary during the intermissions between the dances for the drummers to rub a handful of snow over the skins to prevent them from cracking under the heavy blows. The drum is held aloft and struck with a thin stick (múmwa). ${ }^{3}$ It gives a deep boom in answer. The shaman uses a smaller baton with which he beats a continuous tattoo as an accompaniment to his songs. The

1 Tcáuyak, Yukon dialect.

${ }^{2}$ Lóftak, Yukon dialect.

${ }^{3}$ Múmra, Yukon dialect. 
northerners strike the back of the rim with their sticks, while the Yukon people belabor the face of the drum.

The leader of the chorus frequently flourishes a baton, made from a fox tail or the skin of the ermine which is mounted on a stick. With this he marks the time of the dance. In Plate XIV, the white blur is the ermine at the end of his stick. It is very difficult to obtain a good picture in the ill lighted kásgi, and not often that the natives will allow one taken there.

One indispensable part of a male dancer's outfit is his gloves. I have never seen a man dancing without them. These are usually of wolverine, or of reindeer with elaborate trimmings, but on ordinary occasions any kind will do. The women do not share this peculiarity. In place of gloves they wear handlets of grass decorated with feathers of duck or of ptarmigan. The men in the Totem Dances also wear handlets which are carved and painted to represent the particular totem they seek to honor. These too are fantastically decorated with feathers, usually of the loon. The central feather is stripped, and crowned with a tuft of white down. Both men and women wear armlets and fillets of skin or feathers according to the animal character they represent. When in the full swing of the dance with fur and feathers streaming they present a pleasing spectacle, a picture full of the same wild grace and poetic motion which characterizes the animal forbears from which they claim descent.

The chief characters in the Totem and Comic Dances wear masks and carry staves decorated with feathers. Occasionally the women assistants carry feathered wands (Kelízruk).

Of the masks there is a great variety ranging from the plain wooden masks to those of such great size that they are suspended 
from the ceiling of the kásgi by a cord while the dancer performs behind them.

The Cape Prince of Wales (Kinigumiut) Eskimo construct complete figures of their totems. These are worked by means of concealed strings by the performers, a climax of art which is supposed to be particularly pleasing to the spirits addressed. Then the shaman (Túngalik) ${ }^{1}$ has his own set of masks, hideous enough to strike terror to even the initiated. Each one of these represents a familiar spirit (túnghat) ${ }^{2}$ which assists him in his operations.

Ordinary dance masks may be made by anyone, but the masks for the ceremonial dances are made by some renowned shaman, engaged for the occasion. These masks are burned at the close of the festival, but may be sold by the actors if they supply an equal amount of wood for the sacrificial fire.

Many of the masks are very complicated, having appendages of wood, fur and feathers. They are all fashioned with an idea of representing some feature in the mythology of the spirit (Inua) or animal shade (Tunghat) which they represent. In the latter case they are nearly always made double, the mythical beings who inhabited the early world being regarded as able to change from animal to human shape, by merely pushing up or pulling down the upper part of the face as a mask. Such masks are often hinged to complete the illusion, the actor changing the face at will.

It might be mentioned here that when the actor puts on the mask he is supposed to become imbued with the spirit of the being represented. This accounts, to the native mind, for the very lifelike imitation which he gives. 
The masks are painted along conventional lines; the favorite colors for the inua masks are red (Karékteoak), ${ }^{1}$ black (Auktoak), green (Cúngokyoak), white (Katéktoak), and blue (Taúkrektoak), in the order named. These colors ${ }^{2}$ may hold a sacred or symbolic significance. The inua masks are decorated with some regard to the natural colors of the human face, but in the masks of the tunghat the imagination of the artist runs riot. The same is true of the comic masks, which are rendered as grotesque and horrible as possible. A mask with distorted features, a pale green complexion, surrounded by a bristling mass of hair, amuses them greatly. The Eskimo also caricature their neighbors, the Dènè, in this same manner, representing them by masks with very large noses and sullen features.

1 These are the northern names. In the southern or Yukon dialect black is Túnguli; white Katughúli; red, Kauigúli; green, Tcunungúli.

The endings and pronunciation of similar Eskimo words are somewhat different in Arctic Alaska and on the Yukon River; sufficiently so as to produce two distinct dialects. For this reason 1 have given the forms from both sections.

2 Red is obtained from red ochre; white from white clay; black from soot or ashes; green from oxide of copper. 


\section{THE DANCE FESTIVALS}

The Dance Festivals of the Alaskan Eskimo are held during that cold, stormy period of the winter when the work of the year is over and hunting is temporarily at an end. At this season the people gather in the kásgi to celebrate the local rites, and at certain intervals invite neighboring tribes to join in the great intertribal festivals. This season of mirth and song is termed "Tcauyávik" the drum dance season, from "Tcaúyak" meaning drum. It lasts from November to March, and is a continuous succession of feasts and dances, which makes glad the heart of the Eskimo and serves to lighten the natural depression caused by day after day of interminable wind and darkness. A brisk exchange of presents at the local festivals promotes good feeling, and an interchange of commodities between the tribes at the great feasts stimulates trade and results in each being supplied with the necessities of life. For instance, northern tribes visiting the south bring presents of reindeer skins or múkluk to eke out the scanty supply of the south, while the latter in return give their visitors loads of dried salmon which the northerners feed to their dogs.

The festivals also serve to keep alive the religious feeling of the people, as evidenced in the Dance to the Dead, which allows free play to the nobler sentiments of filial faith and paternal love. The recital of the deeds of ancient heroes preserves the best traditions of the race and inspires the younger generation. To my mind, there is nothing which civilization can supply which can take the place of the healthy exercise, social enjoyment, commercial advantages, and spiritual uplift 
of these dances. Where missionary sentiment is overwhelming they are gradually being abandoned; where there is a mistaken opinion in regard to their use, they have been given up altogether; but the tenacity with which the Eskimo clings to these ancient observances, even in places where they have been nominal christians for years, is an evidence of the vitality of these ancient rites and their adaptation to the native mind.

The festivals vary considerably according to locality, but their essential features are the same. Taken in order of celebration they are as follows

Local Festivals.

1. The Aiyáguk or Asking Festival.

2. The Tcaúiyuk or Bladder Feast.

3. The Ailígi or Annual Feast to the Dead.

Intertribal Festivals.

4. The Aithukátúkhtuk or Great Feast to the Dead.

5. The Aithúkuguk or Inviting-In Feast.

The Asking Festival, which begins the round of feasting and dancing, takes place during the November moon. It is a local ceremony in which gifts are exchanged between the men and women of the village, which result in offers of temporary marriage. It takes its name from the Aiyáguk or Asking Stick, ${ }^{1}$ which is the wand of office of the messenger or go-between. The Annual Feast to the Dead is held during the December moon, and may be repeated again in spring after the Bladder Feast, if a large number of Eskimos have died in the interim. It consists of songs and dances accompanied by offerings of food and

${ }^{1}$ The Asking Stick is also used in the Inviting-In Feast (Aithúkaguk). 
drink to the dead. It is a temporary arrangement for keeping the dead supplied with sustenance (they are thought to imbibe the spiritual essence of the offerings) until the great Feast to the Dead takes place.

This is held whenever the relatives of the deceased have accumulated sufficient food, skins and other goods to entertain the countryside and are able to properly honor the deceased. At the same time the namesakes of the dead are richly clothed from head to foot and showered with presents. As this prodigal generosity entails the savings of years on the part of the feast givers (náskut), the feast occurs only at irregular intervals of several years. It has been termed the Ten Year Feast by the traders (Kágruska), but so far as I have been able to inquire, it has no fixed date among the Eskimo. It is by far the most important event in the life of the Alaskan native. By it he discharges all debts of honor to the dead, past, present and future. He is not obliged to take part in another festival of the kind unless another near relative dies. He pays off all old scores of hospitality and lays his friends under future obligations by his presents. He is often beggared by this prodigality, but he can be sure of welcome and entertainment wherever he goes, for he is a man who has discharged all his debts to society and is therefore deserving of honor for the rest of his days.

In the Bladder Feast which takes place in January, the bladders of the animals slain during the past season, in which the spirits of the animals are supposed to reside, are returned to the sea, after appropriate ceremonies in the kásgi. There they are thought to attract others of their kind and bring an increase to the village. This is essentially a coast festival. Among the tribes of the islands of Bering Sea and the Siberian Coast this festival is repeated in March, in conjunction with a 
whaling ceremony performed at the taking down of the ūmiaks.

The dance contests in the Inviting-In Feast resemble the nith songs of Greenland. They are Comic and Totem Dances in which the best performers of several tribes contest singly or in groups for supremacy. The costumes worn are remarkably fine and the acting very realistic. This is essentially a southern festival for it gives an opportunity to the Eskimo living near the rivers to display their ingenious talent for mimicry and for the arrangement of feathers.

There are a few purely local ceremonies, the outgrowth of practices of local shamans. An example of this is the Aitekátah or Doll Festival of the Igomiut, which has also spread to the neighboring Dènè. Such local outgrowths, however, do not appear to spread among the conservative Eskimo, who resent the least infringement of the ancient practices handed down from dim ancestors of the race.

It is not often that they will allow a white man to witness the festival dances, but, owing to the friendliness of the chief of the Diomede tribes, who always reserved a seat for me next to him in the kásgi, I had the opportunity of seeing the local rites and the Great Dance to the Dead. The same favor continuing with the chief of the Unalit, during my residence on the Yukon, I witnessed the Inviting-In Feast as celebrated by the southern tribes. Having described the dances in general, I will proceed to a detailed account of each.

\section{The Asking Festival}

The Aiyáguk or Asking Festival is the first of the local feasts. It occurs about the middle of November when the Eskimo have all returned from their summer travels and made 
their iglus secure against the storms of the coming winter. So, with caches full of fish, and houses packed with trade goods after a successful season at the southern camps, they must wait until the shifting ice pack settles and the winter hunting begins. Such enforced inaction is irksome to the Eskimo, who does not partake of the stolidity of the Indian, but like a nervous child must be continually employed or amused. So this festival, which is of a purely social character, has grown up.

My first intimation that there was a celebration taking place was being attracted by a tremendous uproar in the native village just as darkness had fallen. Suspecting that the Eskimo were making merry over a native brew, called "hoosch,"' I slipped down to the village to see what was the matter. I was met by the queerest procession I have ever seen. A long line of men and boys, entirely naked and daubed over with dots and figures of mingled oil and charcoal, ${ }^{2}$ were proceeding from house to house with bowls in their hands. At each entrance they filed in, howling, stamping and grunting, holding out their dishes until they were filled by the women of the house.

All this time they were careful to keep their faces averted so that they would not be recognized. This is termed the "Tutúuk" or "going around." Returning to the kásgi they washed off their marks with urine, and sat down to feast on their plunder.

1 This is a liquor distilled from flour and molasses. In the operation an old cask and a gun barrel are used. The liquid is fermented with sour dough and allowed to distill through the barrel. The Eskimo had no liquor prior to the advent of the whalers, who supplied them with the materials and probably taught them the art of distilling. The U. S. Revenue Cutter "Bear" has been active in breaking up the practice. In 1909, six illicit stills were seized on the Diomede Islands.

${ }_{2}$ The first night of the feast the men and older boys meet in the kásgi, and two boys named the Raven (Tulukaúguk) and the Hawk (Tcibúriak) mix the paint and assist the men in ornamenting themselves. 
The next day the men gathered again in the kásgi and the Aiyáguk or Asking Stick was constructed. It was made by a man especially chosen for the purpose. It was a slender wand about three feet long with three globes made of thin strips of wood hanging by a strip of oklinok from the smaller end. It was carried by the messenger between the men and women during the feast, and was the visible sign of his authority. It was treated with scrupulous respect by the Eskimo and to disregard the wishes conveyed by means of it during the feast would have been considered a lasting disgrace. When not in use it was hung over the entrance to the kásgi.

The wand maker, having finished the Asking Stick, took his stand in the center of the room, and swaying the globes, to and fro, asked the men to state their wishes. Then any man present had the privilege of telling him of an article he wished and the name of the woman from whom he wished it. (Among the southern tribes the men made small wooden models of the objects they wished which were hung on the end of the Asking Stick.) The messenger then proceeded to the house of the woman in question, swinging the globes in front of her, repeated the wish and stood waiting for her answer. She in turn recollected something that she desired and told it to the messenger. Thereupon he returned to the kásgi, and standing in front of the first party, swung the globes, and told him what was desired in return. In this way he made the round of the village., The men then returned to their homes for the article desired, while the messenger blackened his face with charcoal and donned a costume betoking humility. This was considered the only proper attitude in presenting gifts. The costume consisted of wornout clothing, of which a disreputable raincoat (Kamleíka) and a dogskin belt with the tail behind were indispensable parts. 
Then the men and women gathered in the kásgi where the exchanges were made through the messenger. If anyone did not have the gift requested he was in honor bound to secure it as soon as possible and present it to his partner. Those exchanging gifts entered a relationship termed oiloǵgk, and among the northern tribes where the ancient forms persevere, they continued to exchange presents throughout succeeding festivals.

After this exchange, a dance was performed by the women. They stripped to the waist, and taking their places on the ińglak, went through a series of motions in unison. These varied considerably in time and movement from the conventional women's dance.

According to custom at the conclusion of the dance any man has the privilege of asking any unmarried woman through the messenger, if he might share her bed that night. If favorably inclined, she replies that he must bring a deerskin for bedding. He procures the deerskin, and presents it to her, and after the feast is over remains with her for the night.

Whether these temporary unions lead to permanent marriage I was unable to find out. The gift of reindeer skin is very like the suit of clothing given in betrothal and would furnish material for the parka which the husband presents to his bride. The fact that the privilege is limited to unmarried women might be also urged in turn. As the system of exchanging wives was formerly common among the Alaskan Eskimo, and as they distribute their favors at will, it is rather remarkable that the married women are not included, as in the licentious feasts recorded of the Greenlanders. ${ }^{1}$ From talks with some of the older Eskimo I am led to regard this as a relic of an ancient custom similar

${ }^{1}$ See Hans Egede, Det Gamle Grönlands Nye Perlustration, p. 78. 
to those which have been observed among many nations of antiquity, in which a woman is open to violation at certain feasts. This privilege is taken advantage of, and may become a preliminary to marriage.

\section{The Bladder Feast}

The Bladder Feast (Tcaúiyuk) is held in December at the full of the moon. The object of this feast is the propitiation of the inua of the animals slain during the season past. These are believed to reside in the bladders, which the Eskimo carefully preserve. The ceremony consists in the purification of - the bladders by the flame of the wild parsnip (Aíkituk). The hunters are also required to pass through the flame. They return the bladders then to the sea, where entering the bodies of their kind, they are reborn and return again, bringing continued success to the hunter.

The first three days are spent in preparation. They thoroughly clean the kásgi, particularly the kenéthluk or fireplace, the recognized abode of all spirits visiting the kásgi. Then the men bring in their harvest of bladders. ${ }^{1}$ They tie them by the necks in bunches of eight to the end of their spears. These they thrust into the walls at the rear of the room leaving ample room for the dancers to pass under the swaying bladders in the rites of purification. Offerings of food and water are made to the inua, and they are constantly attended. One old man told me that they would be offended and take their departure if left alone for a moment. Dogs, being unclean, are not allowed to enter the kásgi. Neither is anyone permitted to do any work during the ceremony.

1 The mothers also preserve with greatest care the bladders of the mice, ground squirrels, and other small animals killed by the children. These are purified at the same time. 
Meanwhile four men, ${ }^{1}$ especially chosen for the purpose, scour the adjoining country for parsnip stalks. They bind these into small bundles, and place them on top of the latorak, the outer vestibule to the entrance of the kásgi. In the evening they take these into the kásgi, open the bundles and spread out the stalks on the floor. Then each hunter takes a stalk, and they unite in a song to the parsnip, the burden of which is a request that the stalks may become dry and useful for purification. The heat of the seal oil lamps soon dries them, and they are tied into one large bundle. The third day the sheaf is opened, and two bundles made. The larger one is for the use of the dancers; the smaller is placed on a spear and stuck in front of the bladders.

The fourth day the bladders are taken down and painted. A grayish mixture is used which is obtained by burning a few parsnip stalks and mixing the ashes with oil. The designs are the series of bands and dots grouped to represent the totems of the hunters. When the paint is dry the bladders are returned to their places.

In the evening the men gather again in the kásgi, and the dancers proceed to strip off every vestige of clothing. Snatching a handful of stalks at the common pile they light them at the lamps, and join in a wild dance about the room. The resinous stalks shoot into flame with a frightful glare, lighting up the naked bodies of the dancers, and dusky interior of the kásgi. Waving the flaming torches over their heads, leaping, jumping, and screaming like madmen they rush around the room, thrusting the flame among the bladders and then into the faces of the

1 The number four appears to have a sacred significance among the Alaskan Eskimo. The Raven Father (Tulukaúguk) waves his wings four times over the objects of his creation; the heroes of ancient legends take four steps and are transported great distances; and important events occur on the fourth night. I understand that the four men who gather the wild parsnips represent the four clans of the tribe. 
hunters. When the mad scene is at its height, they seize one another, and struggle toward the púgyarok (entrance hole). Here each is thrust down in succession until all the dancers have passed through. I am informed that this is a pantomime enactment, an indication to the inua it is time for them to depart.

The next day a hole is made in the ice near the kásgi, and each hunter dips his spear in the water, and, running back to the kásgi, stirs up the bladders with it. The presence of the sea water reminds the inua of their former home, and they make ready to depart. The bladders are then tied into one large bundle, and the people await the full moon.

At sunrise the morning after the full moon each hunter takes his load of bladders, and filing out of the kásgi starts for the hole in the ice on a dead run. Arriving there, he tears off the bladders one by one, and thrusts them under the water. This signifies the return of the inua to the sea.

As the bladders float or sink success is prophesied for the hunter by the shaman in attendance.

In the meantime the old men build a fire of driftwood on the ice in front of the kásgi. The small bundle of parsnip stalks which stood in front of the bladders is brought out and thrown on the fire, and as the stalks kindle to the flame, each hunter utters a shout, takes a short run, and leaps through in turn. This performance purifies the hunter of any matter offensive to the inua, and concludes the ceremony.

During the Bladder Feast all intercourse between the married men and their wives is tabooed. They are required to sleep in the kásgi with the bachelors. Neither is any girl who has attained puberty (Wingiktóak) allowed near the bladders. She is unclean (Wáhok). 


\section{The Feasts to the Dead}

The Eskimo idea of the life after death and the rationale for their most important ritual, the Feast to the Dead, is nowhere better illustrated than in a quaint tale current along the Yukon, in which the heroine, prematurely buried during a trancelike sleep, visited the Land of the Dead. She was rudely awakened from her deathlike slumber by the spirit of her grandmother shaking her and exclaiming, "Wake up. Do not sleep the hours away. You are dead!" Arising from her grave box, the maiden was conducted by her guide to the world beneath, where the dead had their dwellings in large villages grouped according to the localities from which they came. Even the animal shades were not forgotten, but inhabited separate communities in human shape. ${ }^{1}$ After some travel the girl found the village allotted to her tribe, and was reclaimed by her departed relatives. She was recognized by the totem marks on her clothing, which in ancient times the Eskimo always wore. She found the inmates of this region leading a pleasant but somewhat monotonous life, free from hardships and from the sleet and cold of their earthly existence. They returned to the upper world during the feasts to the dead, when they received the spiritual essence of the food and clothing offered to their namesakes ${ }^{2}$ by relatives. According to the generosity or stinginess of the feast givers there was a feast or a famine in spirit land, and those who were so unfortunate as to have no namesake, either through their

${ }_{1}^{1}$ The shapes of animals are thought by the Alaskan Eskimo to be like those of men, and in ancient times animals possessed the power of changing their forms at will. This was effected by pulling the muzzle up over the head to become people or of pulling it down again to regain their original form.

2 The first child born in the village after his death becomes the deceased's namesake. However, if born in camp, its mother gives it the name of the first natural object to catch her eye. 
own carelessness ${ }^{1}$ or the neglect of the community, ${ }^{2}$ went hungry and naked. This was the worst calamity that could befall an Eskimo, hence the necessity of providing a namesake and of regularly feeding and clothing the same, in the interest of the beloved dead.

${ }^{1}$ Childless people provide for this contingency by adoption

${ }^{2}$ One who has made himself odious to his fellow villagers is purposely neglected in the feasts to the dead. 


\section{THE ANNUAL FEAST, AILIGI}

The Annual Feast to the Dead is a temporary arrangement, whereby the shades of those recently departed are sustained until the advent of the Great Feast to the Dead. The essence of the offerings of food and drink are supposed to satisfy the wants of the dead until they can be properly honored in the Great Festival. In the latter event the relative discharges all his social obligations to the dead, and the ghost is furnished with such an abundance that it can never want in the world below.

The makers of the feast (náskut) are the nearest relatives of those who have died during the past year, together with those villagers who have not yet given the greater festival The day before the festival the male mourners go to the village burial ground and plant a newly made stake before the grave of their relative. The stake is surmounted by a wooden model of a spear, if the deceased be a man; or a wooden dish, if it be a woman. The totem mark of the deceased is carved upon it. In the north simple models of kayak paddles suffice. The sticks are a notification to the spirits in the land of the dead that the time for the festival is at hand. Accordingly they journey to the grave boxes, where they wait, ready to enter the kásgi at the song of invocation. To light their way from the other world lamps are brought into the kásgi and set before their accustomed places. When the invitation song arises they leave their graves and take their places in the fireplace (Kenéthluk), where they enjoy the songs and dances, and receive the offerings of their relatives. 
The Annual Feast is celebrated after the Bladder Feast during the December moon. By the Yukon tribes it is repeated just before the opening of spring. During the day of the festival a taboo is placed on all work in the village, particularly that done with any sharp pointed tool which might wound some wandering ghost and bring retribution on the people.

At midday the whole village gathers in the kásgi, and the ceremony begins. Soon the mourners enter bearing great bowls of food and drink which they deposit in the doorway. Then the chorus leader arises and begins the song of invitation accompanied by the relatives of the dead. It is a long minor chant, a constant reiteration of a few well worn phrases.

"Tukomalra-ā-, tung lík-a, Dead ones, next of kin, Túntum komúga thetámtatuk, Reindeer meat we bring you, tis-ká-a a-a-yung-a-a-yung-a, etc. come hither, móqkapik thetámtatuk moqsúlthka. water we bring you for your thirst."

When the song is completed the mourners arise, and going to the food in the doorway set it on the planks over the fireplace, after which they take a ladleful from each dish pouring it through the cracks in the floor, and the essence of this offering supplies the shades below with food until the next festival. The remainder of the food is distributed among those present. When the feast is over, the balance of the day is given over to songs and dances. Then the spirits are sent back to their homes by the simple expedient of stamping on the floor. 


\section{THE GREAT FEAST, AITHUKÁTUKHTUK}

After making offerings to his relative at the annual feast the chief mourner begins saving up his skins, frozen meat, and other delicacies prized by the Eskimo, until, in the course of years, he has accumulated an enormous amount of food and clothing. Then he is prepared to give the great feast in honor of his kinsman. Others in the village, who are bereaved, have been doing the same thing. They meet and agree on a certain time to celebrate the feast together during the ensuing year. The time chosen is usually in January after the local feasts are over, and visitors from neighboring tribes are free to attend. There are no set intervals between these feasts as has been generally supposed. They are celebrated at irregular intervals according to the convenience of the givers.

At the minor festival preceding the Great Feast, the usual invitation stakes planted before the dead are supplemented by others placed before the graves of those in whose honor the festival is to be given. On these is a painted model of the totemic animals of the deceased. The feast giver sings an especial song of invitation, requesting the dead kinsman to be present at the approaching feast.

On the first day of the Great Feast the villagers welcome the guests. Early in the morning they begin to arrive. The messenger goes out on the ice and leads them into the village, showing each where to tie his team. During the first day the guests are fed in the kásgi. They have the privilege of demanding any delicacy they wish. After this they are quartered on various homes in the village. Salmon or meat 
must also be provided for their dogs. This is no small item, and often taxes the resources of a village to the utmost. I have known of a village so poor after a period of prolonged hospitality that it was reduced to starvation rations for the rest of the winter.

Immediately on tying up their dogs, the guests go to the kásgi. On entering each one cries in set phraseology, "Ah-kaká- Píatin, Pikeyútum.” "Oh, ho! Look here! A trifling present." He throws his present on a common pile in front of the headman, who distributes them among the villagers. It is customary to make the presents appear as large as possible. One fellow has a bolt of calico which he unwinds through the entrance hole, making a great display. It may be thirty yards long. Sometimes they accompany the gift with a short dance. It is considered bad form for one coming from a distance ${ }^{1}$ not to make the usual present, as in this way he purchases the right to join in the festival dances.

As soon as all are gathered in the kásgi, a feast is brought in for the tired travelers. Kantags of sealmeat, the blackskin of the bowhead, salmon berries swimming in oil, greens from the hillsides, and pot after pot of tea take off the edge of hunger. After gorging themselves, the guests seem incapable of further exertion, and the remainder of the day is spent in.visiting.

\section{The Feast Givers}

The feast givers or näskut assemble in the kásgi the second day, and the ceremony proper begins. They range themselves around the púgyarok or entrance, the chorus and guests occupy-

\footnotetext{
${ }^{1}$ During the inter-tribal festivals, guests are given seats of honor next to the headman of the village according to the distance from which they have come. The back of the room (káan), the place of honor, is reserved for this purpose.
} 
ing the back of the room and the spectators packing themselves against the walls.

Each feast giver is garbed according to the sex of his dead relative, not his own, so that some men wear women's clothes and vice versa. Each bears in his right hand a wand about two feet long (Kelézruk). ${ }^{1}$ This is a small stick of wood surmounted with tufts of down from ptarmigan (Okozregéwik). All are dressed to represent the totem to which the deceased belongs. One wears a fillet and armlet of wolfskin (Egóalik); others wear armlets of ermine (Táreak); still others are crowned with feathers of the raven (Tulúa) or the hawk (Tciakaúret). ${ }^{2}$ After a short dance they withdraw and the day's ceremony is finished.

The following day the näskut assemble again, but they have doffed their fine feathers, and are dressed in their oldest clothes. The suits of the day before they carry in a grass sack. They wear raincoats of sealgut tied about the waist with a belt of dogskin, and enter the kásgi with eyes cast on the floor. Even in the dances they keep their faces from the audience.

This attitude of humility is in accord with Eskimo ethics. They say that if they adopt a boastful air and fail to give as many presents as the other näskut they will be ashamed. So they safeguard themselves in advance.

\section{The Ritual}

Advancing with downcast eyes, the näskut creep softly across the kásgi and take their places before the funeral lamps. Then taking out their festival garments, they slip them on.

\footnotetext{
1 The same arrangement characterizes the finger masks of the Inviting.In Dance. (Kiggilúnok), meaning wand, in southern dialect.

${ }^{2}$ Southern dialect. Akkizhzhígik, Ptarmigam. Tcibúviak, hawk; Tulukaúguk, meaning raven.
} 
Immediately the drummers start tapping lightly on their drums, and at a signal from their leader the song of invitation begins. Each nấskuk advances in turn, invoking the presence of his dead in a sad minor strain.

Toakóra ílyuga takína

Dead brother, come hither

A-yunga-ayunga-a-yunga

Or:

Nuleága awúnga toakóra

Sister mine, dead one,

Takína, núleaga, takína,

Come hither, sister, come hither, Or:

Akága awunga takína

Mother mine, come hither.

Nanáktuk, takína,

We wait for you, come hither.

To which the chorus answer:

llyúga awúnga takína,

Our brother, come hither,

Takináka, ilyúga, takínaka,

Return, dead brother, return.

The women advance in line, holding their wands in the right hand, and singing in unison; then the men advance in their turn, then both nấskut and chorus sing together:

Takinaka, awunga, tungalika,

Return to us, our dead kinsmen,

Nanakátuk, kineáktuk tungalíka

We wait your home coming, our dead kinsmen. 
Suddenly the drummers cease and rap sharply on the inglak with their drumsticks. The dancers stop in the midst of their movements and stamp on the floor, first with one foot then with the other, placing their hands on their shoulders, bringing them down over their bodies as though wiping off some unseen thing. Then they slap their thighs and sit down. I am informed that this is to "wipe off" any uncleanness (wahok) that might offend. the shades of the dead.

Then the namesakes of the dead troop into the kásgi, and take their places in the center of the room between the two lines. To each, the nä́skuk hands a bowl of water and a kantag of frozen reindeer meat cut into small pieces. The namesakes drop a small portion of the meat on the floor. The essence is evidently thought to pass below to the waiting inua. Then they finish the remainder. At the same time a large amount of frozen meat and fish is brought in and distributed among the guests. This is done at the end of each day.

The fourth day the chorus leader mounts the top of the kásgi and begins again the invitation song. The people scatter to the burying ground or to the ice along the shore according to the spot where they have lain their dead. They dance among the grave boxes so that the shades who have returned to them, when not in the kásgi, may see that they are doing them honor.

During the dancing the children of the village gather in the kásgi, carrying little kantags and sealskin sacks. The women on returning bring great bags of frozen blueberries and reindeer fat, commonly called "Eskimo Ice Cream," with which they fill the bowls of the children, but the young rogues immediately slip their portions into their sacks.(póksrut) and hold out their dishes for more, crying in a deafening chorus, "Wunga-Túk" (Me too). This part of the festival 
is thoroughly enjoyed by the Eskimo, who idolize their children.

At the conclusion of the day's feast many presents are given away by the näskut, the husbands of the female feast givers distributing them for the ladies, who assume a bashful air. During the distribution the nấskut maintain their deprecatory attitude and pass disparaging remarks on their gifts. Sometimes the presents are attached to a long line of óklinok (seal thong) which the näskut haul down through the smokehole, making the line appear as long as possible. At the same time they sing in a mournful key bewailing their relative:

Ah-ka- ilyúga toakóra, tákin,

Oh! oh! dead brother, return,

Utiktutátuk, ilúga awúnga,

Return to us, our brother,

Illearúqtutuk, ilyúga,

We miss you, dear brother,

Pikeyútum, kokítutuk,

A trifling present we bring you.

\section{The Clothing of the Namesakes}

The following day occurs the clothing of the namesakes. This is symbolical of clothing the dead, who ascend into the bodies of their namesakes during the ceremony and take on the spiritual counterpart of the clothing.

After a grand distribution of presents by the nắskut, bags of fine clothing are lowered to the feast givers and the namesakes take the center of the floor, in front of their relatives, the feast givers. Then each näskuk calls out to the particular namesake of his dead kinsman: "ITtakín, illorahug- 
náka," "Come hither, my beloved," and proceeds to remove the clothing of the namesake and put on an entirely new suit of mukluks, trousers, and parka, made of the finest furs. Then the feast giver gathers up the discarded clothing, and stamps vigorously on the floor, bidding the ghost begone to its resting place. It goes, well satisfied, and the dancers disperse until another great festival. Until the feast is concluded no one can leave the village. 


\section{THE INVITING-IN FESTIVAL}

The Inviting-In Festival (Aithúkaguk) is a great intertribal feast, second in importance to the Great Feast to the Dead. It is a celebration on invitation from one tribe to her neighbors when sufficient provisions have been collected. It takes place late in the season, after the other festivals are over. Neighboring tribes act as hosts in rotation, each striving to outdo the other in the quality and quantity of entertainment offered. During this festival the dramatic pantomime dances for which the Alaskan Eskimo are justly famous, are performed by especially trained actors. For several days the dances continue, each side paying the forfeit as they lose in the dancing contests. In this respect the representations are somewhat similar to the nith contests of the Greenlanders. As I have noticed the dances at length elsewhere, ${ }^{1}$ I shall only give a brief survey here, sufficient to show their place in the Eskimo festival dances.

The main dances of the Inviting-In Festival are totemic in character, performed by trained actors to appease the totems of the hunters, and insure success for the coming season. These are danced in pantomime and depict the life of arctic animals, the walrus, raven, bear, ptarmigan, and others. Then there are group dances which illustrate hunting scenes, like the Reindeer and Wolf Pack dance already described, also dances of a purely comic character, designed for the entertainment of the guests. During the latter performances the side which laughs has to pay a forfeit.

${ }^{1}$ Canadian Geological Survey. Memoir 45. The "Inviting-In" Feast of the Alaskan 
Elaborate masks are worn in all of the dances. The full paraphernalia, masks, handmasks, fillets, and armlets, are worn by the chief actors. They are supported by richly garbed assistants. An old shaman acts as master of ceremonies. There is an interchange of presents between the tribes during the intervals but not between individuals, as in the Asking Festival. At the close of the festival the masks are burned. 
KEY TO PLATE XI

A-Outer Vestibule. (Lā'torăk.)

B-Summer Entrance. (Amēk')

C-Front Platform. (Oaklim.) Seat of Orphans and Worthless.

D-Plank Floor. (Nā'tūk.)

E-Rear Platform. (Kā'an.) Seat of Honored Guests.

F-Smoke Hole. (Ra'lǒk.) Entrance for Gift-lines.

G-Entrance Hole. (Pug'yărăk.)

H-Fireplace. (Kēne'thluk.) Seat of Spirit-Guests.

I-Underground Tunnel. (Ag'vēak.)

J-Side Platforms. (Káaklim.) Seats for Spectators.

$\mathrm{K}$-Chorus of Drummers.

L-Feast Givers. (Nä'skut.)

M-Namesakes of Dead. 


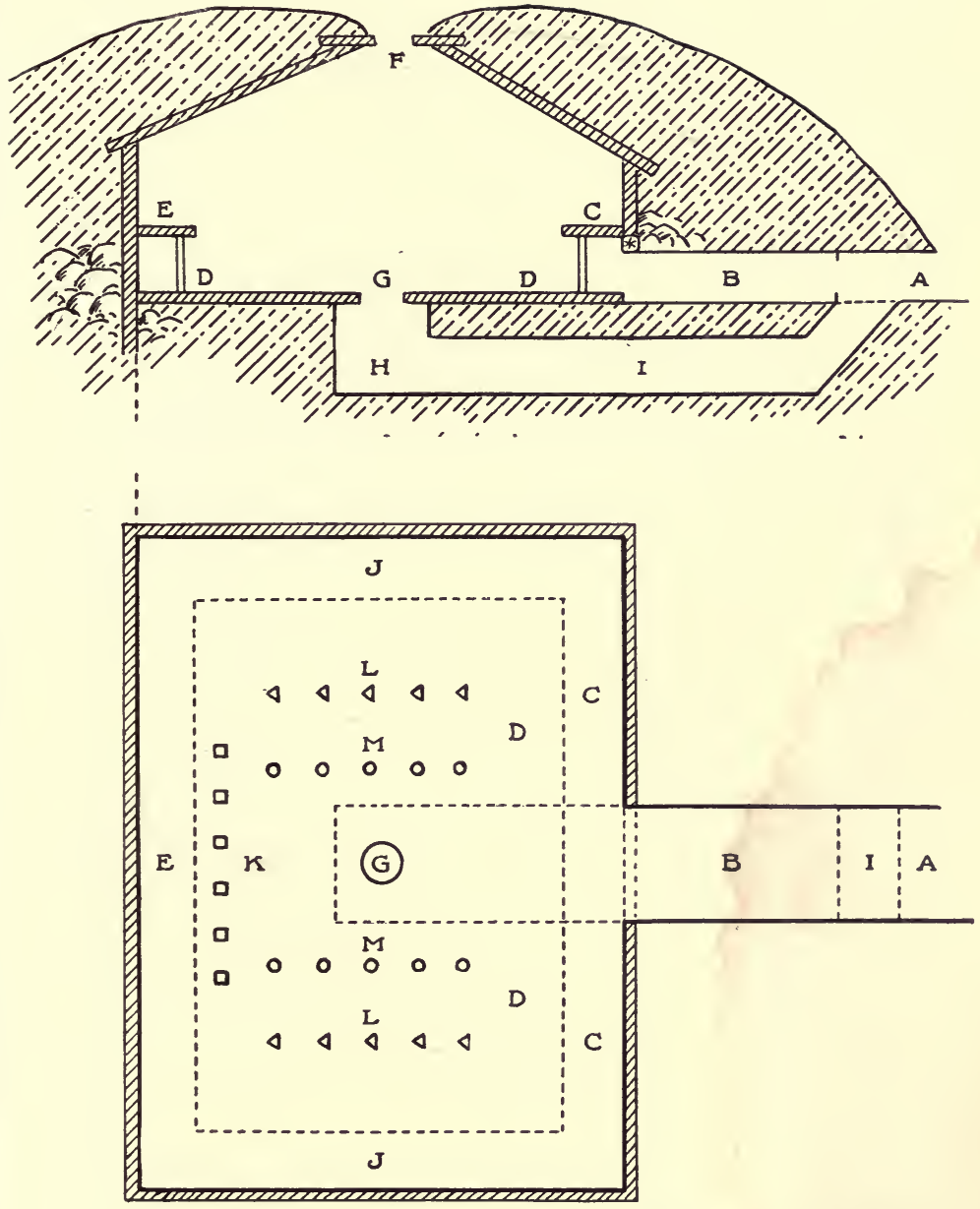

Arrangement of Kásgi during the Great Feast to the Dead. The Kásgi or Dance House. 
KEY TO PLATE XII

A-First Movement. The Chief's Son, Okvaíok is dancing.

B-Second Movement. 

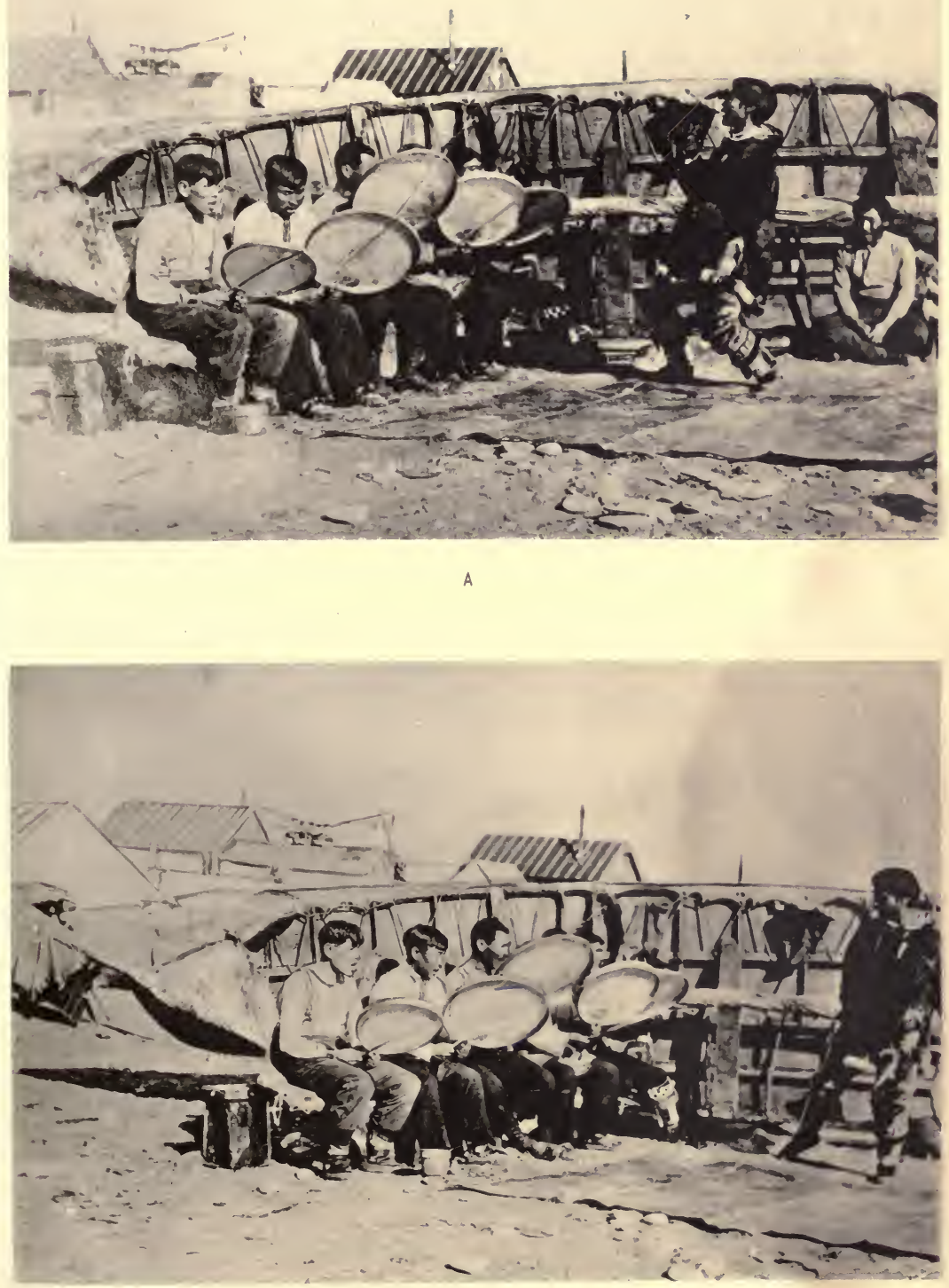



\section{.}


KEY TO PLATE XIII

C-Third Movement.

L-Fourth Movement. 

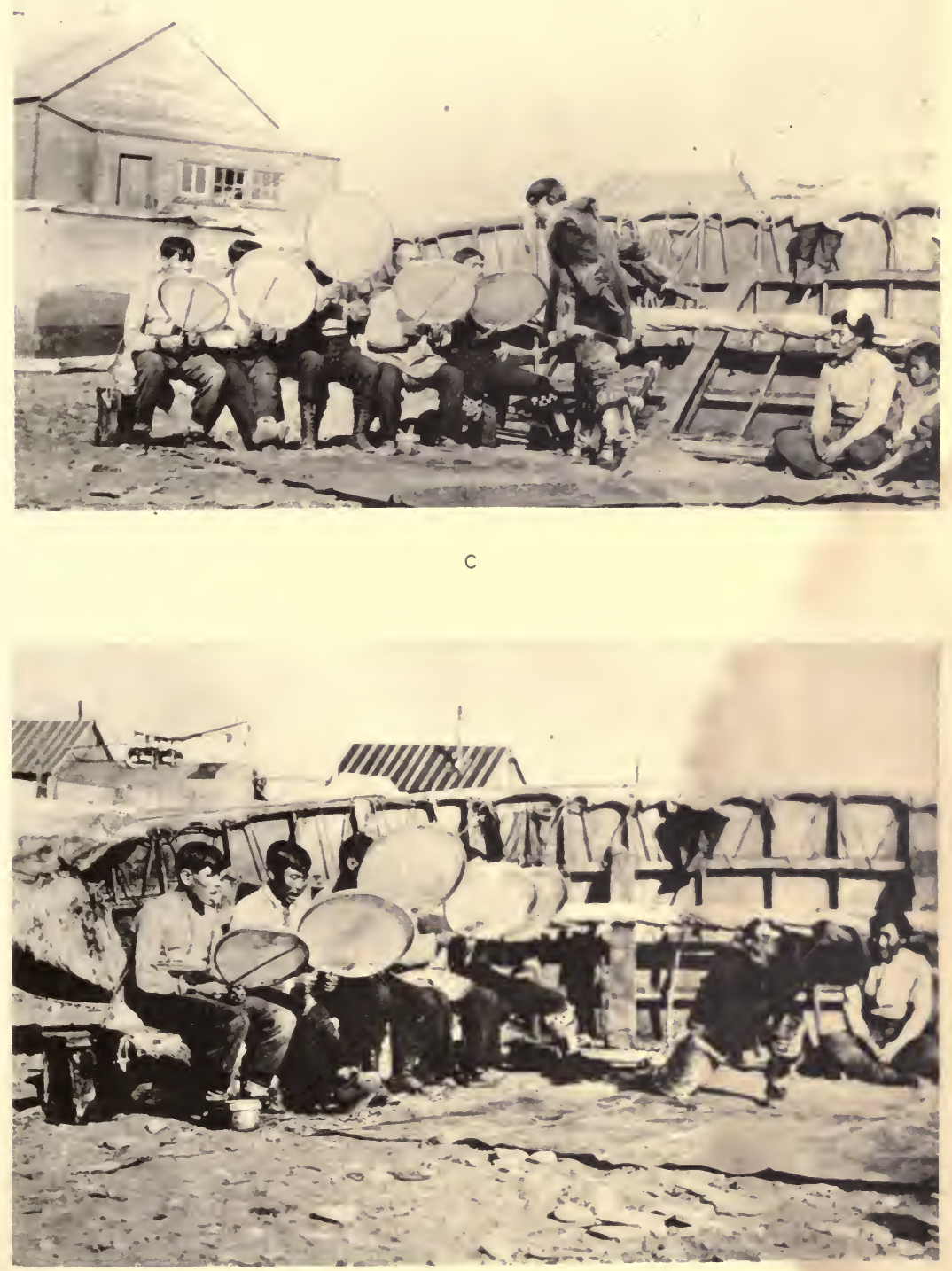



\section{KEY TO PLATE XIV}

Children's Dance.

The Chorus. Leader in Center Beating Time With an Ermine Stick. 


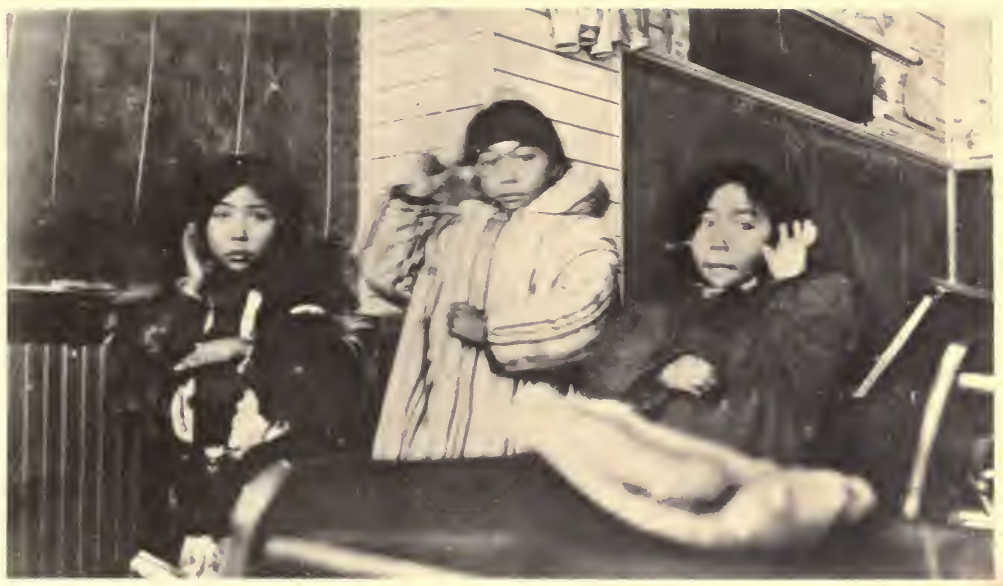

CHILDREN'S DANCE
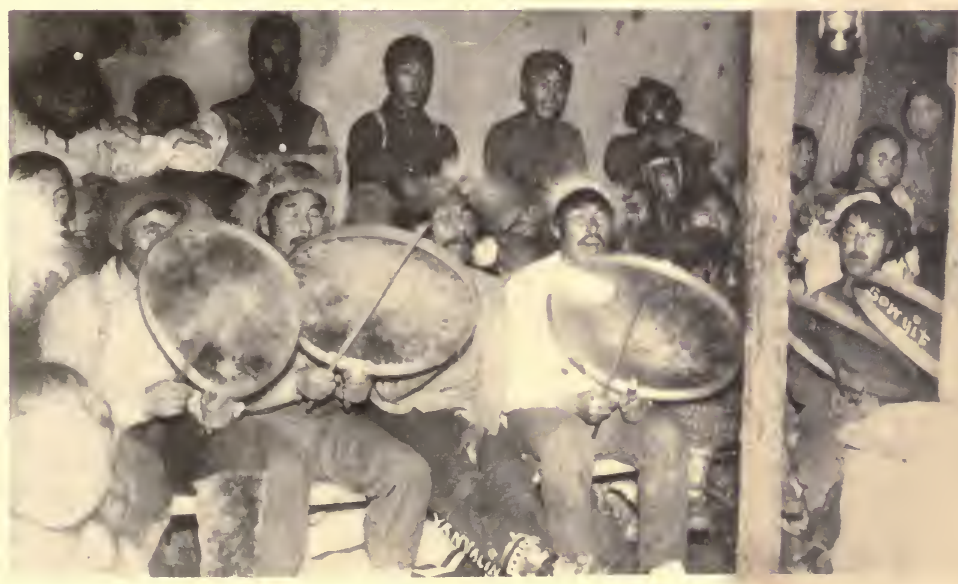

THE CHORUS 


\section{•}



KEY TO PLATE XV

Women's Dance. 


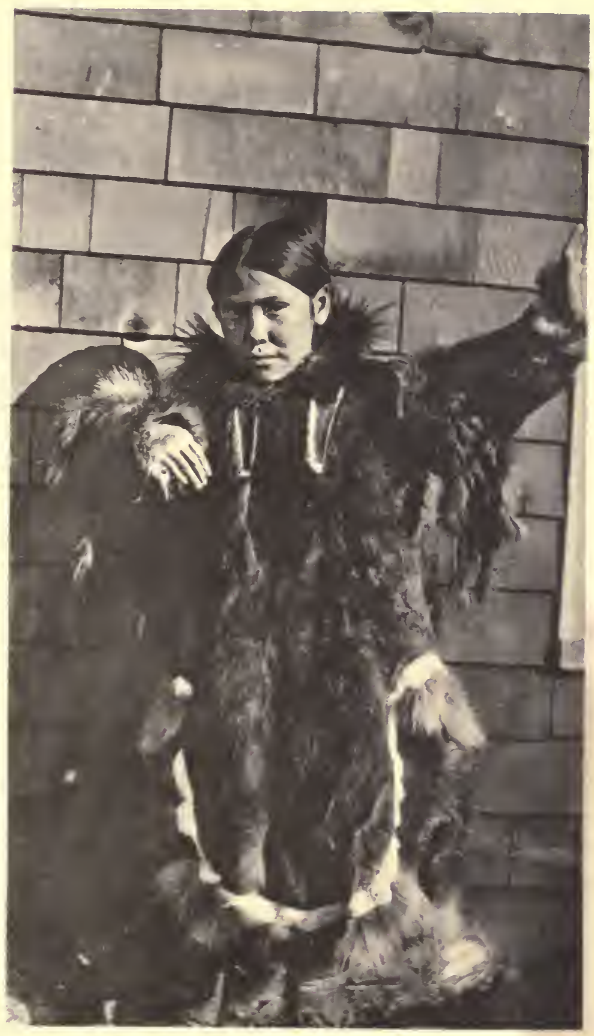

WOMEN'S DANCE 



UNIVERSITY OF PENNSYLVANIA THE UNIVERSITY MUSEUM ANTHROPOLOGICAL PUBLICATIONS VOL. VI

NO. 3

A PRE-LENAPE SITE IN NEW JERSEY BY

E. W. HAWKES AND RALPH LINTON

PHILADELPHIA

PUELISHED BY THE UNIVERSITY MUSEUM 1916 


UNIVERSITY OF PENNSYLVANIA

THE UNIVERSITY MUSEUM

A NTHROPOLOGICAL PUBLICATIONS

Vol. VI

No. 3

\section{A PRE-LENAPE SITE IN NEW JERSEY \\ BY}

E. W. HAWKES AND RALPH LINTON

PHILADELPHIA

PUBLISHED BY THE UNIVERSITY MUSEUM

1916 



\section{CONTENTS}

PAGE

FOREWORD $\ldots \ldots \ldots \ldots \ldots \ldots \ldots \ldots \ldots \ldots \ldots \ldots \ldots \ldots \ldots \ldots \ldots$

GENERAL DISCUSSION. . . . . . . . . . . . . . . . . 49

PREDECESSORS OF THE LENAPE INDIANS........... 55

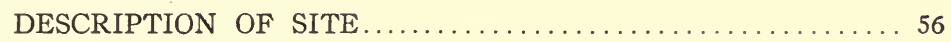

ARGILLITE WEAPONS AND IMPLEMENTS............. 59

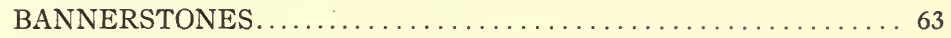

CEREMONIAL OBJECTS OTHER THAN BANNERSTONES... 72 INTERMEDIATE POINTS AND POTTERY ............ 76 



\section{FOREWORD}

The investigation which forms the subject of this Memoir was undertaken at the instance of Mr. George L. Harrison, Jr., who generously provided the funds for the purpose. The actual excavation, which occupied the summer of 1915, was done in person by Dr. E. W. Hawkes and Mr. Ralph Linton, and the preparation of this report is their joint work.

During the progress of the digging, the site was visited by Prof. Amos P. Brown of the University of Pennsylvania, who studied the geological conditions and who has given us the benefit of his observations. According to Prof. Brown, there are indications that the yellow sand is a wind-borne deposit laid down upon the layer of white glacial sand, and though its age is not clearly defined, it must be of considerable antiquity.

The publication of this paper is due to the generosity of Mr. Eckley B. Coxe, Jr., President of the Museum.

$$
\text { G. B. Gordon, }
$$

Director of the Museum.

April 1, 1916. 



\section{A PRE-LENAPE SITE IN NEW JERSEY}

There are few regions in North America which are of greater interest archeologically than the North Atlantic seaboard, as throwing light on the possible antiquity of man in America. Beginning with the much disputed paleoliths of Abbot, which may or may not represent glacial man, we pass to the so-called argillite culture, which is characterized by the exclusive use of this material and the entire absence of pottery, and from this period to the culture of the recent Lenape of Pennsylvania and New Jersey, represented by well-chipped implements and the manufacture of pottery. In the excavations made in the vicinity of Trenton by Volk, these three culture levels were found conforming to three geological strata: a surface black loam, in which the recent implements were found; a layer of yellowish sand of varying depth, in which occurred the crude implements of the argillite users; and the underlying glacial gravel, where the paleoliths are said to have been found. A similar arrangement of the strata, with the exception that the gravel was replaced by white glacial sand overlying cretaceous marl, was found in the site excavated by the authors. The location of the excavation, which is about fifteen miles south of Trenton in an air line, and about six miles from the Delaware makes it fall well within the region of the earlier investigations. As in the sites excavated by Volk, the modern implements were found in a surface stratum of leaf mold, but the argillite implements were found at the bottom of the yellow stratum, lying on the white glacial sand. A few scattered points of argillite exhibiting better workmanship and less signs of decay, were found in the yellow soil in a 
position intermediate between the ancient level and the modern. This level also contained a few sherds of very crude pottery, quite distinct in material from that found on the surface. 'The intermediate points although showing an advance in technique, were related in material and form to those of the lowest level, and taken in connection with the beginnings of pottery, may indicate a stage of culture intermediate between that of the lowest level and the modern Lenape. The presence of a large number of bannerstones in the caches of the lowest level in connection with ceremonial points of argillite, precludes any such antiquity as that claimed for the "Dweller of the Yellow Soil" by Volk, ${ }^{1}$ although they fall in the same intermediate period between glacial man and the modern Lenape, but evidently at a later date.

Our classification, based on the material excavated, begins with argillite implements, and passes through an intermediate period to the works of the modern Indian, whereas in the classification of Volk argillite represent the intermediate period between glacial man and the present Lenape. Our material leaves the question of glacial man untouched, while offering a possible link between argillite users and the modern Indian.

Volk's description of the dweller of the yellow soil offers so many points in common with our observations on the material from the lowest level, that we quote it here. Dr. Volk's work, extending over a period of twenty-two years, was characterized by such extreme patience and care that we feel no question as to its scientific accuracy.

"The existence of the Dweller of the Yellow Soil who lived on the drift underlying the black, during its progress of making and after its final drying off, previous to the accumulation of the black soil above by the decaying vegetation-has now been firmly established; this in spite of the fact that the traces of his existence are far less numerous than those of the black soil dweller following him.

${ }^{1}$ Volk claims that the traces of man in the yellow soil are pre-Indian. See Archæology of the Delaware Valley, Ernest Volk, Papers of the Peabody Museum, Vol. V, p. 108. 
"The implements of the yellow drift man must, however, have been fairly numerous judging from the numbers of specimens and from the many chips scattered throughout the drift. These implements were of two or three distinct types: the spear-head, and possibly the arrow-head, the implements with a jagged cutting edge, and the drill-like specimen found with one of the heaps of human bones. The material of these was always argillite.

"The pits found at different depths with the charcoal and the pebbles broken by fire indicate that cooking was done.

"The finding of pieces of pigment in the undisturbed stratum of coarse whitish sand was of more than ordinary interest as such a discovery is thus far unique for this locality.

"The skeletons found show that these people were strongly built; the skulls and other bones were so far decomposed as to make it impossible to gather any further information.

"The habitation of this Dweller of the Yellow Soil has given him the name of the Man of the Intermediate Period, and his use of argillite in the manufacture of his implements gives him that of the Argillite man."

Beginning with the implements from the lowest level, our excavation furnished not only the types of points described by Volk, but a number of others, which are described later in detail. This diversity of types, in connection with the finely worked bannerstones, indicates that the culture of argillite users in this locality had become fairly well specialized.

Fire pits of varying size were also found at the lowest level, the largest marking the ceremonial center around which the caches had been deposited. Smaller pits, outside the circle of caches, where the soil furnished scattered implements, may have marked the camp. In every case these pits extended down into the white sand and were in no way connected with

${ }^{1}$ Archæology of the Delaware Valley, Ernest Volk, Papers of the Peabody Museum, Vol. V, 1911, pp. 125-126. 
the upper strata. ${ }^{1}$ Many fire-cracked stones marked the vicinity of the fire pits, but there were no other signs of cooking.

Three pieces of pigment were found in the yellow soil, two of red ochre and one which left a greenish stain. Several specimens in the caches were coated with red paint which came off in a fine scale when they were exposed to the air. The red stain, however, persisted on several specimens, notably the painted fossils found in caches.

Only fragments of bone were found, and these were always associated with two point caches, and evidently represented offerings rather than food. They were so badly broken and decayed as to make identification difficult, but a paleontologist to whom they were shown recognized in one the leg bone of a wild turkey and thought the others belonged to either deer or bear. .

The resemblance of the implements figured by Volk, Plate CXVIII, to the points from our lowest level (see Plate XVII) is striking. Compare also the specimen figured in Plate CXIX with the blunt pear-shaped axe in Plate XVIII, A (found in cache B 5).

A number of chipped rejects, similar to those figured by Volk in Plate CXVI were scattered in the yellow soil, but in the presence of so much better material they are not described here.

In conclusion, the material from our lowest and intermediate levels agrees with that of Volk's Dweller of the Yellow Soil in geological position, but appears to belong to a later period within that time.

The lower village revealed by Mercer's excavation at Lower Black's Eddy, ${ }^{2}$ where he found two stages of occupancy, also offers interesting comparisons with our types from the lowest level. The "fish spear" type, seen in Fig. 28, page 29,

${ }^{1}$ The pits described by Volk were of two kinds; those which extended to the surface and those which were entirely within the yellow layer.

${ }^{2}$ The Antiquity of Man in the Delaware Valley and the Eastern United States, Henry C. Mercer. Publications of the University of Pennsylvania, Vol. VI, 1897. 
of Mercer's monograph may be compared with the fish spears in Plate XVII, I, J, K, L.

In our excavation, however, this was not the dominant form, the "diamond-shaped" point being most numerous. The occurrence of two potsherds at this level may mark the beginnings of pottery, as in our intermediate level. No jasper was found in our excavations in either the lowest or intermediate levels, but the predominance of argillite (427 to 7) in Mercer's lower village layer, and the presence of a small quartzite blade and worked quartzite pebbles, links his finds with ours as far as material is concerned.

The material from which the specimens at the lower level were made came from the river drift and not from the adjacent quarries, according to Mercer. "As to the quarries, granted that they were connected with the blade-thinning work-shops, the presence of these shops on the upper layer and surface, and their absence on the lower layer, would indicate that the quarries, with all the cultural significance that they involve, belong to the time of the upper layer only, and that the people of the lower site, obtaining their material from the neighboring beaches, had not known or worked them." Whether the argillite users of our lowest level obtained their material from river drift in the same way, or from the quarries around Trenton cannot be determined. The frequency with which inferior material was used, and the manner in which the few rejects had been made available by secondary chipping, seems to indicate that material was scarce.

Mercer, in considering the question whether the people of the lower village were forerunners of the Lenape of the upper village, has had resource to the legends of that people, as preserved by Heckwelder (Indian Nations, p. 51) and the Walum Olum, or Painted Stick Chronicle.

"The latter curious record, whose authenticity is tolerably well established, places eleven chiefs between the arrival of the Lenape in the Delaware Valley and the coming of white man (say Hudson, in 1609); and if we give twenty years to 
a chief's reign, the date of their first coming would have been about 1387. This agrees with what a Lenape told the Reverend Charles Beatty in 1767 (Journal of a Two Months' Tour West of the Alleghany Mountains, Charles Beatty, p. 27, London, 1868). When counting beads on a wampum belt as years, according to a tribal custom, he said that his people had come to the Delaware 370 years before, or in 1397.

"The Heckwelder version of the tradition, however, which gives no means of fixing dates, would infer that the new comers found the country vacant. The exploring parties of the eastward migrating tribe, it says, arriving at the Susquehanna, followed it down to the Chesapeake Bay, then ascended the bay and outer seacoast and discovered the Delaware River, New Jersey, and the Hudson River-a country abounding in game, fruits, and fish, "and with no enemy to be dreaded."

"This seeming absence of prior occupants in the new country is again suggested by the Walum Olum, which refers to the newly discovered land as "a land free from snakes (enemies), a rich land, a pleasant land."'1

"But without attempting to dwell too much on these traditions and their claim that the Lenape only arrived in the Delaware Valley five hundred years ago, and that before that time it had lain uninhabited for an unknown period, suffice it to say that at Lower Black's Eddy we have found two stages of occupancy.

"The layers prove a difference in time, short or long. The character of the objects found a difference in handiwork. Future work can alone prove whether this difference denotes a mere accident of varying tribal conditions, or a wide-spreading difference in cultural status. Let us only say now that at this one spot it exists."

Since the work of Mercer, several finds of exclusively argillite material have been made in other sections of the Delaware Valley. Skinner in his admirable Archæological Survey of New Jersey sums up the situation as follows.

${ }^{1}$ The Antiquity of Man in the Delaware Valley and the Eastern United States, Henry C. Mercer. Publications of the University of Pennsylvania, Vol. VI, 1897, pp. 81-82. 


\section{"Predecessors of the Delaware Indians"}

"The Lenni Lenape, although found here by the first white settlers, were not the oldest inhabitants of the region. Beneath the immediate surface, darkened by the refuse from Indian habitations, chipped implements of argillite have been found in the undisturbed yellow soil under conditions that suggest considerable historical antiquity. No pottery or implements other than large rough argillite points, blades and the like occur, whereas the Lenape layer above is rife with pottery, implements of all kinds, and materials. In the valley of the Delaware this phenomenon has been amply observed and investigated by Dr. C. C. Abbot, Dr. Ernest Volk, and others. Mr. Lockwood is said to have noted it at Keyport, in the shell heaps, and Messrs. Edmund Shimp and R. W. Emerson, of Bridgeton, have recorded the presence of at least one site, on Cohansey Creek, where crude argillite tools alone occur. Mr. Schrabisch, in his work on New Jersey rock shelters, Mr. Gregor in Pennsylvania, and Mr. Harrington in New York, report the presence of a non-pottery using people as shown by the bottom, hence the oldest, layers in the débris of the caves." 1 This would indicate that the area occupied by the argillite users has yet to be definitely outlined, although the center appears to have been the lower Delaware Valley.

Mr. Skinner concludes: "Possibly there was an argillite culture here before the Delaware or Lenape Indian that our ancestors knew, but to say that these people were of different race, a race that could be called pre-Indian, is too much, although they may be called pre-Delaware with some certainty." Our conclusions agree with the latter part of $\mathrm{Mr}$. Skinner's statement, that the argillite culture represents a people which may be called pre-Delaware, although it may not be pre-Indian. The authenticity of the argillite culture itself we believe is proven beyond a doubt.

${ }^{1}$ Archæological Survey of the State of New Jersey. Alanson Skinner and Max Schrabisch. Geological Survey of New Jersey. Trenton, 1913. 
The excavations of the present site in which numerous types of implements from both the ancient argillite and modern Lenape cultures are found in undisturbed soil in successive geologic strata, with a possible intermediate culture between, gives a firm footing for the consideration of the problem. It determines the position and enlarges the extent and form of the older culture, but raises the broader question as to whether the argillite culture extended with modifications through the intermediate into the modern. A further and intensive investigation over the area covered by reported argillite finds will be necessary to settle this aspect of the question.

\section{Description of THe Site}

The site excavated is situated in southern New Jersey, on one of the branches of Rancocas Creek, about six miles from the Delaware River. It is on a farm belonging to Edward Crispin, situated midway between Masonville and Medford, and some two and a half miles from the former. The stream on which the site is located offers evidence of having once been much larger than at present, as is shown by an adjoining swampy area which is flooded in wet seasons. In early times this locality must have been easy of access from the Delaware by canoe. The elevation above sea level is slight. Excavations showed conclusively that the site had never been cleared, which gives the material unique value as archeological evidence. The modern Lenape material was found undisturbed beneath the leaf mold of the present hardwood forest, while occasional cedar stumps in the yellow soil showed the nature of the former forestation. Some two feet beneath the leaf mold a few scattered finds, representing a possible intermediate culture were located; and from five to seven feet beneath the surface, caches of argillite implements, bannerstones, etc., were found lying on white glacial sand at its juncture with the overlying yellowish sand. (See Fig. 1.)

The caches were found arranged in three roughly parallel 
rows around a large central fire pit. (See Fig. 2.) They were separated from each other by a distance of about six feet, with a distance of from ten to twelve feet between the rows. There did not seem to be any special outline indicated by the caches other than a parallel order. The caches may be divided into two groups. First, those containing bannerstones and ceremonial objects, which were by far the most numerous, and secondly, those containing two large points associated with fragments of bone. We have designated these as banner-

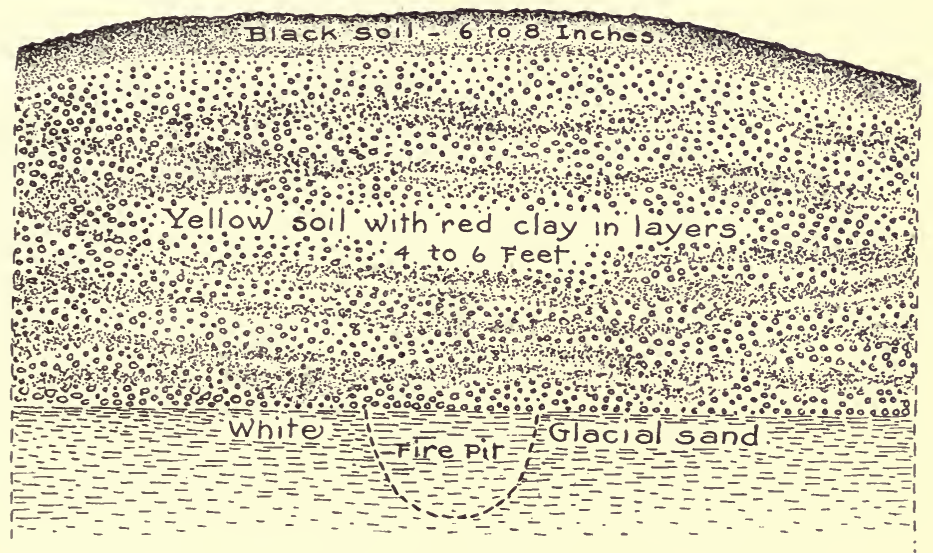

Fig. 1. Cross Section of Excavation.

stone and two-point caches. There was a considerable variety in the value of the objects in the different caches, one cache containing no less than three bannerstones, all of them large and of fine quality. The usual form of cache, however, consisted of a single banner stone and a few ceremonial objects. One cache situated rather apart from the others, contained only one large and very fine bannerstone which was stained by decayed animal matter, probably a wrapping. The difference in value of the caches may represent a corresponding difference in the wealth and station of those who made the 
offerings, but as there were no other indications of rank, it is impossible to decide this question. It has also been suggested that the caches were not properly offerings, but marked the position of dignitaries around the council fire. As a rule, the caches adjacent to the fire pit were the richest.

The great central fire pit had discolored the glacial sand to a depth of three feet. No remains were found in the fire
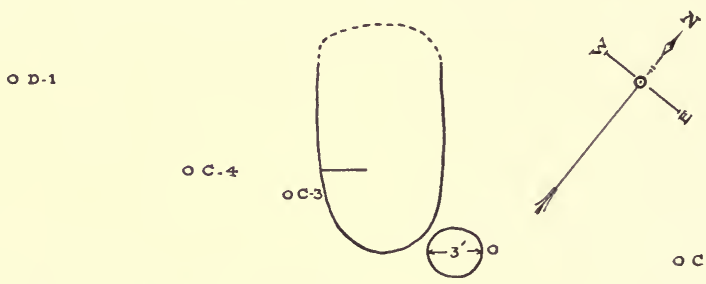

OB.8
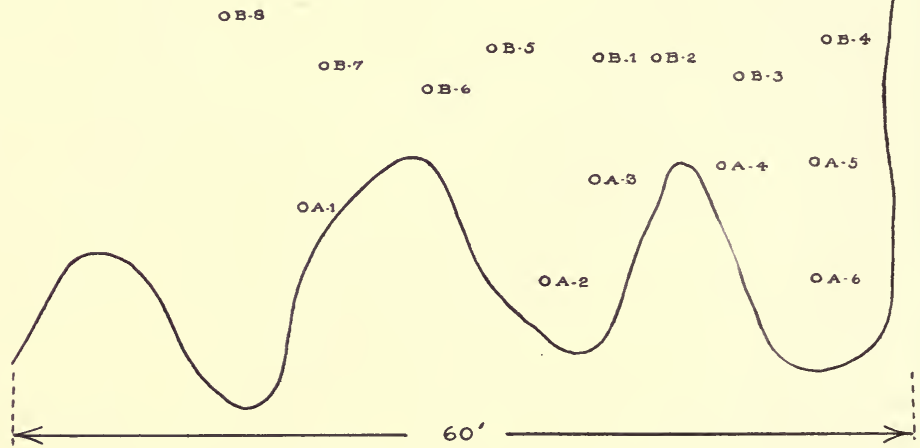

Fig. 2. Diagram Showing Arrangement of Deposits about Fire Pit in the White Sand Stratum.

pit itself, although the third line of caches ran close to the edge. There was a small circular fire pit three feet in diameter due east of the large one with a cache adjacent. (See Fig. 2.) To the west of the rows of caches and the central fire pit, several small fire pits were found, associated with scattered implements which may have marked the temporary camping place of those who took part in the ceremonies. An interesting point in 
connection with all the fire pits was that while the white sand was discolored for some distance down, the yellow layer above was unmarked, proving conclusively that they had no connection with the upper layer.

\section{ARgillite Weapons and Implements}

All the weapons and implements found in the lowest level were, with one exception, of argillite. The exception was a very large and beautiful point of bluish quartzite, which was found in a cache of ceremonial objects. Mr. Skinner, in the Archæological Survey of New Jersey, ${ }^{1}$ calls attention to the fact that, while the Lenape used argillite, such points are always found commingled with others of jasper, flint and quartz, not isolated, and generally in a different cultural horizon. One argillite point was found in the top stratum of the site, associated with points of the above materials. It was, however, finely worked, modern in shape, and unweathered. The points from the leaf mold show none of the signs of decay and great age characterizing those from the lowest level. The intermediate points show slight signs of decay.

As far as this site is concerned, the sequence seems to be as follows. First, an early period characterized by crude workmanship and an exclusive use of argillite; second, an intermediate period, characterized also by the use of argillite, but with improved workmanship and the beginnings of pottery, and third, the modern period, in which the material corresponds to the ordinary surface finds of New Jersey. The intermediate material resembles the earlier culture rather than the modern.

Whether the argillite culture represents a race of migration which was pre-Lenape in other places, it certainly preceded the modern culture in this locality. The length of time required for the deposition of the strata, separating the cultures, cannot be determined exactly but it represents a considerable period of time. If the deposit is æolian, the time might be

${ }^{1}$ Archæological Survey of New Jersey, Skinner and Schrabisch, p. 19. 
comparatively short, but if the strata were laid down under water, the time would be immensely extended.

Among the argillite points found in the lowest level, six types were clearly distinguishable. In every case the entire surface had decayed until it could be easily scratched with the finger nail. The decay in some cases had gone so far as to obscure all marks of the workmanship. Although the ancient workman seemed to have a good sense of form, the technique is poor, the implement having been formed by knocking off a few large flakes. The argillite implement shows no sign of the secondary chipping and finishing characteristic of the modern work. The ordinary type is diamond-shaped, without welldefined barb or stem, and is characterized by a very heavy midriff. The lances are leaf-shaped. The knives have a barb on only one side, but the stem is developed. One type only has the broad face and well-developed barb and stem of the modern type. All of the specimens are much larger than corresponding modern forms.

1. Lances. The lances are fairly thin, ovoid in form, roughly chipped, but well-shaped as to outline. They resemble in form the Eskimo lance, and must have been used for large game. They do not, however, equal in size the large ceremonial point. In every case they were found in pairs, associated with crumbling fragments of bone. They were enclosed in a matrix of decayed animal matter, which, when split open, revealed the points lying on either side of the bone. The matrix may represent a skin wrapping, which enclosed the complete offering of a small animal and the implements. The bones were so badly broken and decayed as to render the species indistinguishable. These two-point caches were found interspersed among others containing bannerstones, fetiches, etc. In one case a single large ceremonial point appeared to take the place of the customary two. A single large bannerstone answered the same purpose in one of the bannerstone caches. All the caches were separated by an interval of at least five feet. The dimensions of two typical lances are as follows. (See Plate XVI, A, B.) 


$\begin{array}{lccc}\text { Ref. } & \begin{array}{c}\text { Length } \\ \mathrm{cm} .\end{array} & \begin{array}{c}\text { Width } \\ \mathrm{cm} .\end{array} & \begin{array}{c}\text { Thickness } \\ \mathrm{cm} .\end{array} \\ \text { A........ } & 11.5 & 6.7 & 1.2 \\ \text { B....... } & 10.9 & 6.5 & 1.3\end{array}$

Hand daggers(?).-Four large crude points, which from their shape could not have been hafted, were found scattered between the caches. As far as workmanship goes they are the poorest of the series. One face is formed by a single large flake, while the other has been formed by three or four heavy strokes. ${ }^{1}$ Apparently these represent lost implements of no particular ceremonial import. The dimensions of three specimens are as follows. (See Plate XVI, C, D, E.)

$\begin{array}{lccc}\text { Ref. } & \begin{array}{c}\text { Maximum } \\ \text { Length } \\ \mathrm{cm} .\end{array} & \begin{array}{c}\text { Maximum } \\ \text { Width } \\ \mathrm{cm} .\end{array} & \begin{array}{c}\text { Maximum } \\ \text { Thickness } \\ \mathrm{cm} .\end{array} \\ \text { C..................... } & 12.5 & 4.4 & 2.1 \\ \text { E........ } & 12.4 & 3.4 & 1.3 \\ & 10.5 & 3.9 & 1.4\end{array}$

It will be seen from the above measurements that these specimens are a crude, long, thick point, in direct contrast to the broad, oval, carefully outlined lance.

Knives.-At the lowest level, but some distance to the left of the bannerstone caches, several rude knives were found. These specimens were more carefully worked than the hand daggers, with a distinct stem for hafting. They have only one barb, and the blade has a distinct curve, along the lower side of which the edge is better worked, which suggests that only one edge was used for cutting. The points were well sharpened. (See Plate XVI, F, G, H.) Dimensions:

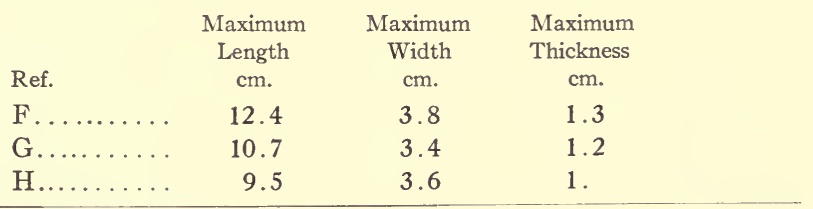

1 They have no resemblance, however, to the "Turtlebacks," either glacial or modern. 
Diamond-shaped points.-As mentioned above, the characteristic point was diamond-shaped, without clearly marked barb or stem. These specimens varied largely in size, from minute points to some as large as lances. They also exhibited a considerable variety of workmanship. Typical measurements are as follows. (See Plate XVII, A, B, C, D, E.)

$\begin{array}{lccc}\text { Ref. } & \begin{array}{c}\text { Maximum } \\ \text { Length } \\ \mathrm{cm} .\end{array} & \begin{array}{c}\text { Maximum } \\ \text { Width } \\ \mathrm{cm} .\end{array} & \begin{array}{c}\text { Maximum } \\ \text { Thickness } \\ \mathrm{cm} .\end{array} \\ \text { A........ } & 10 & 3.1 & .9 \\ \text { B........ } & 8 & 3.2 & .7 \\ \text { C....... } & 7.7 & 2.8 & .85 \\ \text { (D and E are smaller specimens, showing range in size.) }\end{array}$

In common with the broad, barbed points, they are much thinner than the foregoing, but still very thick in comparison with the modern points.

Broad-faced, barbed points.-These specimens are in direct contrast with the general diamond-shaped type in being roughly triangular, with broad faces, well-developed barbs, and stout stems for hafting. They were probably bound on the shaft with a "figure eight" lashing, whereas the diamond-shaped point must have been inserted in the split end of the shaft. Characteristic specimens (see Plate XVII, F, G, H) give the following measurements.

$\begin{array}{lccc}\text { Ref. } & \begin{array}{c}\text { Maximum } \\ \text { Length } \\ \mathrm{cm} .\end{array} & \begin{array}{c}\text { Maximum } \\ \text { Width } \\ \mathrm{cm} .\end{array} & \begin{array}{c}\text { Maximum } \\ \text { Thickness } \\ \mathrm{cm} .\end{array} \\ \text { F................. } & 7.4 & 5 & .9 \\ \text { G..... } & 8.3 & 4.4 & .85 \\ \text { H...... } & 7.9 & 3.6 & .9\end{array}$

It will be seen from the above measurements that these points are more uniform in size than the diamond-shaped specimens. The thickness is about the same.

Fish spears(?).-This type (see Plate XVII, I, J, K, L) has already been named by Abbot. It is thick, heavy, narrow, 
barbless or slightly barbed point with a rounded stem. From its shape it may have been inserted in a hollow reed. In one case a point of this type was found in a cache associated with fossil brachypods painted red.

\begin{tabular}{|c|c|c|c|}
\hline & Maximum & Maximum & Maximum \\
\hline Ref. & $\begin{array}{l}\text { Length } \\
\mathrm{cm} .\end{array}$ & $\begin{array}{l}\text { Width } \\
\mathrm{cm} \text {. }\end{array}$ & $\begin{array}{c}\text { Thickness } \\
\mathrm{cm} .\end{array}$ \\
\hline I... & 7.9 & 2.5 & 1.9 \\
\hline J........ & 8.2 & 1.9 & 1.2 \\
\hline K......... & 7 & 2 & 1.2 \\
\hline L......... & 12 & 3.7 & 1.3 \\
\hline
\end{tabular}

\section{BAN NERSTONES}

The site excavated was remarkable for the large number of bannerstones found. The presence of these objects raises an interesting question, for in size, beauty, and finish of workmanship they far surpass those found on the recent village sites of this region, and are absolutely at variance with the crude character of the implements with which they were associated. At first the authors were inclined to believe that they must have been imported from some adjoining area of higher culture, but a study of specimens from other regions where these peculiar objects occur showed that they did not agree in either form or material. It is a well-known fact that many tribes in a low grade of development have acquired a disproportionate skill in some one direction, usually artistic or technical. As an example we might cite the savage tribes of the Amazon, who have acquired great skill in the making of crystal tubes, while their ordinary artifacts are of the crudest type. The manufacture of bannerstones is not necessarily connected with skill in chipping. The specimens excavated show that they have been formed by pecking and polishing. They required skill in boring and a good sense of proportion. These qualities are often exhibited by peoples whose chipped artifacts are inferior.

In this particular group the methods of manufacture 
seem to have been uniform. The mean diameter of the bore was $1.4 \mathrm{~cm}$. Outside of a single specimen with an unusually large bore, the variation in nineteen specimens was not over $.2 \mathrm{~cm}$. The variation in diameter at the two ends was not over $.3 \mathrm{~cm}$. which is the more remarkable as a number of the specimens have been bored from both ends. The maximum length of the centrum, that part of the bannerstone surrounding the boring, was $7.7 \mathrm{~cm}$., and the minimum 4.2. The average length was approximately $6 \mathrm{~cm}$. The width of the centrum was remarkably uniform throughout the series, $2.3 \mathrm{~cm}$. in four specimens, $2.2 \mathrm{~cm}$. in five other specimens and $2.4 \mathrm{~cm}$. in three, all of varying size. The thickness of the wings was also remarkably uniform; $1.2 \mathrm{~cm}$. in five specimens, $1.3 \mathrm{~cm}$. in four others, $1.1 \mathrm{~cm}$. in two, and $1 \mathrm{~cm}$. in two. The wings of No. 5 were only $.9 \mathrm{~cm}$. in thickness. In outline and spread of wings the bannerstones varied considerably, from an extremely large specimen with a spread of $15 \mathrm{~cm}$. to one of three small specimens averaging $7 \mathrm{~cm}$. As to outline, they may be divided into two main groups, the pick-shaped and the square ended (see plates) but the individual variation is so great that a separate description has been given for each one.

Plate XXI, 5. The largest of the series. Straight ended type. Rubbed smooth, but not polished. The centrum is evenly rounded and does not project beyond the base of the wings. The wings have been ground to an edge from both sides at the ends, and are not perfectly aligned with each other. It has been drilled from both ends, the bore meeting about one-third of the distance from the top. One side shows stains which may be due to a hide wrapping.

Plate XXII, 4. Large stone of pick form, smoothly rubbed but not polished. The material has been worked in such a way that on one side a patch of different colored strata appear at the tip of either wing and on the centrum. The centrum has three well-marked facets on either side, and there are grooves at the base of the wings on both sides. The centrum protrudes very slightly below the wings. The edges of the wings are 
ground square, and the wings themselves are poorly aligned. A large chipping on the edge of one wing has been partly ground out. It has been drilled from both ends, the bores meeting about one-third of the distance from the top. The juncture is very exact.

Plate XXIII, 3. Large stone of intermediate form, rubbed, and the centrum but not the wings polished. One side of one wing shows a few marks of pecking which have not been entirely rubbed out. The centrum has three well-defined facets and a groove at the base of the wing on only one side. On the other it is smoothly rounded. At the bottom of the centrum, chips have been broken off on both sides and the edges ground back at an angle to destroy the roughness. The side of both wings have been ground from both sides to work out blemishes, but were originally as Plate XXI, 2. The wings are almost perfectly aligned. This stone has been drilled from one end only.

Plate XXI, 4. Fairly large stone of pick form, rubbed and polished. The centrum is rounded, and there are grooves at the bases of the wings, although one of the four is lacking. At the bottom of the centrum a large chip has been broken off on one side, and the stone ground back from the edge of the bore at an angle all round so as to leave a thin knife edge. The upper edge of the centrum has also been slightly broken and ground back. Large chips on the tips of both wings have been partly ground out. The wings are well aligned, but are not at right angles to the axis of the centrum. The boring has been done from one end.

Plate XXI, 3. A very perfect and beautiful stone of the square ended type, rubbed and polished. The centrum is ground flat on either side, but from this face it curves off smoothly into the wings. The lower end of the centrum has been slightly ground back from the bore, but there are no signs of breakage. The wings of this specimen are very thin, and brought to a square edge all round. Chipping on the edge and tip of one wing has been partly ground out. It has apparently been drilled from one end, but the markings at either 
end show that the diameter of the bore has been enlarged after the drilling was finished. In the center the marks of the original boring are still present.

Plate XXI, 2. This is a smaller and cruder replica of No. 5 , but is unpolished. The centrum has a facet on either side, and on one side there are slight grooves at the base of the wings. The wings are thick and heavy at the base and taper rapidly. They are poorly aligned, and a chipping at the end of one has been ground out. The bore is not in the middle of the centrum. The drilling has been done from one end, and the bore has been enlarged at the top, where the usual circular markings are obliterated by horizontal scratches. This specimen has stains on both sides similar to those of No. 1 .

Plate XXI, 1. A large stone of unclassifiable form. The outline is oval, it being scarcely possible to distinguish top from bottom. It is rubbed and partly polished. The centrum is slightly flattened on both sides, but runs off smoothly into the wings. It projects slightly at both ends. The wings are well aligned, and have been ground to a sharp end all round. The boring seems to have been done from one end, but no marks are visible. The opening is oval at both ends, and is not in the middle of the centrum, so that one edge is considerably thinner than the other.

Plate XXIII, 2. A large stone of pick form, ground and polished. When found it lay in three pieces, having been split down the bore. The centrum has three well-defined facets on either side, the top and bottom ones being much the largest. At the bottom of the centrum a large flake has been broken out for its entire width on one side. The centrum has been ground back on this side for almost a third of its entire length, and on one wing and along the bottom of the break is a deep cut left by some sharp edge, probably an argillite flake, showing that the maker had begun to cut away that end of the stone, but thought better of it and contented himself with grinding it down. Chippings have been ground out of the ends of both wings. The sides of the wings are 
square edged, the ends sharpened. The wings are well aligned. The bore shows longitudinal markings, faint in the middle and growing into grooves at either end. At its openings the bore is oval.

Plate XXIII, 4. A large stone intermediate in form between the pick and square ended types, ground and polished. The centrum shows marks of pecking at either end which have not been entirely ground out. The centrum has well-defined facets on either side, the edges being sharp and true. The wings are poorly aligned, and ground to a sharp edge at the bottom and ends. It has been drilled from one end, but there are longitudinal markings the entire length of the bore.

Plate XXIII, 5. A very large stone of intermediate form, ground and polished. This stone is interesting in that it has been broken and mended by the owner. Holes have been drilled in both wings through which thongs. were passed and the parts tied together. There are three of these holes in one wing, and in the other, the end of which is missing, two complete holes and the edges of two more. All the holes have evidently been made with a stone drill. All three in the one wing are drilled through from the one side, and one in the other wing has been made in the same way. The others have been drilled from both sides. The hole in the upper edge of the complete wing has no connection with the mending and may have been made for the attachment of some ornament. The centrum has a single not very well-defined facet on either side.' The wings are perfectly aligned and square edged all round. The implement was evidently broken by a blow on the tip of one wing. The boring has been done from both ends, and the bore shows circular lines.

Plate XXII, 5. Large stone of pick form, ground and polished. The centrum has a well-marked groove down the middle on both sides. The wings have a sharp upward curve, and both wings are decorated on one side with incised lines running at right angles to the centrum. There are a few marks of pecking, imperfectly ground out. The wing tips have been 
ground to an edge from both sides. The stone has been drilled from one end, and shows circular markings.

Plate XXIII, 1. Large and perfect stone of pick form, ground and polished. The centrum has a single well-defined facet on either side, but the facets are not exactly opposite each other. Chips have been broken from the bottom of the centrum at both sides and the roughness ground out. One wing is square edged all round, the other ground to a sharp edge, in an effort to remove the marks of two deep chippings. The stone has been drilled from both ends, but the bore is oval and shows both longitudinal and circular scratchings.

Plate XXII, 3. A very large stone of pick form, ground and highly polished. This is the most beautiful specimen in the collection. The centrum has a small but well-marked facet on either side, from which it runs off smoothly into the wings. At the bottom it projects beyond the wings considerably, but is flush at the top. The wings are square edged, but the tip of one has been chipped and the resulting roughness ground out. The stone has been drilled from one end, and the bore is almost a true circle, although it shows longitudinal markings.

Plate XXII, 2. A fairly large stone of pick form, ground and partly polished, but still showing many striations. The centrum has a large flat facet on one side, and a deep line incised on the surface between the facet and wing, and another at the base of the wing. The corresponding surface on this side is unmarked. On the other side the centrum has three facets. The top one has been deeply incised along either edge and worked out until it is below the level of the sides. The other two facets are also well marked, but one is more sharply cut than the other. The surface of the centrum and wings has been ground back for a little distance at the bottom. One wing is square edged, the other rounded in an attempt to grind out a large blemish. The stone has been drilled from both ends, two-thirds from the bottom and one-third from the top. There are deep grooves running the entire length 
of the bore, except far in the middle on one side, which shows faint circular markings.

Plate XXIV, 6. A medium sized stone of intermediate form. It has been ground, but still shows many marks of pecking. The centrum has a well-marked facet on- either side. The wing tips are recurved and pointed, and the wings are decorated with lines on one side, as in No. 5. The wings are square edged and very thick and heavy for their length. A small chip near the tip of one has been partially ground out. The bore is very large and marked longitudinally, except in the middle, where there is a small patch of the original boring.

Plate XXIV, 5. A medium sized stone, ground and polished, one wing of which approaches the pick, the other the square ended form. The centrum has a concave upper facet on one side, and a very slightly concave, almost flat one on the other. The latter is marked by a deep scratch made with a sharp edge. The wings have a marked upward curve and are very heavy for their length. They are sharpened at the tips. The stone has been drilled from both ends, the bores meeting one-third from the top, and shows circular marking.

Plate XXIV, 4. Medium sized stone of pick form, ground and partly polished. The centrum is smoothly rounded. The wings are well aligned, but uneven in shape, with edges rounded.

Plate XXIV, 3. Small bannerstone of square ended type, ground and polished. There is a groove down the centrum on either side. The wings are square edged all round, and one has been partly broken off and the stub ground into shape. The wings are heavy for its size. The bottom of the centrum has been chipped in several places.

Plate XXIV, 2. Small stone of pick form, ground and polished. Part of the centrum and one wing are missing, a large chip having been split off from the top. The wings are square edged and heavy. The bore shows circular markings, and differs from all the others in that it tapers sharply from the top to the bottom. The perforation was probably made 
with a long stone drill, instead of the reed used in the other specimens.

Plate XXIV, 1. Small stone of triangular shape, ground but not polished. The centrum has a small facet on either side, and the edges of the bore are chipped at the bottom. The bore is not in the middle of the centrum. The wings are very thick and square edged. It has been bored from one end and shows circular markings.

Plate XXII, 1. Large stone of peculiar form, ground and polished. The centrum extends beyond the wings at the bottom, and one side is rounded, the other has a well-marked facet. The wings are very broad and short, so that the effect is that of a mace head rather than a bannerstone. The wings are thick and ground to an edge all round. It has been bored from both ends, and the bore shows circular markings.

With the exception of the three small and the mace-shaped bannerstones, the group is fairly homogeneous, and hence offers an unusual opportunity for study. A careful comparison has been made for the purpose of determining: (1) what were the methods of manufacture, and (2) what uses could they have been put to? In the first case the evidence is clear, and verifies the observations of other investigators, that the bannerstones were first roughly chipped into shape, then pecked and ground, and finally polished. In one object, intermediate in form between the bannerstones and the crescent-shaped stones the pecking had been dispensed with, and the shaping done by rubbing with some instrument which left broad shallow striations. Similar striations are present in a few of the bannerstones, but the finishing seems to have been done with a piece of fine-grained sandstone, or with sand and water. All the stones, with the possible exception of No. 19, were drilled with a reed and sand. The boring was begun at the bottom and carried through, or carried about two-thirds of the way, and then finished from the other end. The exactness with which the two borings meet shows a high degree of skill. In several cases the diameter of the bore has been enlarged at one or both 
ends by rubbing with a sharp point, or with a thong and sand. We know from unfinished specimens found on other sites that the boring was not begun until the shaping was finished.

In regard to the use of the bannerstones, at this site at least, the evidence seems conclusive that they were hafted. In seven specimens the edge of the bore had been broken out. In five the break is at the bottom, and in one at both top and bottom. In the only specimen where the break is at the top alone, it marks the larger end of the bore, which tapers rapidly from top to bottom. This breakage is such as would result from driving into the bore a shaft somewhat too large for it. A similar condition is found in some of the beautiful quartz specimens from the Mississippi Valley, in which the centrum has been broken out on one side for the whole or part of its length, while the other side and the wings remain uninjured.

The soft material from which the bannerstones were made, and the perfect condition in which many of this series were found, suggests that they were never subjected to the rough usage of ordinary implements. It has long been taken for granted that they had some religious significance, but the particular use to which they were put remains an enigma. It seems most probable that they were mounted on the end of a staff and used as religious insignia. They may also represent the double-bladed axe, as a ceremonial weapon.

\section{Measurement of Bannerstones}

(All measurements of banner stones are in centimeters)

Bore

Centrum

\begin{tabular}{|c|c|c|c|c|c|c|}
\hline \multirow[b]{2}{*}{ Ref. } & \multirow{2}{*}{$\begin{array}{c}\text { Diameter of } \\
\text { Top }\end{array}$} & \multirow{2}{*}{$\begin{array}{l}\text { Diameter of } \\
\text { Bottom }\end{array}$} & \multirow{2}{*}{$\begin{array}{l}\text { Maximum } \\
\text { Length }\end{array}$} & \multirow{2}{*}{$\begin{array}{l}\text { Maximum } \\
\text { Width }\end{array}$} & \multicolumn{2}{|c|}{ Wings } \\
\hline & & & & & Thickness & Spread \\
\hline P1. XXI -5 & 5. 1.5 & 1.45 & 6.5 & 2.6 & 1 & 15 \\
\hline P1. XXII -4 & 4. 1.45 & 1.35 & 6.3 & 2.4 & 1.3 & 14.75 \\
\hline 1. XXIII-3 & 3. 1.4 & 1.3 & 6.85 & 2.2 & .75 & 13.7 \\
\hline P1. XXI -4 & 4. 1.55 & 1.4 & 6.4 & 2.2 & 1.2 & 12.1 \\
\hline P1. XXI -3 & 3. 1.45 & 1.45 & 7.5 & 2.4 & .9 & 12.4 \\
\hline
\end{tabular}


Measurement of Bannerstones-(Continued)

Bore

Centrum

Diameter of Diameter of Maximum Minimum

Ref. Top Bottom Length Width Thickness Spread

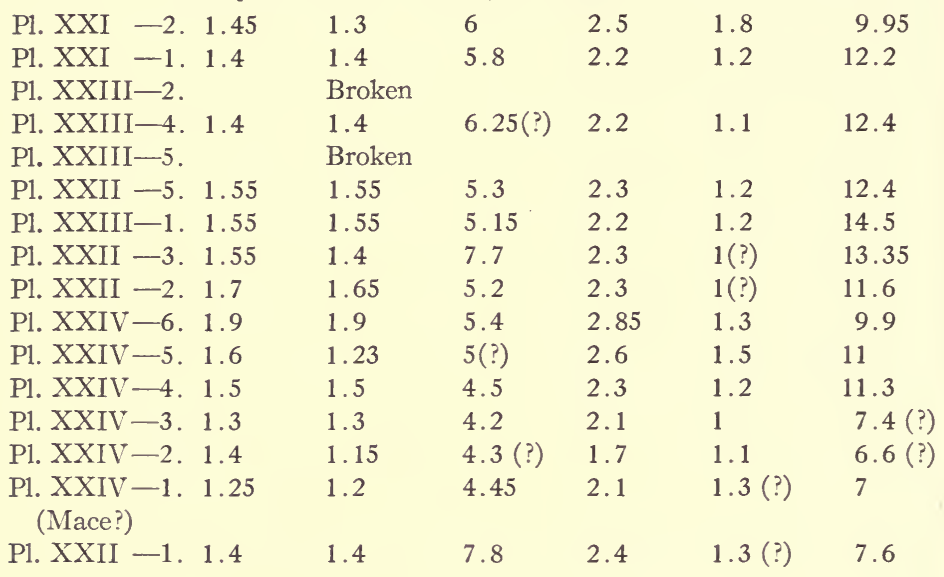

Ceremonial Objects other than Bannerstones

Ceremonial points.-In this class (see Plate XVI, I, J, and $\mathrm{K}$ ) we have included three isolated points which are so far superior in size and workmanship to anything of like sort in the lower level, that they belong in a class by themselves. These points were found directly associated with bannerstones or other ceremonial material. Two were of argillite and the third of quartzite, the only specimen of that material in the entire site: At first we were inclined to believe that both they and the bannerstones were importations from some other area of higher culture, but a careful survey of adjoining regions showed that they were unique, and probably a local product. These points, like the bannerstones, represent the high water mark of local workmanship which was spent on offerings, while the everyday tools were roughly made; or they may have been insignia of rank, as has been suggested for the banner- 
stones. The ceremonial points are characterized by large size, extremely thin blade with carefully chipped edge, perfect barbs and stem, and beautiful proportion. For quality of workmanship considering the poor material, they would rank favorably with specimens from any of the areas with a recognized high culture. The dimensions of the three specimens are as follows:

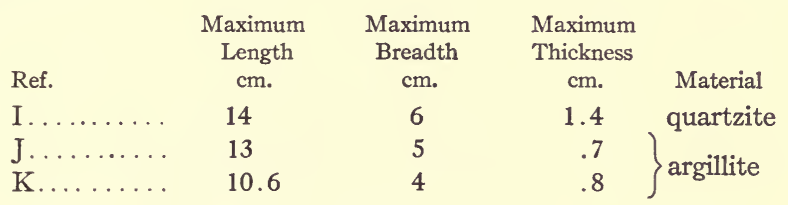

Ceremonial axes.-These specimens, which were found in the caches of sacred objects, represent an entirely new type for New Jersey. (See Plate XVI, L, M, N, O.) They are of argillite, chipped and unpolished, with a ground blade. In one specimen, probably unfinished, the edge is chipped only $(\mathrm{O})$. The general features of all four are: thick cross-sections, rounded upper end, and a well-beveled blade. None are grooved. In size they resemble the Eskimo adze, but the thickness of the midsection would prevent a similar hafting, except in the case of the smallest, unground specimen, which is triangular in crosssection. The other three were probably bedded in the handle. The largest specimen is oblong in shape, and slightly curved. On the outer side of the curve a tang has been left for lashing, or to prevent the implement from slipping through the handle. There is no sign of a groove but the sides of the implement just above the tang have been somewhat smoothed. The edge is sharpened evenly from both sides. The second is much smaller, but agrees with the first in shape and proportions except that it lacks the tang and is straight. It also is evenly ground from both edges, but the surface is unpolished, and it shows no signs of use. The third is of a roughly triangular form, the cutting edge forming the lower side. As the sides narrow, it thickens until the upper end is almost cylindrical 
in cross-section. The implement bears a striking resemblance to some which have been discovered in the Swiss lakes which were hafted in deer horn. The dimensions are as follows:

\begin{tabular}{|c|c|c|c|c|}
\hline Ref. & $\begin{array}{l}\text { Maximum } \\
\text { Length } \\
\mathrm{cm} .\end{array}$ & $\begin{array}{c}\text { Maximum } \\
\text { Width } \\
\mathrm{cm} .\end{array}$ & $\begin{array}{c}\text { Maximum } \\
\text { Thickness } \\
\mathrm{cm} .\end{array}$ & $\begin{array}{c}\text { Breadth } \\
\text { of Blade } \\
\mathrm{cm} .\end{array}$ \\
\hline L... & 12.1 & 5.7 & 2 & 4.8 \\
\hline M........ & 7.8 & 3.9 & 1.7 & 3.4 \\
\hline N........ & 9 & 3.9 & 2 & 2.7 \\
\hline $0 \ldots \ldots \ldots$ & 8.7 & 4 & 1.5 & 3.3 \\
\hline
\end{tabular}

Blunt pear-shaped axe.-This implement, like the chipped axe, is another new type for New Jersey. (See Plate XVIII, A.) The specimens vary in size, but are characterized by the same general outline, which is roughly pear-shaped, with one side concave. The curved side suggests that the axe was held in the hand. There are no signs of hafting. In cross-section the axes are roughly oblong, thickening toward the blunt edge. They show no signs of working except at the lower edge, which battered into shape. They were found associated with fragments of bone, and may have had some sacrificial use. (B, C, and D show other specimens of the same type.)

Ancient chipped axe or hoe.-In the lowest stratum, but outside the circle of the ceremonial caches, was found one large specimen of an ancient chipped axe or hoe. (See Plate XIX, C.) The specimen was roughly oval in form, with the sides parallel, rounding off at either end. The entire surface shows chipping, and the cutting edge is chipped and not ground. The surface was badly decayed. There were signs of hafting. The dimensions of the axe, which much exceed those of the other types mentioned, are as follows.

$\begin{array}{cccc}\begin{array}{c}\text { Maximum } \\ \begin{array}{c}\text { Length } \\ \text { cm. }\end{array}\end{array} & \begin{array}{c}\text { Maximum } \\ \text { Breadth } \\ \mathrm{cm} .\end{array} & \begin{array}{c}\text { Maximum } \\ \text { Thickness } \\ \mathrm{cm} .\end{array} & \begin{array}{c}\text { Breadth } \\ \text { of Blade } \\ \mathrm{cm} .\end{array} \\ 13.3 & 8.5 & 2 & 7.4\end{array}$

Tanged adze.-One specimen of a square, flat adze, with tangs on the sides, was found in one of the caches. These 
implements are flat on one side, curved on the other, with a ground and beveled edge, and were probably hafted at an angle. The spuds at the sides probably held the lashing. The peculiar form of this implement suggests that it may be a local variety. Even the ordinary type of adze is rare in New Jersey. Further investigation may reveal the limits of this variety. (See Plate XVIII, E.)

Hoes(?).-Under this head we have classified half a dozen broad crude argillite implements hollowed on one side. (See Plate XIX, A, B.) One specimen is almost square, with a thin edge (A). These were also found outside the ceremonial circle, but near a small fire pit at one end. All these specimens are roughly made, with no chipping on the edge or sides. A thin stone that suited their purpose seems to have been roughly blocked into shape. The rough but fragile edge suggests that they may have been used for digging in the sand.

Celts.-One large celt, roughly cylindrical in shape and battered at the edge, was found in one of the caches. (See Plate XIX, D.) $\mathrm{E}$ is a celt from the intermediate layer, which has a slightly concave face. No grooved implements were found in the entire collection from the lower area, although two grooved, square-faced axes were found in the top stratum. (See Plate XVIII, F, G.) H shows another modern axe which seems to have been double bitted.

Small hammers.-Two small hammers, cylindrical in shape, and about three inches long, were found in the ceremonial caches. They were simply pebbles of suitable shape, and showed no signs of working except the battered ends. (See Plate XIX, F and G.)

Ear plugs(?).- Three other small cylindrical specimens, with carefully rubbed ends, were also found in the caches. (See Plate XIX, J, H, I.) They had been slightly pecked around the middle. They appear too small and of too soft material to have been implements, and on that account have been classified as ear plugs, for which purpose they are well suited. This opinion, however, may not be final. 
Paint stones.-Two sets of unworked stones, probably used for grinding paint, were found in the caches. They are represented by a flat lower stone and a round upper one, showing signs of wear at the point of contact. (See Plate XIX, $\mathrm{K}, \mathrm{L}$.) In one set the stones were still in position.

Crescent-shaped stones.-A series of crescent-shaped stones more or less carefully rubbed and polished, were found in the ceremonial caches. One suggested in outline a bannerstone, but was too thin to be drilled, and showed no signs of an external groove. The other specimens were much thicker, but roughly followed the same form. They were of various materials, but showed a fine luster, like that of the Southwestern pottery polishing stones. They probably belong to that class of indeterminate stone objects found in the Indian medicine man's outfit.

Other problematical objects.-Beside the crescent-shaped stones, other objects of an evidently sacred nature were found associated with bannerstones. Among these were four fossil brachypods, showing traces of red paint. (Ear plugs also showed signs of red paint.) A beautiful quartz crystal ball, carefully pecked into shape and then polished, was found in one of the caches. Oddly shaped iron concretions, also showing signs of paint, were scattered throughout the caches. Several white quartz pebbles were also found associated with the bannerstones.

\section{Intermediate PoInts AND Pottery}

The intermediate points, which were also of argillite (see Plate XX, D), exhibit all the types found in the lowest level except the lance and the broad-faced barbed point. In addition there was one new type, the drill, represented by one long, finely chipped specimen. No drills were found in the lowest level. The boring of the bannerstones was evidently done with a reed. In one specimen, which had been broken, the fractured wings had been bored for lashing together, with a short, sharp point. The intermediate points are easily 
distinguishable from the early type by a distinct advance in manufacture and the absence of patina. A considerable time must have elapsed for this difference in workmanship and age. The number of specimens found at this level was so small, although representing a number of types, that additional excavations should be made in this area in order to determine whether this culture may be rightly called intermediate. Specimens of modern points of various material from the top stratum are illustrated in (A).

Clearer evidence than that furnished by the points is offered by small sherds of pottery found in the intermediate level. (See Plate XX, C.) No traces of pottery were found in the lowest level. The pottery of the intermediate culture was quite distinct from that of the modern Lenape, many bits of which were found on the surface. (See Plate XX, B.) The fragments from the intermediate level were composed of red clay and pounded steatite, the latter composing more than half the bulk. The red clay could have been obtained from small strips of the same running through the yellowish soil, Judging from its consistency it had been simply sun-dried and not baked. It could be easily scratched with the finger nail. Nevertheless the fragments showed a uniform thickness, and one piece showed the curve of a rim. It is possible that here we have the very beginning of pottery among these people and the steatite, which is not used to temper the recent pottery, marks the transition from the bowls of that material used for similar purposes. 



\section{KEY TO PLATES}

Plate XVI. A to K. Argillite points from lowest level (except I, which is quartzite and from the lowest level).

$\mathrm{L}$ to $\mathrm{O}$. Argillite chipped axes from lowest level.

Plate XVII. A to L. Argillite points from lowest level.

Plate XVIII. A to D. Blunt axes (worked glacial pebbles) from lowest level.

E. Tanged adz from upper level.

$\mathrm{F}$ to $\mathrm{H}$. Grooved axes from upper level.

Plate XIX. A to C. Argillite hoes from lowest level.

$\mathrm{D}$ to $\mathrm{F}$. Celts from lowest level.

J to I. Small hammers or ear plugs (?) from lowest level.

$\mathrm{K}, \mathrm{L}$. Paint stones from lowest level.

Plate XX. A. Points from upper level.

B. Potsherds from upper level.

C. Potsherds from intermediate level.

D. Argillite points of various types from intermediate level.

Plates XXI, XXII, XXIII and XXIV. Bannerstones from lowest level. 



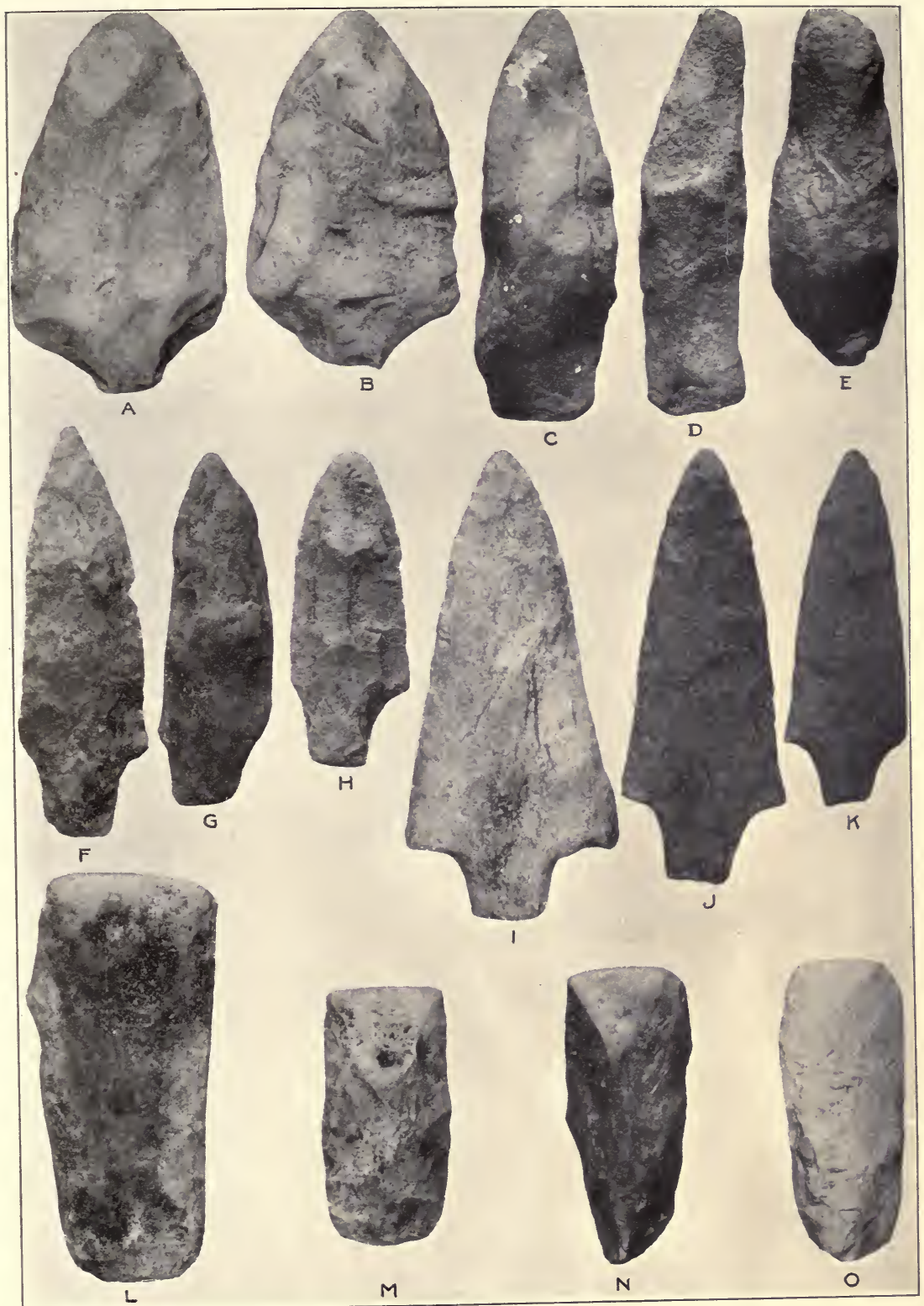

IMPLEMENTS FROM LOWEST LEVEL 



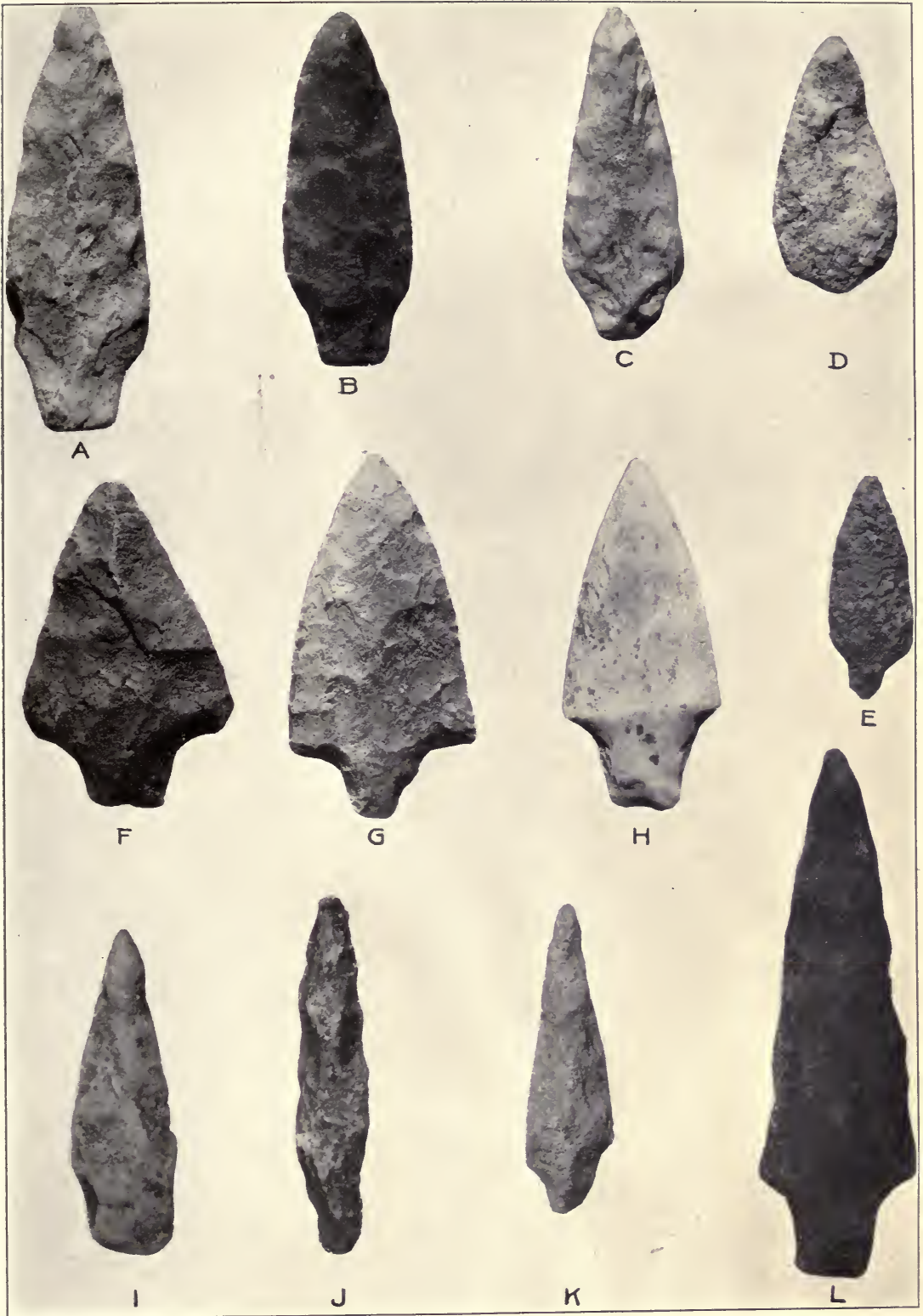





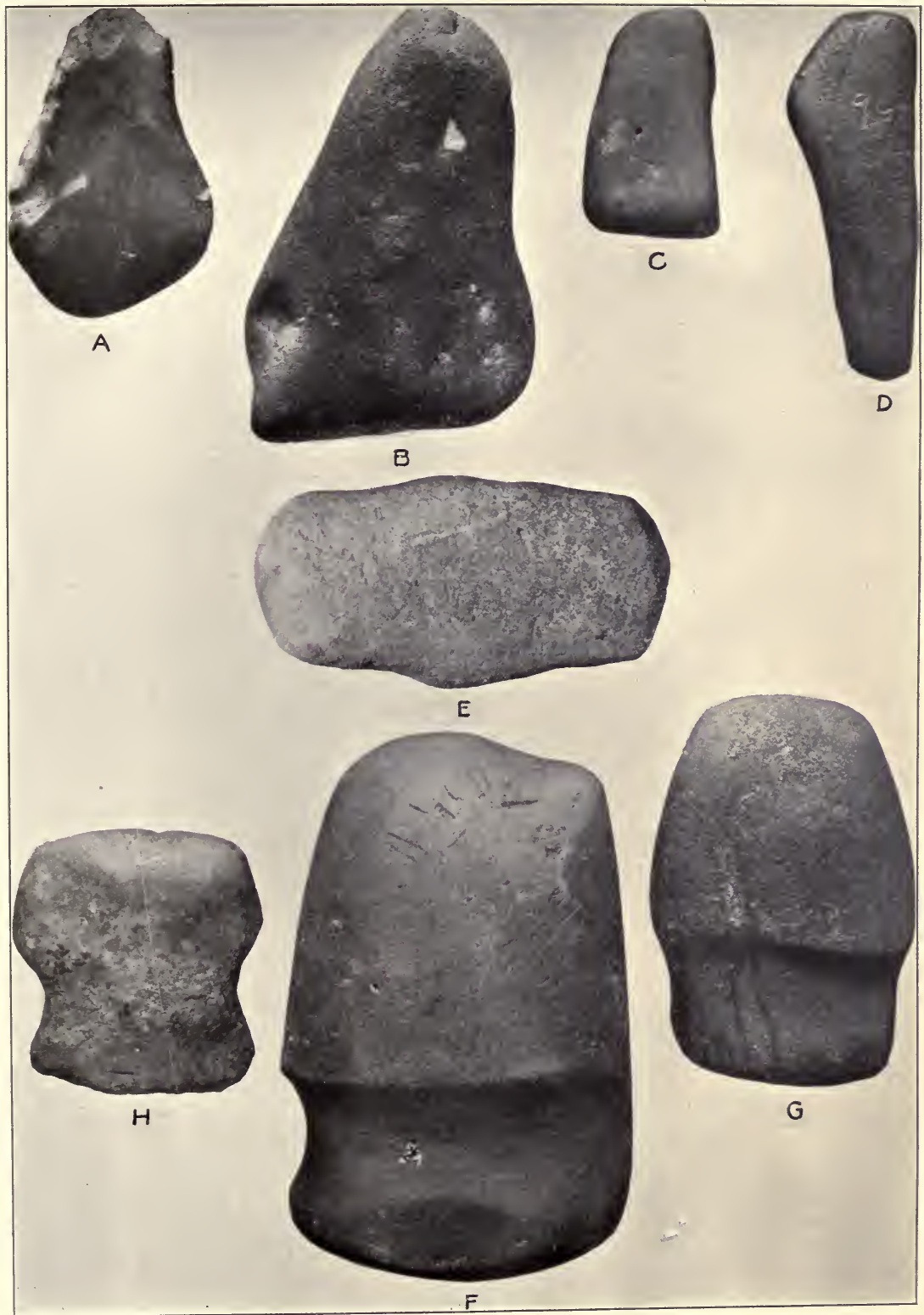

IMPLEMENTS FROM LOWER AND UPPER LEVELS 



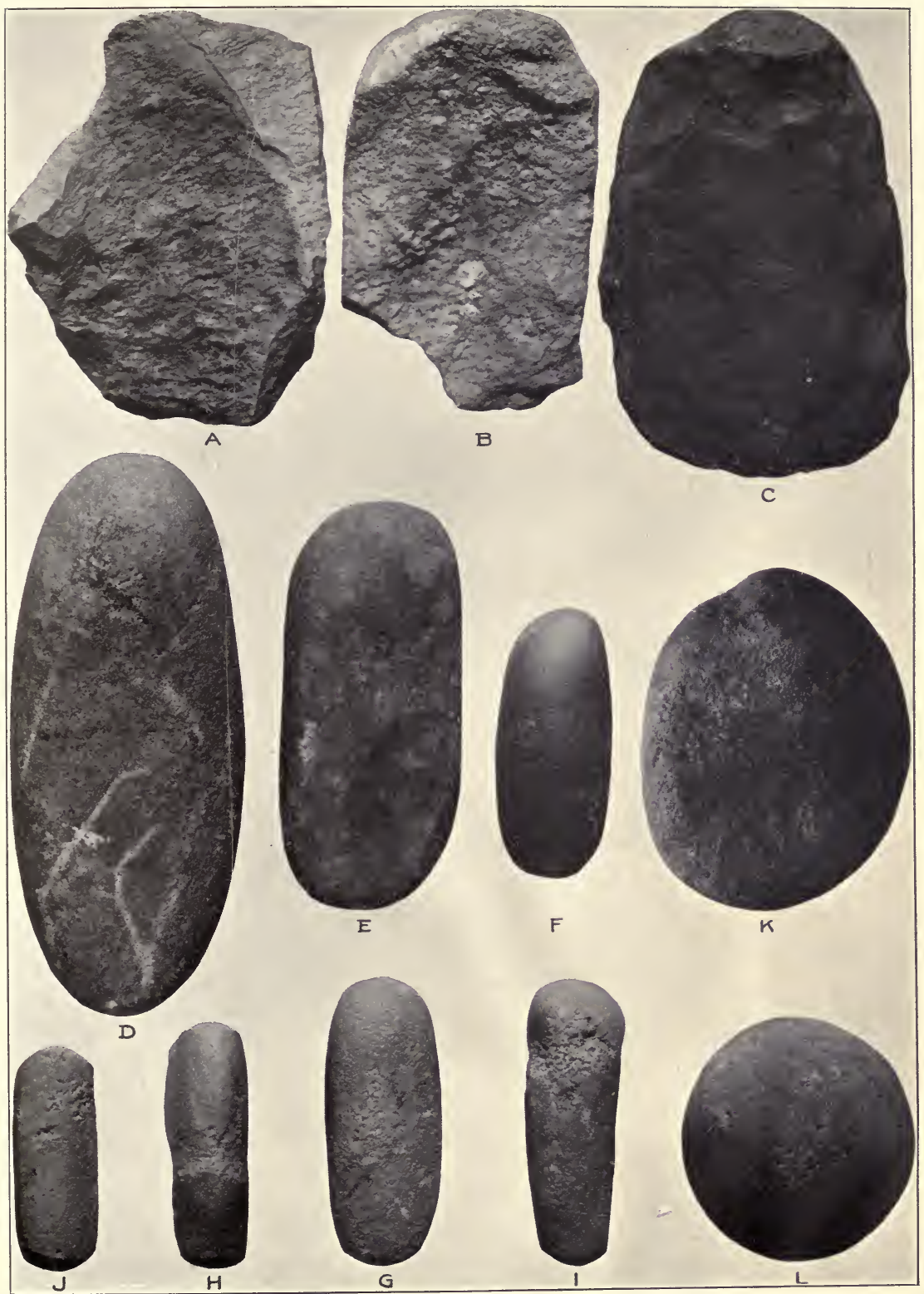

IMPLEMENTS FROM LOWEST LEVELS 



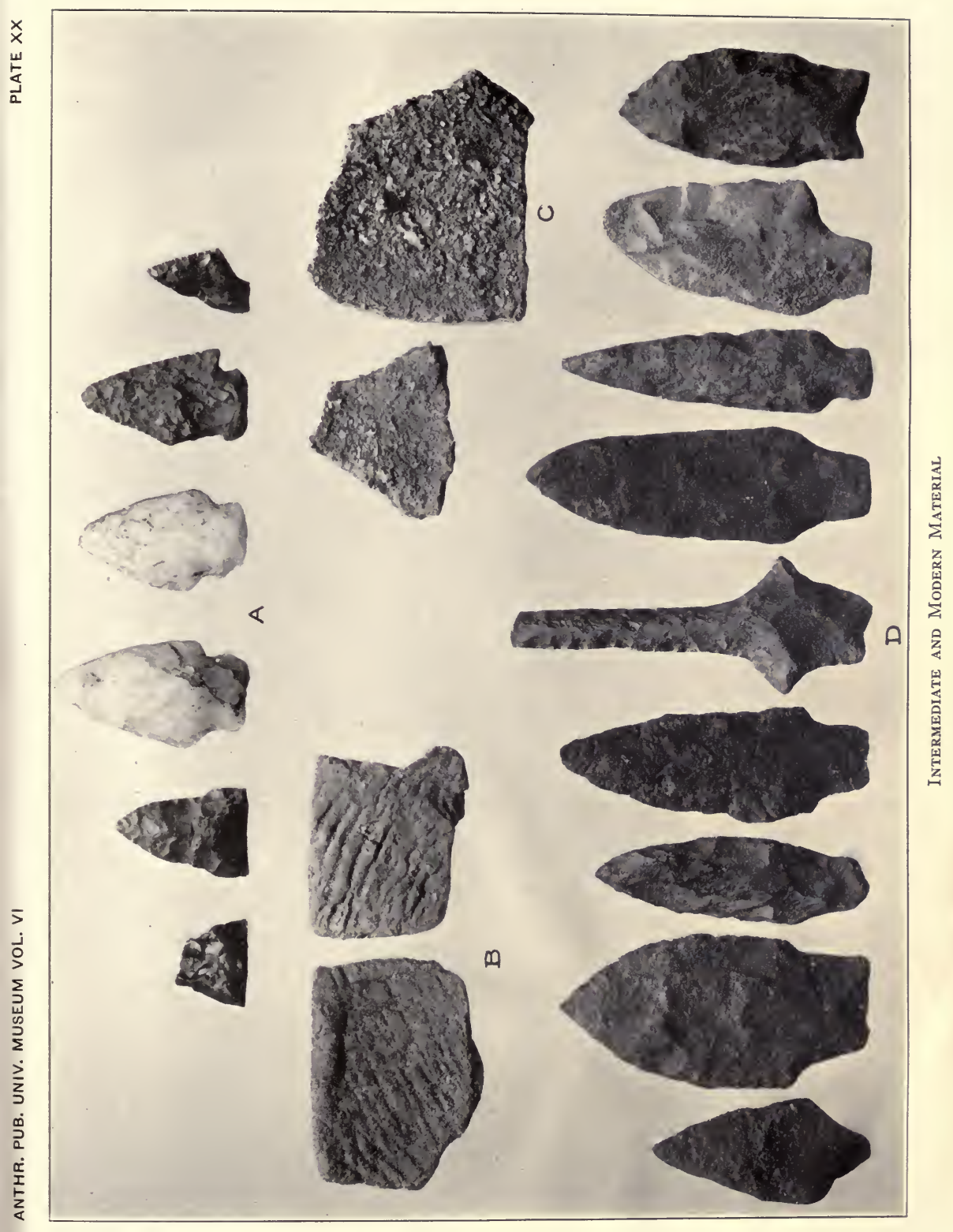





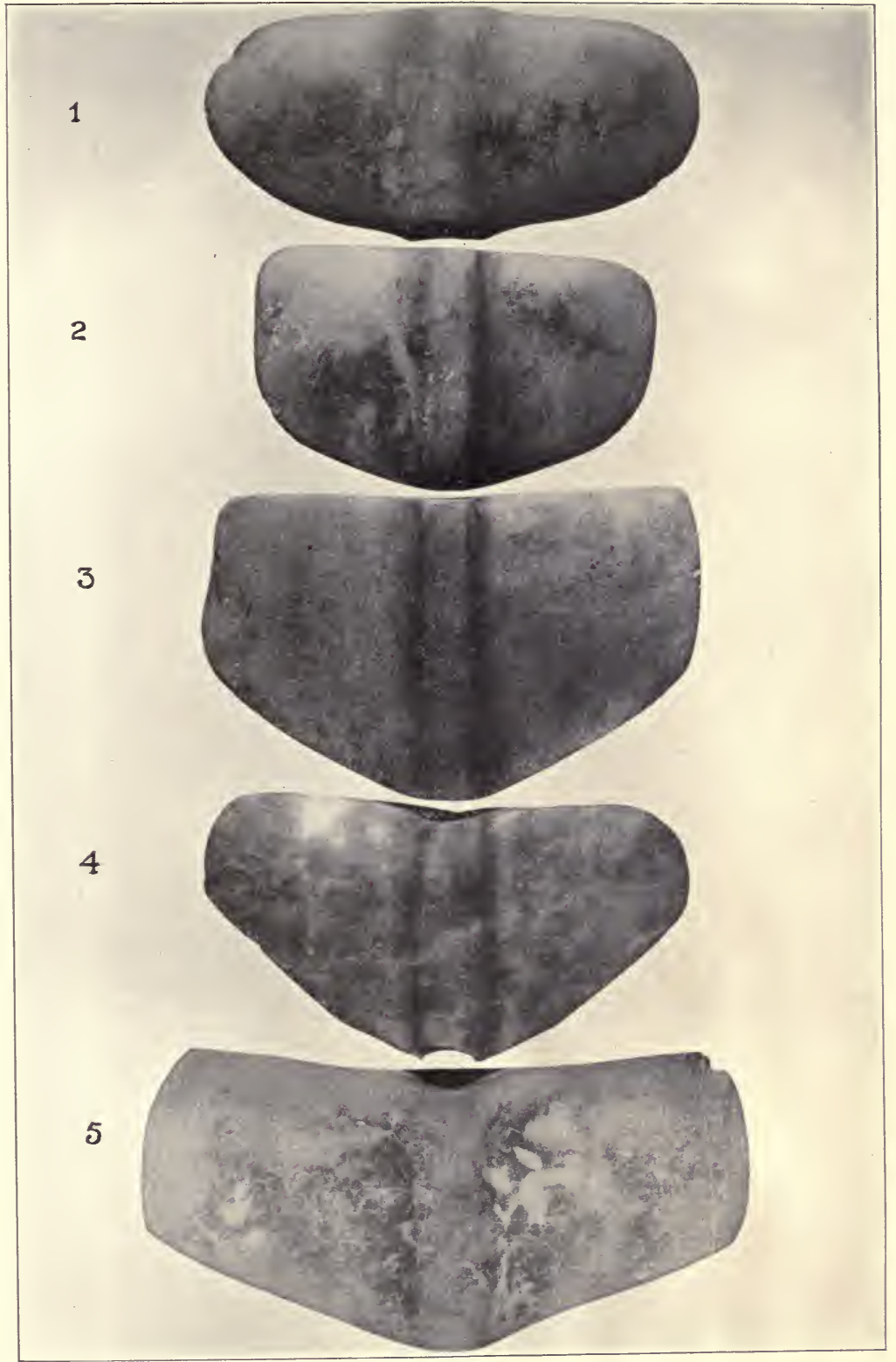

Bannerstones from Lowest Level 



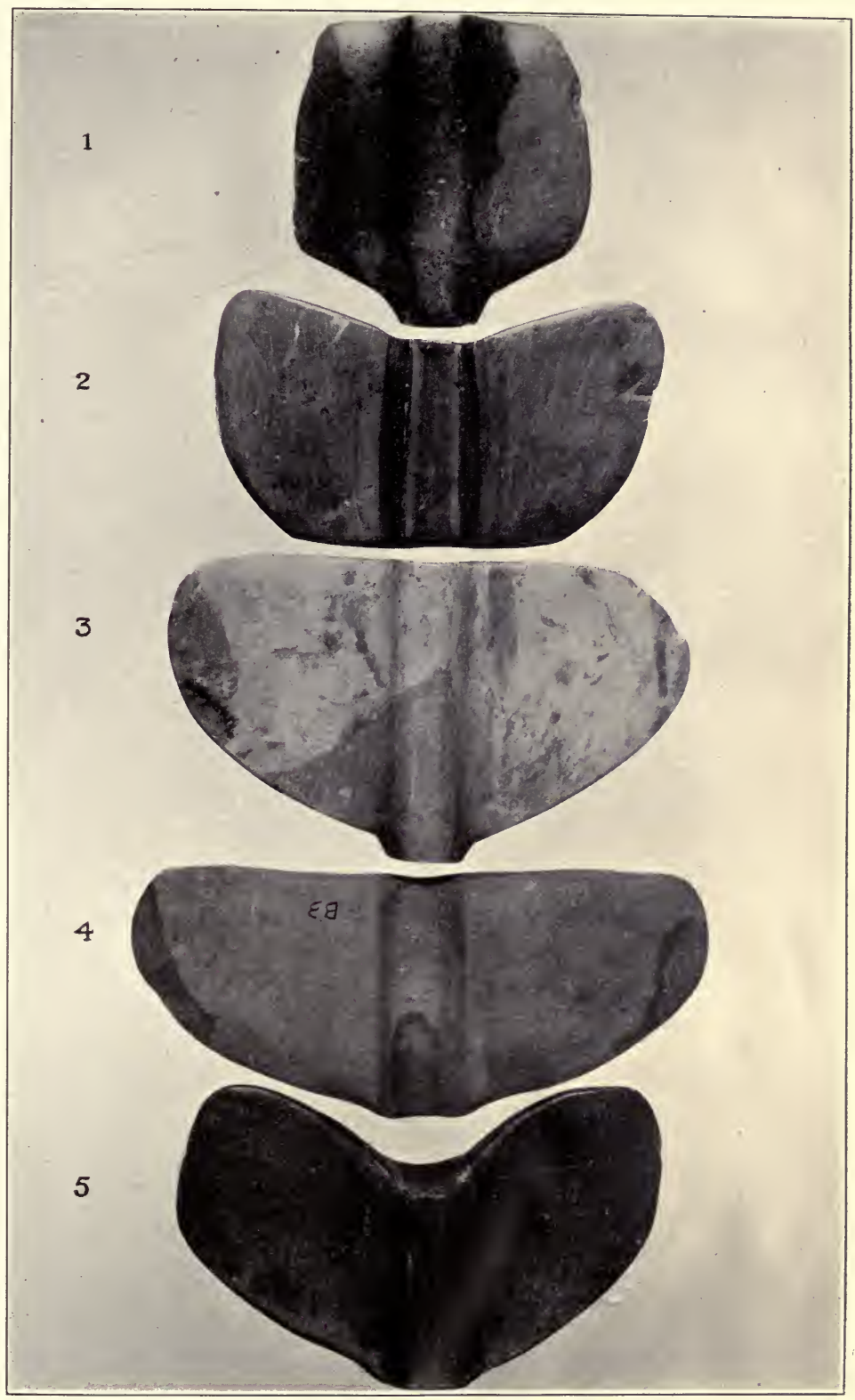

Bannerstones from Lowest Level 



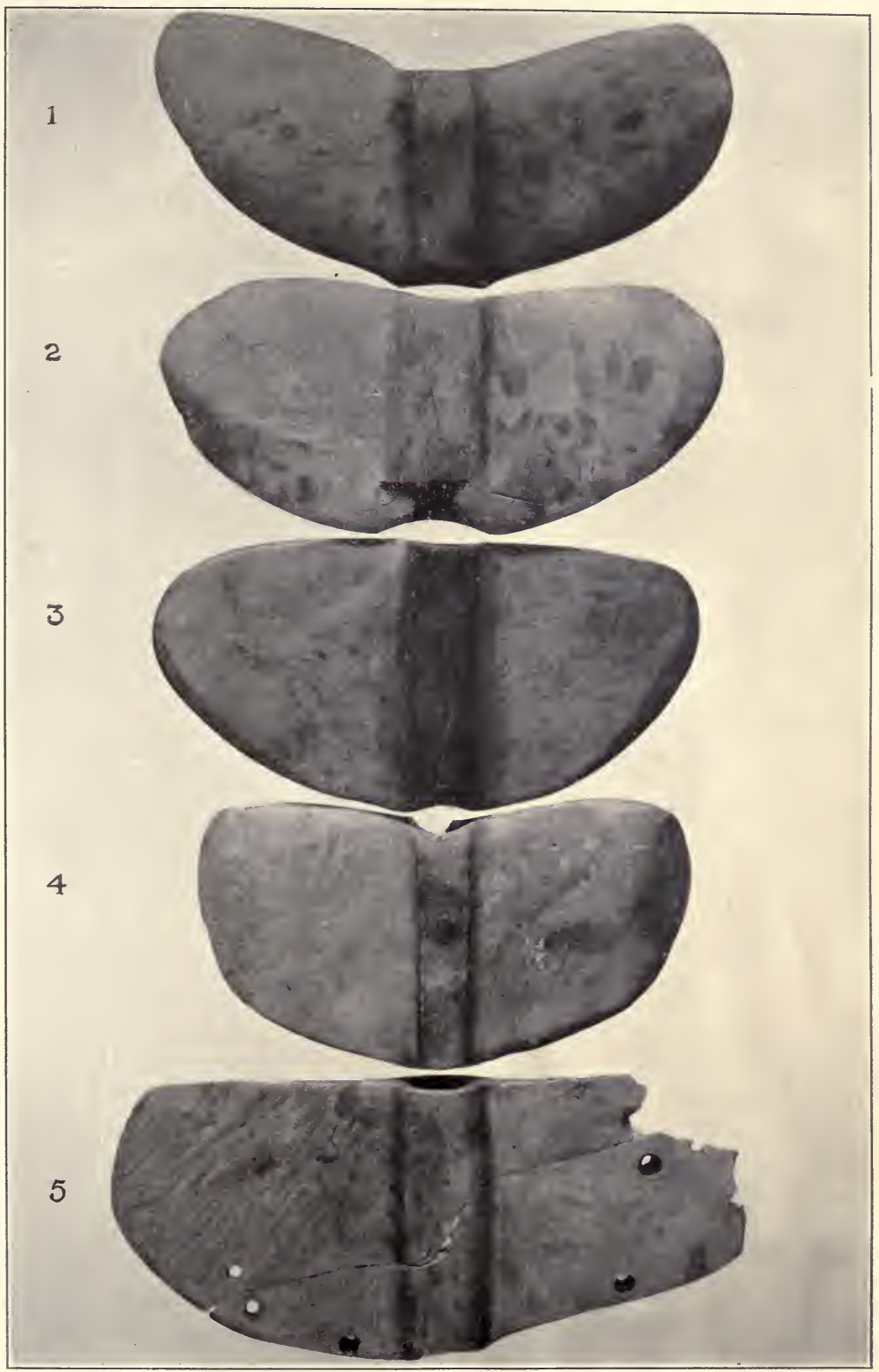

BANNerstones From Lowest LeVEL 



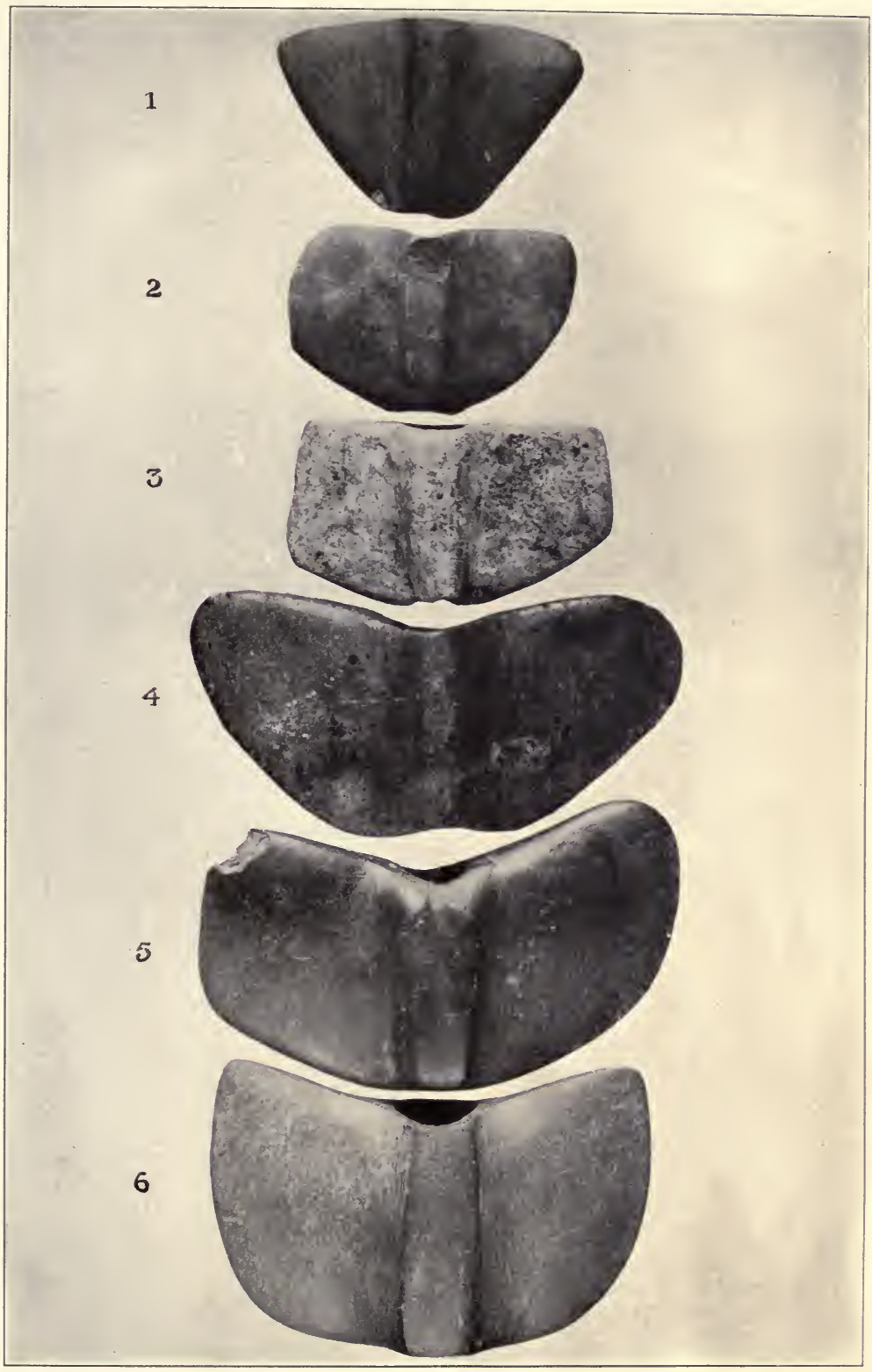

BANNerstones from Lowest Level 



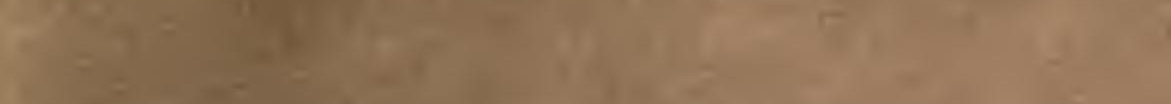
$13=-2,-1$

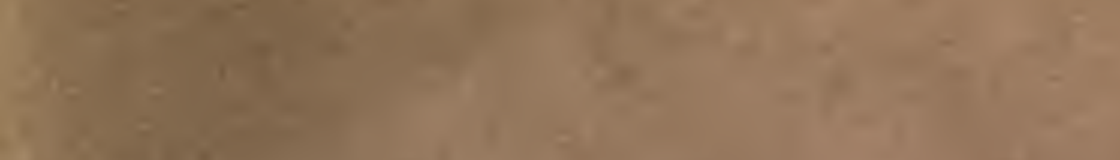
$48962-11=$

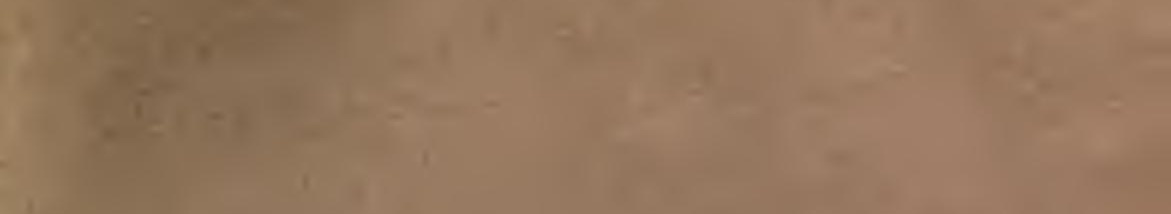

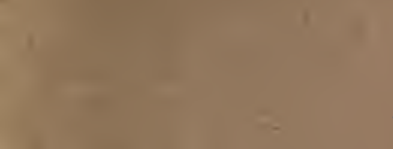

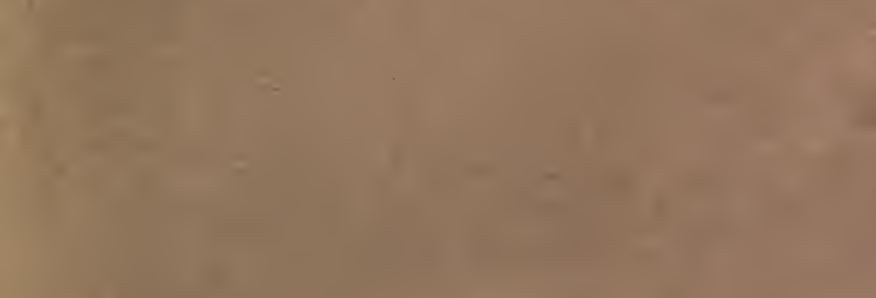

$-1$

$\operatorname{lin}_{1}-1$

$$
1+x=
$$

I.

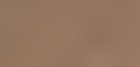

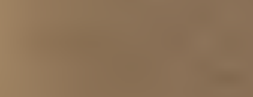

$-$

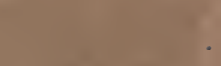

.

$\sqrt{3}+18$

$+\frac{1}{2}$

1

1.
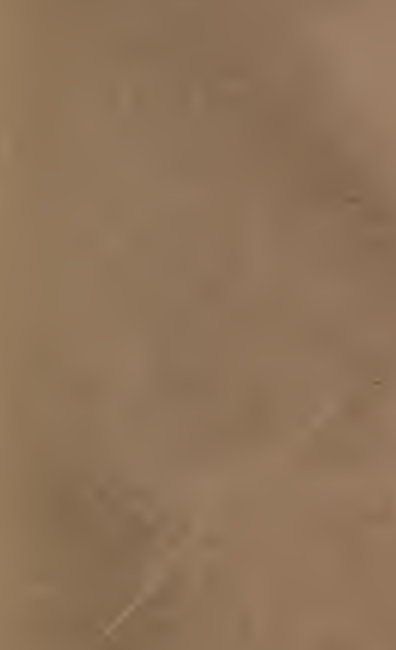

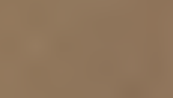
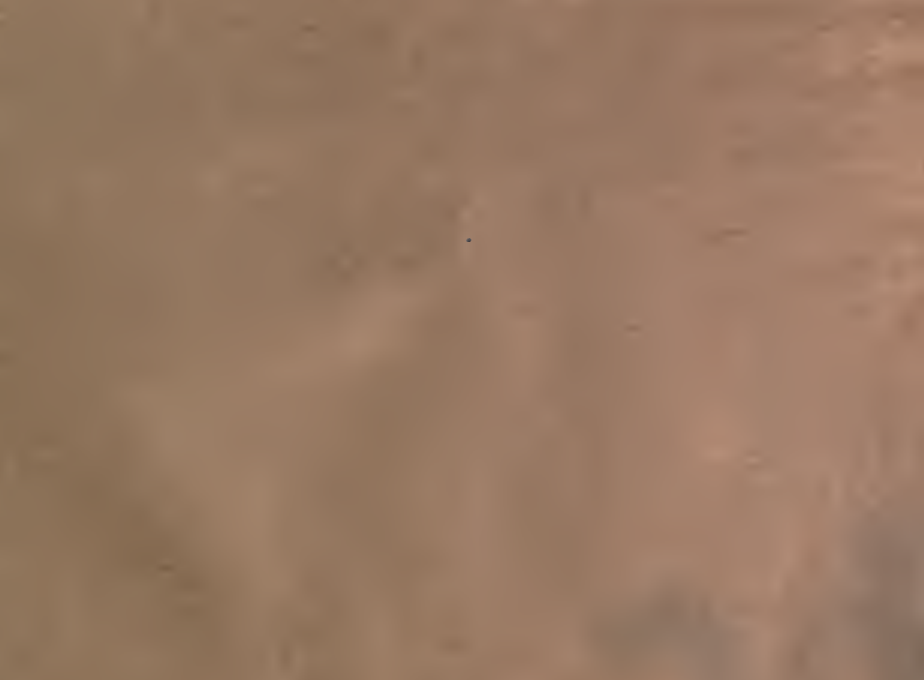

$+\frac{1}{2}$
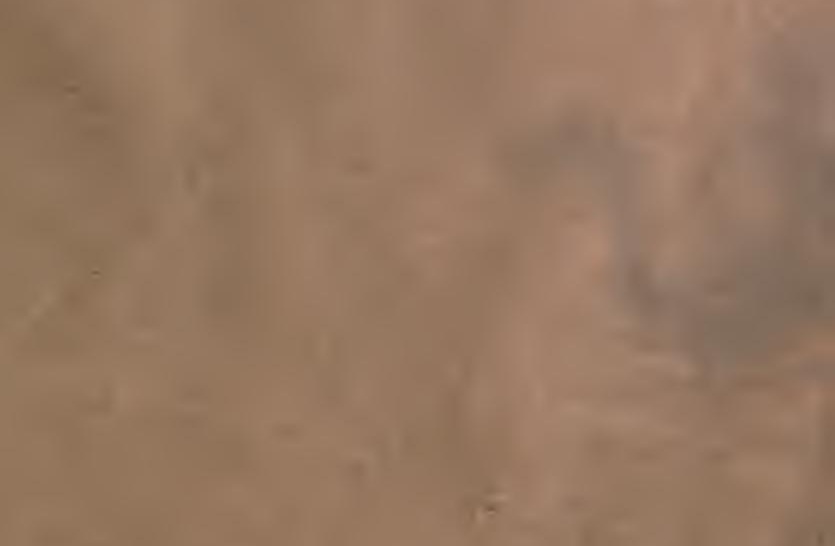

1

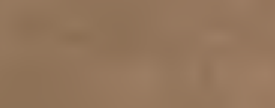

$+7$

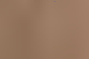

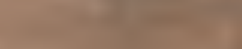

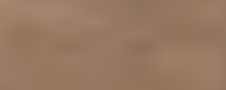

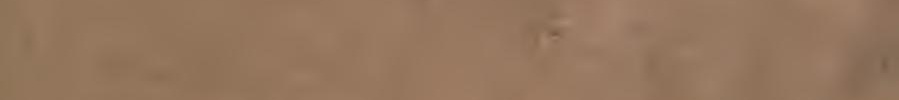

(1)

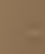

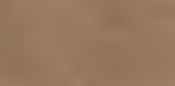




\section{UNIVERSITY OF CALIFORNIA LIBRARY}

Los Angeles

This book is DUE on the last date stamped below.

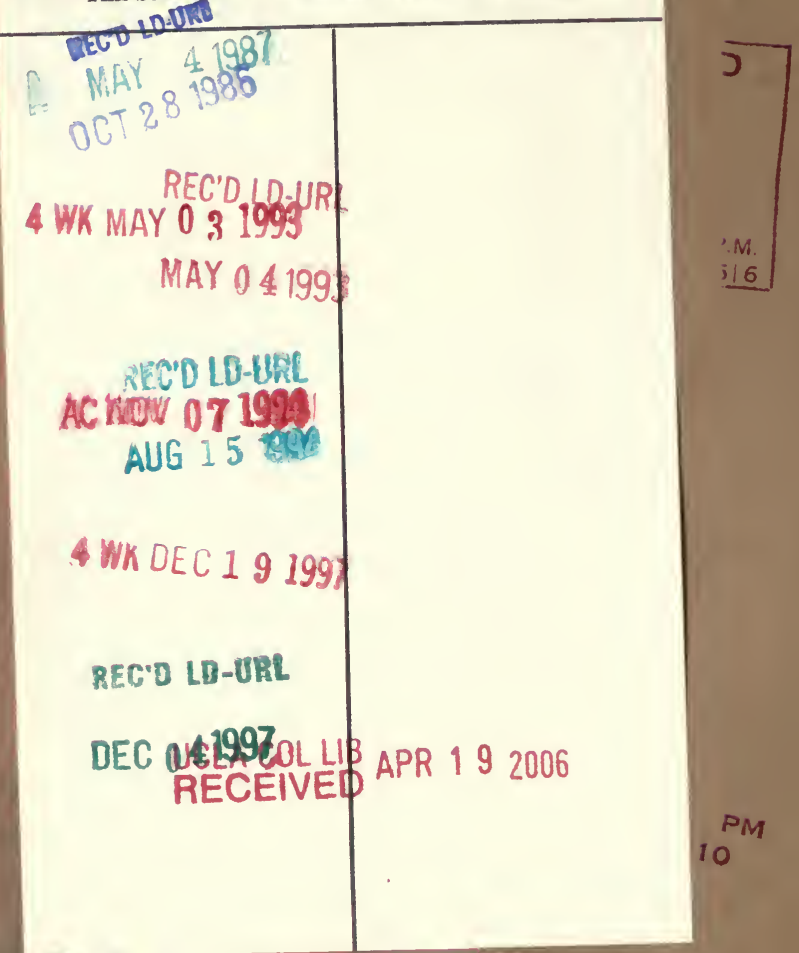




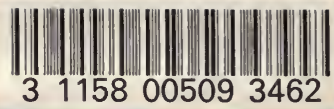
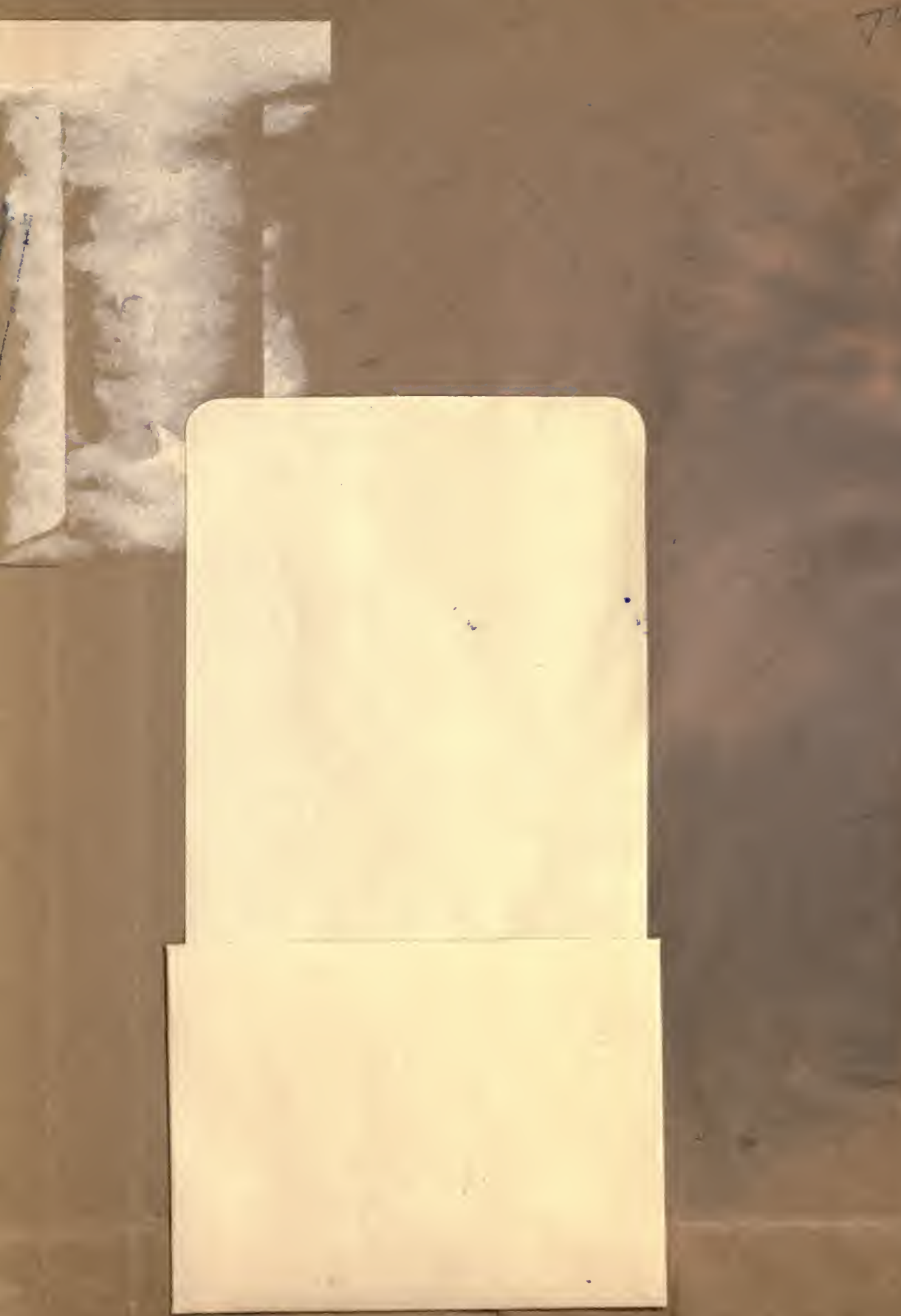
